Portland State University

PDXScholar

$1-1-2011$

\title{
Scaffolding the Development of Early Self- Regulation: The Role of Structure and Routine in Children's Daily Activities
}

Cynthia Lynn Taylor

Portland State University

Follow this and additional works at: https://pdxscholar.library.pdx.edu/open_access_etds

Let us know how access to this document benefits you.

\section{Recommended Citation}

Taylor, Cynthia Lynn, "Scaffolding the Development of Early Self-Regulation: The Role of Structure and Routine in Children's Daily Activities" (2011). Dissertations and Theses. Paper 287.

https://doi.org/10.15760/etd.287

This Thesis is brought to you for free and open access. It has been accepted for inclusion in Dissertations and Theses by an authorized administrator of PDXScholar. Please contact us if we can make this document more accessible: pdxscholar@pdx.edu. 
Scaffolding The Development of Early Self-Regulation:

The Role of Structure and Routine In Children's Daily Activities

by

Cynthia Lynn Taylor

A thesis submitted in partial fulfillment of the requirements for the degree of

Master of Science

in

Psychology

Thesis Committee:

Cathleen Smith, Chair

Thomas Kindermann

Ellen Skinner

Portland State University

2011 


\begin{abstract}
Learning to self-regulate one's behavior is a core developmental task in early childhood. Regulation of behavior is a challenge for young children largely due to cognitive constraints, specifically in the areas of attention and memory. As such, it has been theorized that both caregivers and a child's environment can support the development of behavioral self-regulation by providing cues as to what constitutes acceptable behavior in any given context. Although much research has been conducted on the role caregivers play in this regard, little is known about how a child's environment may also serve to support emerging self-regulation of behavior.

The present study sought to identify differences among children's daily activities in terms of their degree of structure and routine and how they related to changes in patterns of self-regulated behavior over time. Twenty-one children ages 6 to 60 months in three agegraded classrooms at a constructivist child-care center were video-taped at three measurement points over a six-month period as they engaged in a variety of daily activities (i.e., free play, meals and clean-up). Trained observers coded for nine self-regulatory behaviors and the daily activities during which they occurred.

It was hypothesized that structured and routine daily activities would scaffold the development of self-regulation and internalization such that these behaviors would occur more frequently during activities high in structure and routine. Over time, practice during activities that are high and low in structure and routine should support self-regulated behavior in the absence of structure and routine as well. Overall, results demonstrated that
\end{abstract}


in the presence of environmental cues for expected behavior (i.e., structure and routine) children tend to engage in more self-regulated behavior than in the absence of such cues. 


\section{ACKNOWLEDGMENTS}

The successful completion of this thesis project would not have been possible without the guidance and support received from many people, to whom I extend my deepest thanks and appreciation. First, to Cathleen Smith, my advisor and thesis committee chair, for her long commitment to both my thesis and the larger project. I have benefitted hugely from your wealth of knowledge as well as your enthusiasm and am so grateful that you decided to take on one last student. My other two committee members have also been invaluable sources of help and inspiration: Ellen Skinner for her amazing insights, organization and constructive support throughout this process, and Thomas Kindermann for his guidance since day one and ongoing assistance with the difficulties associated with observational research.

I had such a wonderful and hard-working group of lab assistants, my thanks to you

all, and to Deb and Rhenne in particular, for going beyond the call of duty and sticking it out until the very end. To my graduate student colleagues and members of the developmental "support group" I have so appreciated your feedback and insights. A special thank you goes out to Una and Jen, you two are the best.

Lastly, I would like to recognize my family, David, Autsen, Susan and Dad; all of you have been just wonderful - so patient, kind, and understanding of my desire to undertake such a project at this juncture in my life. And to Mom, for believing in me and for knowing it was a good idea. 
TABLE OF CONTENTS

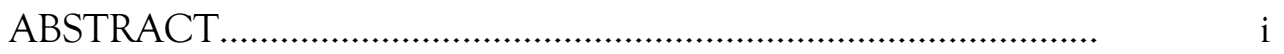

ACKNOWLEDGMENTS........................................................... ii

LIST OF TABLES............................................................... vi

LIST OF FIGURES................................................................. vii

CHAPTER

I INTRODUCTION.........................................................

II LITERATURE REVIEW .................................................. 6

The Development of Behavioral Self-regulation.......... 6

Self-Regulation and the Development of Prosocial Behavior......................................................... 10

Supporting the Development of Behavioral Self-Regulation.................................................. 12

The Constructivist Classroom..................................... 15

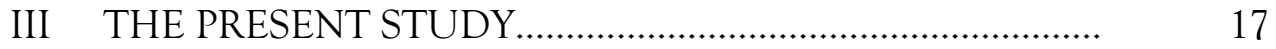

The Developmental Sequence of Self-Regulation....... 19

Research Questions.................................................... 23

IV METHOD ........................................................................ 29

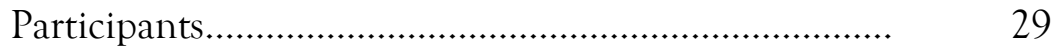

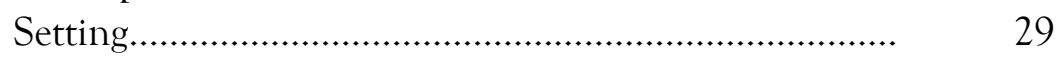

Activity Contexts..................................................... $\quad 30$

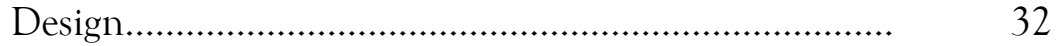

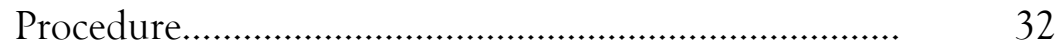

Measures.................................................................... 33

Coding of Observations............................................... 40

Research Questions \& Hypotheses............................... 43 
Data Reduction.....................................................

Research Question 1.............................................. $\quad 52$

Research Question 2.......................................... 55

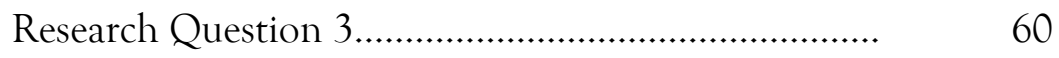

Research Question 4................................................ $\quad 70$

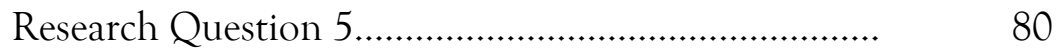

Research Question 6............................................. 83

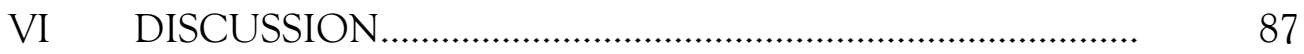

Comparing the Cross-sectional and Longitudinal

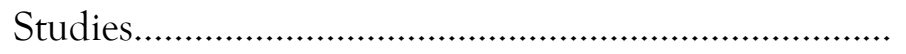

The Effect of Structure and Routine on Self-Regulated Behavior........................................................ 90

The Effect of Structure and Routine on Self-Regulated Behavior for Children of Different Ages........... The Effect of Structure and Routine on Self-Regulated Behavior Over Time........................................... 113

Interactions Among Structure and Routine, Age, and Time.................................................... 123

Complex Prosocial Behaviors....................................... 125

Strengths and Limitations.......................................... 126

Implications and Directions for Future Research........ 132

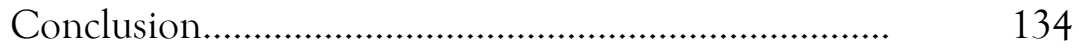

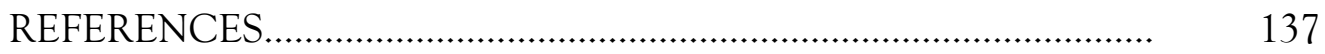

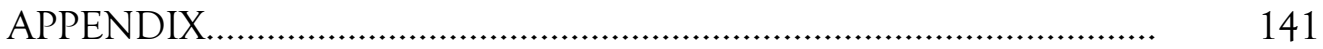




\section{LIST OF TABLES}

Table 1. The developmental sequence for self-regulation and compliant behavior.. 21

Table 2. Expectations for compliant and noncompliant behavior.......................... 46

Table 3. Low and high structure and routine activities...................................... 46

Table 4. Descriptive statistics, p-values and estimates of effect size for compliant and noncompliant behaviors in low and high structure and routine

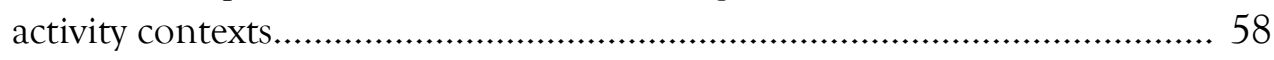

Table 5. Descriptive statistics for compliant and noncompliant behaviors in low and high structure and routine activity contexts for transitioners, toddlers

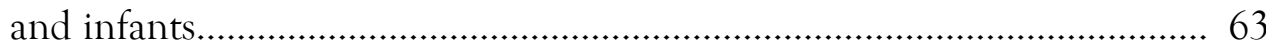

Table 6. Descriptive statistics for compliant and noncompliant behaviors in low and high structure and routine activity contexts at each time of measurement for toddlers and transitioners.

Table 7. Means and standard deviations for complex prosocial behaviors at each time of measurement for toddlers and transitioners

Table 8. The developmental sequence for self-regulation and compliant behavior.. 88

Table 9. Number of observations of self-regulatory behaviors by location for each time of measurement. 


\section{LIST OF FIGURES}

Figure 1. Developmental trajectories for compliant behavior

Figure 2. Mean levels of self-initiated compliance (SICOMP) from Time 1

to Time 3 for toddlers and transitioners.

Figure 3. Main effect of activity context on compliant behavior

Figure 4. Main effect of activity context on noncompliant behavior...............

Figure 5. Effect of context on compliant behavior for transitioners......

Figure 6. Effect of context on noncompliant behavior for transitioners......

Figure 7. Effect of context on compliant behavior for toddlers.

Figure 8. Effect of context on noncompliant behavior for toddlers.....

Figure 9. Effect of context on compliant behavior for infants.

Figure 10. Effect of context on noncompliant behavior for infants........

Figure 11. Effect of context over time on self-initiated compliance (SICOMP) for toddlers and transitioners

Figure 12. Effect of context over time on adult-initiated compliance (AICOMP) for toddlers and transitioners

Figure 13. Effect of context over time on noncompliance by omission (NONO) for toddlers and transitioners.

Figure 14. Effect of context over time on noncompliance by commission (NONCO) for toddlers and transitioners.

Figure 15. Effect of context over time on resource violation (RV) for toddlers and transitioners.

Figure 16. Effect of context over time on aggression (AGG) for toddlers and transitioners 
Figure 17. Effect of context and time on self-initiated compliance

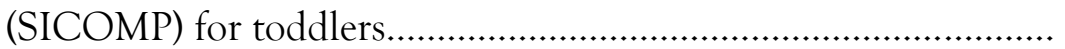

Figure 18. Effect of context and time on self-initiated compliance

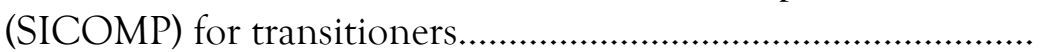

Figure 19. Average frequencies per day of complex prosocial behaviors

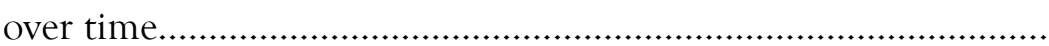

Figure 20. Average frequencies of self-initiated compliance (SICOMP) for toddlers and transitioners in two activity contexts........................

Figure 21. Average frequencies of adult-initiated compliance (AICOMP) for toddlers and transitioners in two activity contexts...........................

Figure 22. Average frequencies of noncompliance by omission (NONO) for three age groups in two activity contexts.

Figure 23. Average frequencies of noncompliance by commission (NONCO) for three age groups in two activity contexts.

Figure 24. Average frequencies of resource violation (RV) for three age groups in two activity contexts

Figure 25. Average frequencies of aggression (AGG) for three age groups in two activity contexts 


\section{Chapter I}

\section{Introduction}

One of the most important developmental tasks of infancy and early childhood is self-regulation, or developing the capacity to intentionally control one's own behavior. This capacity refers to both the performance of desired actions and the inhibition of impulsive ones. Different capacities for self-regulation can be observed to emerge at different times during early development. For example, signs of physiological selfregulation in the form of motor control are visible in infancy; however, it has been theorized and demonstrated that the self-regulation of behavior is not seen with any degree of consistency until a child's second year (Kopp, 1982). Regardless of its form (e.g., physiological, emotional, behavioral), the capacity to self-regulate is both supported and constrained by developmental progress in other areas (Calkins, 2007), quality of parentchild interactions (Dix, Stuart, Gershoff, \& Day, 2007) and the general home and/or school environment.

Regulation of one's behavior, specifically, is associated with numerous positive outcomes for children. Behavioral self-regulation is contingent upon an understanding and awareness of what constitutes acceptable social behavior (Kopp, 1982) and is, therefore, inextricably linked with successful socialization. Self-regulation has been associated with more success in the transition to school and in the cultivation of schoolbased peer relationships (Calkins, 2007). Successful navigation of the social realm is also contingent upon the development of one’s own "moral compass" or conscience. 
Kochanska (2006) and colleagues have demonstrated relationships between the nature of children's early self-regulation and the development of conscience. Further, selfregulation underpins the development of certain pro-social behaviors as children move from infancy into toddlerhood and preschool ages (Hay \& Rheingold, 1983). Indeed, selfregulatory abilities have been posited to underpin increases in prosocial behavior throughout childhood (Eisenberg, 1998). Hay and Cook (2007) suggest that as children develop, prosocial behavior (i.e., sharing or attending to the needs of others) becomes increasingly complex and, consequently, more dependent on self-regulation for its execution. Conversely, some negative child outcomes are linked to children's inability to appropriately self-regulate. Deficits in self-regulatory capacity have a negative impact on how well children are able to address developmental challenges and develop social competence (Calkins \& Fox, 2002). In a study of the relationship between self-regulation and behavior problems in later childhood, lower levels of regulation were associated with externalizing problems, such as anger and impulsivity (Eisenberg, et al., 2001).

The developmental trajectory for self-regulation and "acceptable behavior" can be investigated by directly observing the nature and frequency of children's compliant behaviors. Compliance, simply stated, is a child's cooperation or "going along with" the rules and standards of behavior for his or her immediate environment (e.g., home or school). As a child's ability to self-regulate develops, so does the nature of compliant behavior. It is helpful to conceptualize compliance as existing on a developmental continuum such that when it begins to emerge, compliant behavior requires a high degree 
of caregiver support, less support as it continues to develop, and very little direct support as children develop more and more self-regulatory competence. For example, within the context of mealtime, a very young child will need assistance with hand washing, putting on a bib, and getting seated. A child of two may be able to perform these tasks without assistance, but will likely require a reminder and perhaps direct supervision to do them. Finally, an older child, who is furthest along the continuum, will be able to perform the necessary tasks without prompting or assistance. In other words, a child's movement along the compliance continuum represents a shift from assisted, externally motivated behavior to independent, internally motivated behavior. The development of independent, internally motivated compliance is referred to as "internalization" and represents a child's acceptance and understanding of, and willingness to behave in accordance with, the rules and standards of his or her environment.

Given the strong evidence for the benefits of a child's solid capacity to self-regulate his or her behavior, in terms of individual outcomes as well as benefits to others, gaining an understanding of how the development of this capacity can be supported is of interest to developmental scientists. To this end, numerous studies have investigated the impact of a variety of factors thought to influence on the development of self-regulated behavior, from social interactions (e.g., parenting style) and quality of day care settings, to individual differences (e.g., temperament). Although it has also been theorized that environmental cues play a role in supporting young children as they move along the continuum of self- 
regulatory development (Kopp, 1982), to date no studies have explored the direct effect of such cues on children's self-regulated behavior.

The goal of this thesis was to address this gap in the literature by examining the impact of environmental cues on developing self-regulation in terms of two characteristics of children's daily activities: structure and routine. For the purposes of this study, structure referred to the degree to which an activity followed a set protocol. Routine referred to the frequency and predictability with which a given activity occurred. For example, mealtime was a routine activity because it occurred several times and at similar times each day. Routines provide regular opportunities for practice, or rehearsal of expected behaviors, which can lead to a child's feelings of competence (Bronson, 2002) and a greater likelihood that the behavior will be performed in the future (Staub, 1979), thereby providing support for developing self-regulation. Activities that are routine and structured may be particularly supportive because cues exist both in terms of predictability and protocol.

To determine how the nature of children's every day activities might serve to scaffold early efforts at self-regulation and internalization, observations of young children's self-regulatory behavior were conducted over a six-month period. Prosocial behaviors were also observed. If self-regulation does underpin certain prosocial behaviors, then scaffolding self-regulation should have increased instances of the prosocial behaviors over the sixmonth period as well. Observations were conducted at a state of the art, corporateaffiliated child development center that employed a constructivist (i.e., child-centered) 
curriculum. Children in three age-graded classrooms were videotaped on three occasions over a six-month period as they engaged in their daily activities. Frequencies of self-regulatory behavior were tallied and comparisons of each type of behavior were made among different daily activities, over time and among age groups.

In the following literature review the development and support of self-regulatory and prosocial behavior are considered. First, two perspectives on the development of selfregulated behavior and an overview of prosocial behavior and its development are presented. Second, a discussion is presented of the importance of structure and routine for young children and the role these two aspects of the environment play in supporting selfregulation and prosocial behavior. Lastly, an overview of constructivist, or child-centered, day care is provided. 


\section{Chapter II}

\section{Literature Review}

The Development of Behavioral Self-Regulation

Two theories of the development of self-regulation. Theories addressing the development of self-regulation echo the idea of a continuum. Kopp (1982) described the emergence of self-regulation as occurring in five qualitative phases. Of Kopp's five phases, the last three discuss behavior and are those most relevant to this study: control, self-control, and selfregulation. Each requires that a child use his or her cognitive resources to be aware of social expectations and behave accordingly. She describes the developmental end point of early self-regulation as having the ability to behave, "in accordance with various family and social values in the absence of external monitors, across a variety of situations, but neither slavishly nor mindlessly" (Kopp, 2001, p. 13682). It is important to note that at every stage, regulatory capacity is modulated by cognitive ability, motor skills and language. For example, memory and attention constraints limit an infant's capacity for independent compliance, whereas development in these areas supports it for older children.

By the end of the first year of life, children are experiencing growth and changes in both motor and cognitive capabilities that support the emerging awareness of social expectations that characterizes the control, or third, phase of self-regulatory development. This social awareness is demonstrated by what Kopp terms, "first manifestations" of behaviors associated with self-regulation: compliance with caregiver requests and the ability 
to inhibit prohibited behaviors. Although certain cognitive developments support the capacity to exhibit these behaviors at this age, there still exist limitations in memory and processing capabilities that render control behaviors transitory in nature and highly dependent on environmental cues and caregiver support for their execution. Furthermore, although compliance with caregiver requests is possible in this phase, children this young lack the ability to understand how or why such expectations for behavior may vary across different situations.

Around age two, children begin to exhibit behaviors indicative of the fourth phase, self-control. The emergence of representational thinking and recall memory enable children to begin to understand themselves as "independent identities" in relation to others. Consequently, they begin to draw comparisons between their behaviors and social expectations and become more able to exhibit behaviors appropriate to a given situation or set of environmental cues, and to do so in the absence of a caregiver. Kopp suggests that the strides children make in this phase are indicative of movement along the continuum toward an "internally generated monitoring system" (i.e., internalization). Again, as with control, such behaviors are by no means consistent at this age; they are easily over-ridden by other, more appealing stimuli in the child's environment. Additionally, compliance with caregiver requests for actions that a child does not perceive as pleasurable is more difficult than are those that are perceived as pleasurable.

Kopp describes the shift to self-regulation, the fifth phase in her developmental trajectory that begins at pre-school age, as marked by behavior regulation that is 
increasingly "adaptable and flexible." Determining that expectations for behavior change across situations (the capacity that eludes children in the control phase) is key. Not only are children beginning to make such determinations, they also become able to recall and employ appropriate behaviors. In other words, children become better at employing strategies for performing expected behaviors across a variety of situations. They are also able to sustain a necessary behavior for longer periods of time and rely less on environmental cues and caregiver support to do so. Several studies have found support for the developmental trend toward internal control of behavior posited in Kopp's theory (Granlinski \& Kopp, 1993; Vaughn, Kopp, \& Krakow, 1984), although none examined the role of the environmental cues that figure heavily in the theory as support for early attempts at self-regulated behavior.

Kochanska, Aksan, and Koenig (1995), building on Kopp's theory of selfregulation, examined self-regulatory development in a longitudinal study that investigated the relationships between early compliance behaviors and later internalization. The researchers began by identifying two forms of compliance: situational and committed. Situational compliance refers to behavior that is cooperative, but unstable or "shaky," and requires a high level of caregiver involvement for its execution; whereas committed compliance represents a willing acceptance of a caregiver's expectation. The latter form represents an "internally driven and self-regulated" (p. 1753) form of compliance that is thought to be an antecedent of internalization. Kochanska and colleagues also drew an important distinction between types of behavioral regulation required in response to 
different (maternal) directives. Although technically describing the type of behavior a child is asked to perform, maternal directives were referred to in terms of "do" and "don't" contexts. In a "do" context a child is directed to sustain an unpleasant activity (i.e., being asked to clean up toys after play time), whereas a "don't" context requires the suppression of a desired behavior (i.e., being asked not to play with appealing toys placed within the child's reach).

Children's compliant behavior was observed in the laboratory at toddler age and again at pre-school age in both do and don't contexts. Internalization was measured using maternal reports of independent compliance with expectations at home. It was also observed in the laboratory using a scenario in which mothers would issue a directive in one of the two contexts and then leave the room. Evidence of internalization was indicated if a child complied with the request in the mother's absence. Generally, the findings indicated developmental trends for self-regulated behavior that mapped onto Kopp's $3^{\text {rd }}$ and $4^{\text {th }}$ phases, such that older children exhibited higher rates of committed compliance, the more independent form, more often than did younger children. The findings also indicated that the ability to comply was strongly influenced by the type of behavior required. Committed compliance was more difficult for children of all ages in the "do" contexts, when sustaining an unpleasant behavior was required. Correlations showed that early committed compliance (but not situational compliance) was a significant predictor of later internalization, lending support to the notion that internalization arises from early 
compliance and that there exists a developmental continuum for compliance and self-regulated behavior.

The fine-grained distinctions drawn by Kochanska and colleagues in terms of the two types of compliance and "do" versus "don't" behaviors represent important contributions to the understanding of how self-regulation of behavior unfolds during early childhood. However, because the observations conducted in support of these constructs and associated behaviors were done in a laboratory, they could not capture the role that everyday activities and familiar environments may play in guiding a child's actions. Self-Regulation and the Development of Prosocial Behavior

Staub (1979) has defined prosocial behavior simply as, "behavior that benefits other people” (p. 2). Given this definition, for many years researchers operated under the assumption that infants and very young children did not exhibit prosocial behavior due to developmental constraints (i.e., lack of mobility, language, self-regulation of behavior). However, more recent conceptualizations consider certain behaviors exhibited by very young children (e.g., affection, attending to another's distress), while not necessarily directly benefiting another, to be the foundation from which later beneficial behavior arises, or, in other words, "the roots of personal and civic virtue" (Hay \& Cook, 2007, p. 100).

In much the same way that the emergence of self-regulated behavior can be conceptualized as lying on a continuum, so too, can prosocial behavior. Very early prosocial behavior is constrained by limitations in infants' mobility, cognition, and 
language. Therefore, it occurs most often in response to environmental events, for example attention or distress in response to another's discomfort or suffering, or as affection during interactions with others (Hay \& Rheingold, 1983). As infants gain some mobility and motor control, they begin to engage in what has been termed "share my experience" behavior, such as eliciting joint attention by pointing and showing or sharing objects (Hay \& Rheingold, 1983). According to Hay and Cook (2007), these types of behaviors are, "a basic impulse to interact positively with other people" (p. 101). They further posit that as children continue to develop these spontaneous behaviors, they become, in turn, more "selective, socially appropriate, self-regulated and morally informed" (p. 101).

Although several processes are thought to be associated with movement along the developmental continuum (e.g., language acquisition, emotional understanding), it is the effect of developing self-regulation that is of interest to the present study. It has been posited that regulatory capacity underpins increases in the frequency of prosocial behavior throughout childhood (Eisenberg, 1998). As children become more adept at managing their behavior in general, prosocial behavior also becomes more regulated, as well as more complex (Bronson, 2002; Hay \& Cook, 2007). Successful regulation of behavior informs a child's ability to share, take turns and temporarily forgo his or her own needs to attend to another's needs (Hay \& Cook, 2007), thereby allowing a child to provide help or assistance or engage in caregiving (directed towards persons, animals or inanimate objects such as 
dolls or stuffed animals). Even sharing becomes less spontaneous and more considered after the age of two (Hay, Caplan, Castle, \& Stimson, 1991).

Prosocial behavior appears to be something that arises spontaneously in young children and is rooted in their desire and need to interact in a positive way with others in their environment. However, its continued development, in terms of children's ability to respond to others in helpful and empathetic ways, is contingent upon the development of underlying processes, one of which is behavioral self-regulation.

Supporting the Development of Behavioral Self-Regulation

Given the importance of normative development of behavioral self-regulation for later positive child outcomes, it is not surprising that a rich literature on how to support it exists. Support for emerging behavioral self-regulation can be thought of as existing in two dimensions (Skinner, Johnson, \& Snyder, 2005). The first is through a child's warm and caring relationships that are also autonomy supportive with parents, teachers or caregivers. Although most of the research in support of this dimension has focused on child behavior and outcomes as they relate to parent factors (i.e., parenting style) and the home environment, it seems reasonable that what constitutes a supportive parent and home environment would hold true for other care-giving situations as well (i.e., teaching style and daycare environment). Numerous studies indicate that maternal warmth and positive support are positively related to self-regulatory capacity, compliance and internalization (Jennings, et al., 2008; Kochanska, 2002; Calkins, Smith, Gill, \& Johnson, 1998). 
The second dimension of support is characterized by clear and consistent caregiver expectations, and the provision of structure and routine. According to Bronson (2002), young children are better able to regulate behavior when their environments are predictable in terms of "where things are, what comes next, and how to participate," (p. 191) noting that children look for and rely upon order to construct meaningful expectations about the world around them. Structure and routine serve to provide children with contextual cues about expectations and appropriate behavior, with additional support coming from caregiver communication that is understandable and consistent.

The notion that young children need, and in fact thrive on, structure and routine is well supported; however, there is little research with regard to how daily activities, which vary in terms of their inherent degree of each, might support early attempts at selfregulation. In much the same way daily routines of waking, sleeping and feeding support physiological regulation for infants, it is possible that the presence of routines in older children's daily activities may scaffold behavioral regulation as children move farther along the developmental continuum.

Structure and routine provide consistency in daily experiences that allows children to know what to expect: "After dinner we clear our dishes" or "We brush our teeth before bed" are but two examples of routine activities that seem small within the scope of an entire day, but nonetheless may have an impact on developing self-regulation of behavior. Routines also provide opportunities for practicing self-regulation, which over time can lead to feelings of competency, thereby building self-regulatory strength (Bronson, 2002). 
Some support for the importance of structured daily routines in the lives of young children comes from Staub's (1979) discussion of how children's daily activities and responsibilities contribute to the development of prosocial behavior. He posited that an effective method by which to scaffold the development of prosocial behavior is through "responsibility assignment," which is essentially an opportunity to practice a given (prosocial, i.e., helping) behavior. Responsibility assignment varies in terms of its structure. Spontaneous or unique opportunities (e.g., a caregiver's spontaneous request for help) are considered to be less structured, whereas regular expectations (e.g., cleaning up after meals or caring for family pets) are more structured. Specifically, Staub states that the more an assignment or task is associated with clear expectations in terms of what it is, as well as when and how it is to be performed, the more structured it is. Not surprisingly, it is the more structured of these two types of responsibility assignment that has been associated with positive outcomes in terms of children's prosocial development (Staub, 1979; De Guzma, Edwards, \& Carlo, 2005).

Caregiver-child and child-environment interactions that encapsulate the above elements and, ultimately, provide solid support or scaffolding for a child's developing behavioral self-regulation, are said to be "high quality." While most often thought of in terms of parenting and the home environment, for the purposes of this study, it is important to consider what constitutes "high quality" teacher-child interactions and classroom environments. 
The Constructivist Classroom

The constructivist, or child-centered classroom represents one such environment. In the constructivist view, which is rooted in Piaget's cognitive developmental theory, a child constructs social and moral understanding in much the same fashion as he or she comes to understand the workings of objects. Social interactions are seen as the building blocks of development of this understanding, hence the guiding principle of the constructivist classroom is: "A sociomoral atmosphere [interpersonal relationships and interactions] must be cultivated in which respect for others is continually practiced" (DeVries \& Zan, 1994, p. 1).

The capacity to have respect for others hinges on the ability to self-regulate; therefore, supporting children as they learn this skill is the overarching goal of constructivist childcare (DeVries \& Zan, 1994). First and foremost, the teacher-child relationship is one of mutual respect in which teachers recognize that children are entitled to their own feelings, ideas, and opinions. To this end, teacher-child interactions are characterized by warmth, caring and low power assertion, thereby affording children the opportunity to learn to regulate from within, which over time results in regulation that is not contingent upon the adult's presence.

Developmentally appropriate practice is another key component of the teacherchild relationship and the support of emerging self-regulation. In general, this practice involves awareness on the part of the teacher as to a child's abilities and stage of development. A teacher employing developmentally appropriate practice will not ask a 
child to perform a task or behave in a manner that is beyond his or her abilities. It also means that the environment is attuned to a child's age and developmental level both in terms of its physical characteristics and with regard to schedules. Finally, rules and expectations are straightforward, are presented in a way that "makes sense" for young children, and are concise and consistently implemented.

For Devries and Zan, these classroom characteristics and types of teacher-child interactions are the primary processes through which the gradual shift from external to internal regulation occurs. However, in addition to these supports for developing selfregulation, the very organization of the classroom itself may contribute to the process as well. Each classroom provides the "reasonable amount of order and routine" that Bronson (2002, p. 195) described as being beneficial to children in terms of predictability that governs the sequence of daily activities. It is the contention here, however, that in addition to this regular sequence, there exist varying degrees of structure and routine within individual activities. That is, it is possible that within the larger supportive, organized context of the constructivist classroom, there exist "micro-contexts" in the form of highly structured and routinized activities that have an impact on self-regulation and the progress toward internalization. 


\section{Chapter III}

The Present Study

To date, much of the research on behavioral self-regulation has focused on how it can best be supported and the developmental trajectory that it follows. In terms of supports, of primary interest have been the relationships between children's capacities for regulated behavior and the quality of both their caregivers and environments (home and/or day care). Although Kopp's (1982) theory also posits that environmental cues support the development of self-regulation by helping children remember and understand which behavior is expected in a given situation, very little research has investigated the relationship between such cues and self-regulation.

Studies investigating the developmental trajectory for behavioral self-regulation have shown that it is not consistently visible before age two and its independent form, internalization, emerges even later at pre-school age. Further, for children of all ages, committed compliance has been found to be more difficult in the context of tedious activities that children are expected to sustain. Prior analysis of the data that were used for the present study, however, showed evidence of compliant behavior, particularly independent compliance (i.e., internalization), earlier than predicted in the literature (Vale, 2006). Additionally, casual observations conducted by the author of this thesis in the same setting in which Vale's data were collected revealed that children as young as two exhibited behavior indicative of internalization during activities which mirrored Kochanska's (1995) tedious "do" contexts. This observation apparently contradicts Kochanska's finding that 
committed compliance was more difficult when children were directed to sustain an unpleasant activity.

This contradiction can perhaps be explained by considering that Kochanska's observations were conducted in a laboratory setting, whereas Vale's observations (as well as the author's casual observations and those for the present study) were conducted in a natural setting. No matter how well a laboratory setting is designed to mimic a natural one, it is still an artificial setting - a point that may be particularly relevant when studying young children who rely, in part, on routines and familiar environmental cues as guides for appropriate behavior. For a child, any laboratory setting represents a break from his or her normal routine. Despite Kochanska's findings, there may be a place for "do" contexts in supporting internalization. "Do" contexts, although often activities in which a child is not eager to engage, occur regularly and may be part of an established routine in a child's home or school environment. Cleaning up, for example, is a necessary part of life and happens every day, often more than once a day. Is it possible to capitalize on such routines? In other words, is there room in Kochanska's model of early compliance for structured and routine "do" contexts that facilitate, rather than make difficult, compliance and internalization?

Snyder \& Ickes (1985) theorized that certain "situational moderating variables" are good predictors of social behavior. Specifically, they identify what are termed "psychologically strong situations" in which more structure and definition provide an individual with cues that serve to guide behavior. In the context of the present study, some 
of the children's activities in the child care center may represent strong situations because they are highly structured and provide cues to behavior that enable children to comply with expectations independently of direct adult support. It was during such a structured activity that the evidence for internalization seen during the author's casual observations was noted.

The goal of the present study was to investigate the nature of children's daily activities and their relationships with self-regulated behavior though observations conducted in natural settings (i.e., three age-graded classrooms). The child-centered classroom was ideal for such observations because it consistently provided the support and scaffolding that research has shown to be beneficial to young children in their early efforts at behavioral self-regulation. Since warm and caring relationships, clear rules and expectations, and a general structure were well integrated in these classrooms, it was possible to examine whether variation in the degree of structure and routine in daily activities affected children's ability to self-regulate their behavior. Did highly structured and routinized activities represent "strong psychological situations" that served to scaffold self-regulated behavior and internalization over and above what was already provided for the children in terms of support?

The Developmental Sequence for Self-Regulation

Before presenting the research questions, it would be helpful to first outline a developmental sequence for self-regulation and the ages at which different forms of compliance are expected to emerge. Kopp (1982) proposed that children nearing the end 
of the first year of life would be entering the control phase of self-regulation. For Kochanska (1995), early compliance at this age is termed "situational compliance" and is characterized by high levels of caregiver support for compliant behavior. Around age two, children enter Kopp's stage of self-control during which increasing self-awareness prompts attempts to display behaviors that conform to social standards and expectations. Compliant behavior at this age begins to occur with less support from caregivers and children begin exhibiting what Kochanska termed "committed compliance," or a "willing acceptance" of behavioral standards and expectations. Throughout the stage of selfcontrol, children become more and more adept at monitoring their own behavior as they internalize social standards and expectations for appropriate behavior.

By pre-school or around age 4, Kopp posits that children enter the stage of selfregulation, during which behavior regulation becomes more flexible and adaptable. Children are able to comply with standards and expectations with less and less support from caregivers and the environment, a sign of internalization or internalized compliance. Behaviors identified by Kopp and Kochanska as being indicative of emerging self-regulation as are summarized in Table 1 for children ages one through four. Figure 1 presents developmental trajectories for Kochanska's two forms of compliance (i.e., situational, committed) as well as internalized compliance for children ages one through four. 
Table 1. The developmental sequence for self-regulation and compliant behavior

\begin{tabular}{|c|c|c|c|}
\hline & $\begin{array}{l}\text { Kopp: } \\
\text { Control } \\
\text { Kochanska: } \quad \rightarrow \\
\text { Situational compliance }\end{array}$ & $\begin{array}{l}\text { Kopp: } \\
\text { Self-control } \\
\text { Kochanska: } \quad \rightarrow \\
\text { Committed } \\
\text { compliance }\end{array}$ & $\begin{array}{l}\text { Kopp: } \\
\text { Self-regulation } \\
\text { Kochanska: } \\
\text { Internalization }\end{array}$ \\
\hline Ages $1-2$ & Central & Early emergence & Not yet available \\
\hline Ages 2-3 & $\begin{array}{c}\text { Decreasing } \\
\text { (No longer needed) }\end{array}$ & Central & Emerging \\
\hline Ages 3-4 & $\begin{array}{c}\text { Decreasing } \\
\text { (No longer needed) }\end{array}$ & $\begin{array}{l}\text { Central } \\
\text { (leaving) }\end{array}$ & Central \\
\hline
\end{tabular}

Note: Central behaviors are those which best reflect a developmental task that is the focus of a specific stage of development 


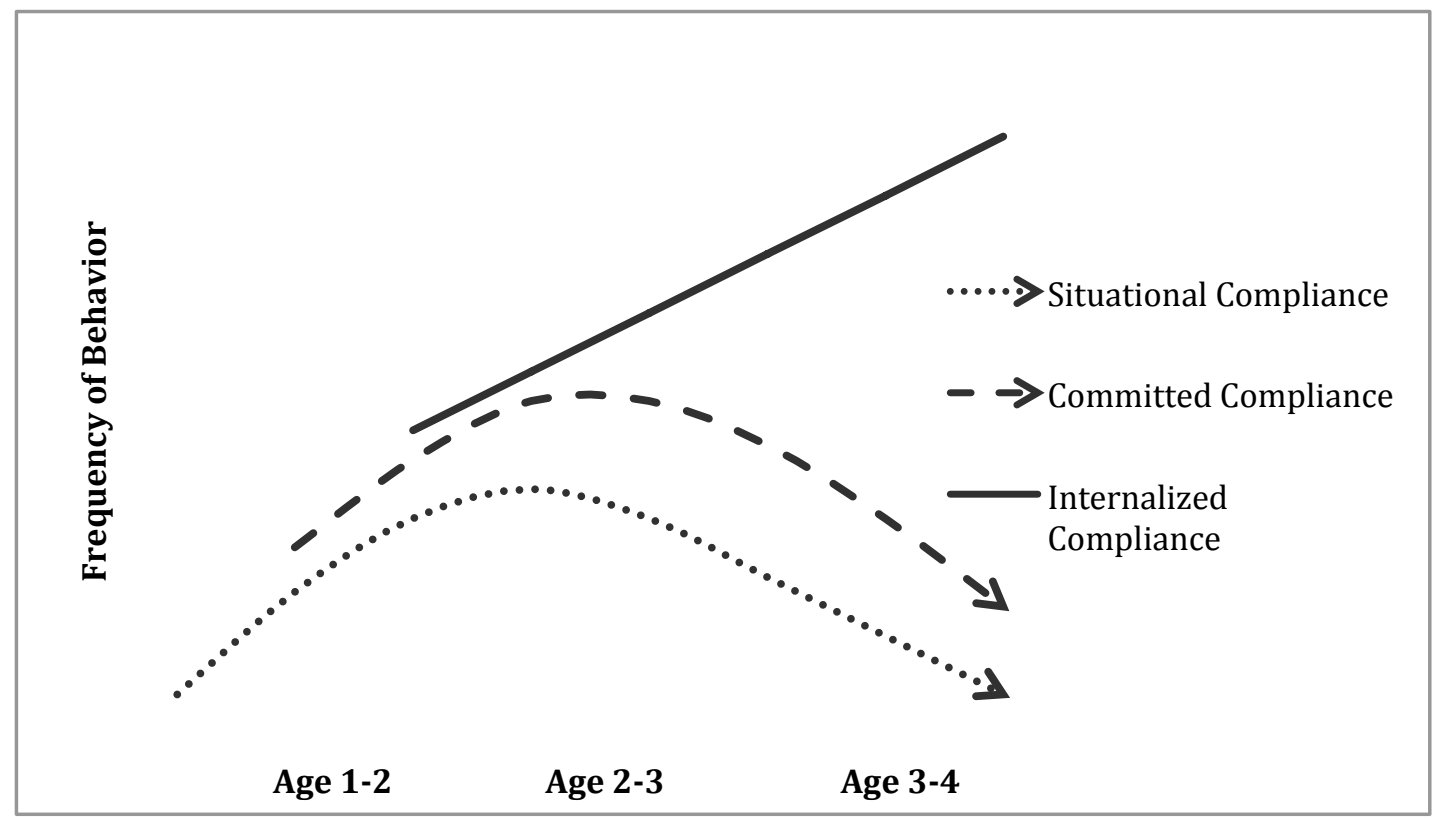

Figure 1. Developmental trajectories for compliant behaviors presented in Table 1 


\section{Research Questions}

The present study sought to determine if, within the organized and supportive environment of the constructivist classroom, there were structured and routine subcontexts or activities that provided additional scaffolding for developing self-regulatory capacities and internalization. Were there "do" contexts in which children were able to sustain an "unpleasant or undesired" activity? This question will be addressed by comparing observed frequencies of compliant and non-compliant behavior (indicators of self-regulated behavior) between daily activities that were characterized by high and low degrees of structure and routine. Additionally, if self-regulation does underpin certain, more complex, prosocial behaviors (e.g., sharing, helping), then scaffolding self-regulation should lead to increased instances of more complex prosocial behaviors as well.

1. In general, does the environment of the constructivist classroom support children's developing self-regulation such that it emerges before age two (earlier than predicted in the literature) and increases in average frequency over time?

Prior analysis of the cross-sectional data collected in the larger study indicated that self-regulatory behavior indicative of emerging internalization was seen in children whose mean age was 1.8 years, which is earlier than predicted in the literature. Further, average frequencies of this behavior were greater for the older children whose mean age was 2.75 years (Janssen, 2005; Vale, 2006). Will the longitudinal data support the cross-sectional findings? 
2. Does the degree of structure and routine in children's daily activities affect children's ability to self-regulate?

Discussions regarding the supporting roles that consistency and environmental cues play in early development are seen throughout the developmental literature. Consistency and its relationship to positive outcomes are documented in the parenting and early childhood education literature (Bronson, 2002; Skinner et al., 2005). Kopp (1982), in describing the emergence of self-regulatory behavior, highlighted the role of environmental cues in supporting early development of this capacity. Snyder \& Ickes (1985) also discussed the role of environmental cues, referring to them as a characteristic of "psychologically strong situations" in which structure and clear definitions serve as cues to behavior. In keeping with these discussions, this research question posits that daily activities that are highly structured and routinized should provide children with cues about what behaviors are expected. These cues, in turn, should enable children to exhibit a higher frequency of self-regulated behavior than would have been possible in situations that do not provide those cues.

3. How does the degree of structure and routine in daily activities affect self-regulatory behavior in children of different ages?

This question addresses the developmental sequence and how patterns of selfregulatory behavior may vary between activities that are low and high in their degree of structure and routine for children of different ages. In other words, although structure and routine may scaffold behavioral self-regulation, children themselves are also developing. 
Although there is variability in terms of when the different forms of regulated behavior emerge that may be due to external factors, Kopp's stages are, at the most fundamental level, age graded. For example, as children get older, both memory and attention capacities increase, which help children bring more behavior under their control over the course of early development (Kopp, 1982). It is, therefore, expected that the frequencies of the individual types of compliant behavior will vary not only as a function of activity type, but by age as well.

For example, children around age three are likely to be farther along the developmental continuum for self-regulated behavior than children at age two. Developmental advances (e.g., working memory, language) should contribute to three year olds' capacity for self-regulatory behavior such that internalized compliance occurs more frequently for them than for two year olds. Situational compliance, on the other hand is a behavior that, when present in children around age one, is indicative of emerging selfregulation. However, as children get older and begin to show signs of a "wholehearted acceptance of the adult's agenda" by exhibiting more committed or internalized compliance, compliance requiring caregiver intervention for its execution can be seen as an indicator of low self-regulation (i.e., a step backward).

4. Does the degree of structure and routine in daily activities affect children's self-regulated behavior over time?

This research question addresses mean level changes in self-regulated behavior over time in daily activities that were characterized by low or high degrees of structure and 
routine. The developmental sequence indicates that as children get older, committed compliance and internalized behavior become more central behaviors and increase over time. The opportunity to practice expected behaviors afforded by the presence of structure and routine in daily activities should support the developmental sequence as well.

These changes will be addressed only for children that were approximately two years of age or older. As posited in Kopp's stages of development for self-regulation, the emergence of internalized self-regulatory ability is contingent on developments in other areas, both physical and cognitive. These changes can be thought of as opening a "window of development" for internalized behavior. For the youngest children in the present study, whose mean age was 41 weeks, this window was still closed. Most of these children were pre-verbal and not yet walking, which would have made understanding expectations and following directives for independent behavior difficult, if not impossible.

5. Do structure and routine scaffold internalization such that, over time, the frequency of internalized behavior in the low structure and routine contexts catches up with the frequency of internalized behavior in the high structure and routine contexts, and are there age differences associated with the pattern of change?

This research question addresses the interaction between activities of differing levels of structure and routine, time, and its effect on the frequency of internalized behavior and how the effect may vary depending on age. Following the rationale presented 
in Research Question 4, this research question addresses only children approximately age two or older.

As behavioral self-regulation develops, it becomes more flexible (Kopp, 1982), a hallmark of internalization. Children come to understand what is expected of them across a variety of situations and also become increasingly capable of behaving in accordance with expectations independently (e.g., with less scaffolding or adult support) over time. Within the framework of the present study, evidence for the emergence of such flexibility for the oldest children (mean age $=2.75$ years) will be seen if there is a change in slope for the average frequency of internalized behavior in activities with low levels of structure and routine. Activities low in structure and routine are characterized by fewer cues for expected behavior, but nonetheless convey the same set of expectations as any other activity (i.e., clean up after yourself, abide by the rules of the center). Increases in the frequency of internalized compliance in such activities would be indicative of flexibility in self-regulatory behavior as well as internalization of standards.

6. If the preceding research questions are answered in the affirmative, do more complex prosocial behaviors become more frequent over time?

As children get older the nature of their prosocial behavior changes such that it shifts from being more spontaneous and geared toward the sharing of experiences in infancy and early toddlerhood, toward being more reasoned and/or directed more toward helping or caring for others. These behaviors are less spontaneous and more complex than 
"share my experience" behaviors and the ability to self-regulate behavior is thought to underpin the capacity to engage in them. 


\section{Chapter IV \\ Method}

Participants

Children enrolled at a child development center affiliated with a large software manufacturing corporation participated in this study. Children that participated in the study did so with the informed consent of their parents or primary caregiver. The sample $(N=21)$ was almost evenly divided between boys $(n=10)$ and girls $(n=11)$ and relatively homogeneous in terms of ethnicity. Caucasians made up $86.5 \%$ of the sample, $8.1 \%$ were Indian, and $2.7 \%$ were Asian. Children were grouped in three classrooms according to age at the start of the study: Infants $(n=6, M=41$ weeks), toddlers $(n=9, M=97$ weeks), and transitioners $(n=6, M=143$ weeks). All children had at least one parent that was employed by the company in a professional capacity.

\section{Setting}

The child development center was of exceptional quality, with a state of the art facility and highly qualified teachers. The center provided a constructivist curriculum in each classroom that was led by at least one master teacher who held a Bachelor's degree in early childhood education or human development and had a minimum of six years of teaching experience. Classrooms also had teacher assistants that were held to the same standard for teaching experience and had at least an Associate's degree in early childhood 
education or human development. As children got older and changed classrooms they did so as a group and stayed with the same master teacher for two years.

The content, structure and layout of each of the three classrooms (infant, toddler and transitioner) took into careful consideration the developmental level and needs of the children. The "classrooms" were actually a grouping of areas: A kitchen type space where the children ate and separate play areas that accommodated both active and quiet play. There were slight age-based variations across the three rooms; for example, the infant room had a changing area, while the toddler and transitioner rooms had child sized sinks and bathrooms. All rooms provided children access to a variety of age appropriate educational toys, building materials (e.g., blocks), books and games.

Additionally, there was a large outdoor play area adjacent to a wooded greenspace. The area was landscaped and had paths, several play structures, a large sandbox and a covered area. The children had access to tricycles, scooters, toy lawnmowers, t-ball and sandbox toys and were generally free to choose how they spent their time outdoors. Activity Contexts

Although the timing and duration of activities varied by classroom, particularly for infants, the children generally followed a schedule set forth by the teachers that included free play time, teacher directed activities, morning and afternoon snack, lunch and cleanup after meals. These activities represented the general structure of any given day; however, two finer grained distinctions were later made by the thesis author and will be described in detail in the following sections. There was also a scheduled napping period for the 
toddlers and transitioners after lunch, although no observations were conducted during this time.

Free play took place either inside or outside and was a time when children engaged in self-directed, self-initiated play using the resources that were available to them, such as books, dolls, building toys or the indoor play structures. Teacher directed activities, on the other hand, were teacher initiated, involved the use of limited resources (not usually available to the children) and had direct teacher involvement in the activity. Teacher directed activities included playing at the water tables and sand tables, making necklaces, preparing food, planting plants, painting, and playing with flubber. Children were expected to help with cleaning up at the end of free play or teacher directed activities by putting away toys and materials, hanging up smocks and washing hands.

The children ate as a group (segregated by class) three to four times each day (depending on arrival time) for breakfast, morning snack, lunch and afternoon snack. During meals the children sat at tables of four to five with a teacher. Teachers generally served the food, but provided opportunities for independent behavior. For example, beverages were poured into a small pitcher that the children could manage so that they could fill their own cups. Cleanup followed a set routine after each meal and children, with the exception of infants, were expected to clean up after themselves. Tubs for dishes, silverware and food scraps were provided and were always presented in the same arrangement. 
Design

The larger study was longitudinal with four times of measurement spaced evenly over six months, beginning on February 22, 1994 and continuing through August 23, 1994. The first measurement time was conducted with more participants and yielded a cross-sectional data set. The participants in the longitudinal study were a subset of the larger cross-sectional study conducted at Time 1. Observations were conducted daily for two weeks at each time of measurement. The present study will utilize the data collected at Times 1, 3 and 4, but for the purposes of this thesis, Time 3 will be referred to as the second measurement point (Time 2) and Time 4, as the third measurement point (Time 3). Procedure

All data were collected using videotape. Prior to the start of the actual data collection, each of the eight videographers spent approximately one week in each classroom so that the children could become habituated to both the videographers and their equipment. The children appeared to adjust well to their presence and only occasionally would direct attention to the camera and attempt to interact with the researcher. Only one videographer was on site at any given time.

Children were videotaped in three-minute segments as they went about their daily activities, with the exception of changing, toileting and napping. For each day, the children to be taped were determined by a randomly generated list. Time spent taping the children's varied activities was proportional to the amount of time the children spent in 
each one on a daily basis. Average total video for each child totaled 84 minutes for Time 1, 103 minutes for Time 2 and 113 minutes for Time 4.

Measures

Code Development. The observational coding scheme (henceforth referred to as the full code, with the coders who did that coding referred to as full coders) was developed by the original research team during the six months of videotaping and compiled into a codebook that included operational definitions, general coding instructions and guidelines for coding specific behaviors. Behaviors relevant to self-regulatory and prosocial development were identified through direct observation of the children's behavior and a review of the current literature. It is important to note that a measure of internalization was also developed and is unique to this study. Additionally, a coding scheme for daily activities and their location was developed.

When beginning to consider the relationship between behavior and activity, it became apparent that the coding scheme for activities in the full code was too general, and lacked clear guidelines for determining when certain activities ended and others began. For example, in the full code, the category "Free Play" could potentially include not only play, but putting away toys, and washing up before a meal as well.

A revised, more detailed code was developed by the thesis author by first conducting a review of video segments containing each of the activities recognized by the original code to identify which activities contained within the broader categories needed to be distinguished as unique. This review revealed three additional daily activities: cleanup 
after play, cleanup after meal and transitions between activities. Since a threeminute video segment often encompassed more than one activity, clear rules for determining when one activity ended and another began were needed. In order to address this issue, operational definitions were created for the three new activities, and those for the existing activities were revised to ensure that there was no overlap with the new ones. An extensive, additional review of segments was then conducted using the expanded range of activities and their revised operational definitions to identify the environmental cues and child behaviors that indicated a change in a child's activity. These were then compiled into a set of activity coding guidelines and included in the coding manual (see Appendix).

Behavior Measures. The full code was comprised of nineteen mutually exclusive and exhaustive codes for a range of self-regulatory and prosocial behaviors. When applicable, the codes also designated whether a behavior was self-initiated (performed independently) or adult-initiated (resulting from a teacher directive or prompt), and captured if a behavior was directed toward an adult, peer, or group containing both adults and peers. See Janssen (2005) for a complete listing of behaviors, their operational definitions and instructions for coding. Codes for self-regulatory behavior used in the present study were as follows:

1. Passive Compliance (COMPP). A code of passive compliance was given when a child did not resist a physical intervention made by the teacher. Interventions took many forms, but were often redirections of behavior (e.g., walking a child away from an undesirable behavior toward a desirable one), or assistance (e.g., helping an infant get 
seated at a table, or wiping an infant's nose). There was no initiation code for passive compliance.

It is important to note that COMPP, while it technically indicated compliance, was interpreted differently for children of different ages. For example, if an older child (toddler or transitioner) failed to comply with a teacher's request and the teacher intervened to guide the child's behavior, the ensuing code of COMPP was more indicative of non-compliance than it was outright compliant behavior. In effect, although the child did not resist when the teacher redirected his or her behavior, the intervention by the teacher was necessary in the first place because the child had been non-compliant. Following from this rationale, COMPP represented an analog to Kochanska's situational compliance for the purposes of the present study. Recall that situational compliance was defined as compliance that was cooperative, but unstable and required a high level of caregiver involvement. COMPP indicated non-resistance to a teacher's assistance or redirection (cooperation), but in the case of older children, such assistance or re-direction was typically called for only when a child failed to execute a requested behavior independently.

2. Adult-Initiated Compliance (AICOMP). This code was given when a child complied with a teacher's request within ten seconds following the end of the request. Requests were generally gentle reminders about expected behaviors for given situations, but could occasionally reference the immediate stoppage of an inappropriate or potentially dangerous behavior, such as aggression. 
AICOMP can be viewed as an intermediary step along the continuum of compliance that moves a child toward internalization. A code of AICOMP indicated that a child was able to perform an expected behavior after receiving a gentle reminder. In other words, the child did not remember what was expected independently, but was willing to perform the requested behavior independently once reminded. In this way, AICOMP represented an analog to Kochanska's committed compliance, which was defined as a willing acceptance of a caregiver's expectation.

3. Self-Initiated Compliance (SICOMP). These behaviors were evidence of internalization. A child received this code when he or she behaved in accordance with the center's rules and expectations without a prompt or reminder from the teacher. For example, a child who hung up his or her smock after painting, then went to wash hands without the teacher asking, exhibited that he or she understood what was expected in that situation - the expectation had been internalized.

4. Noncompliance through Commission (NONCO). Noncompliance through commission was coded when a child broke a rule of the center or actively defied a teacher's request by walking away or doing something different than what he or she was directed to do. Particularly for the youngest children, it was also coded when a child actively resisted a teacher's intervention, for example, turning away when it was time to have his or her face and hands washed.

5. Noncompliance through Omission (NONO). This code was given if a child did not directly defy a teacher's request, but nonetheless, failed to comply with the request within 
10 seconds. A child who did not clean up his or her dishes after a meal when

prompted to do so, yet did not actively engage in an opposite behavior, such as running off to play, was considered to be exhibiting noncompliance through omission.

6. Aggression (AGG). For the purposes of this study, an aggressive behavior was coded when a child hit, kicked or otherwise mistreated a peer, adult or object. AGG was also coded if a child made an attempt but missed, or if the intent to cause harm was verbalized but not acted upon. Codes for aggression also included a direction code to indicate whether the act involved a peer (DP), adult (DA) or object (DS).

7. Resource Violation $(R V)$. Resource violations were indicative of a child's failure to adhere to the "use your words" philosophy with regard to others' possessions. If an object or toy that was in the clear possession of or being actively used by another was taken without consent, a code of RV was given. This code also included a direction code that indicated from whom the item was taken \{i.e., an adult (DA) or peer (DP)\}.

Codes for prosocial behavior used in the present study were as follows:

1. Sharing (SHARE). SHARE was coded when a child voluntarily handed over an object that was in his or her possession or that was being used by him or her to another person. It was also coded when a child shared his or her physical space by creating room for another person.

2. Performing the Work of Adults (PWA). PWA was coded when a child took on the responsibility for a task normally done by an adult. Such tasks were not considered to be 
part of the child's regular duties (an example of a regular duty was cleaning up after oneself). Examples included wiping down tables, sweeping or setting up for a meal.

3. Helping (HELP). Help was coded when a job was done or assistance was provided that did not fall within the scope of Performing the Work of Adults. Included in this code were cleaning up after another person and teaching behaviors (e.g., giving advice or instructions that facilitated another's activity).

4. Assertive Problem Solving (APS). Children received a code of APS (either self or adult-initiated) when they used words to avoid or resolve a conflict, express certain desires, or defend their rights. Asking for a turn with a toy as opposed to taking it without asking (RV) was an example of APS.

Note: In prior analyses of these data, APS was considered a self-regulatory behavior. It was classified here as a prosocial behavior because it was seen as an extension of a self-regulatory behavior. For example, a child who refrains from grabbing a toy from a peer is self-regulating in the act of restraint; however, coupling the restraint with the use of words (e.g., "May I have a turn?") extends the regulatory behavior into a prosocial one because the child has shown respect for another and engaged in a social interaction.

Activity Measures. The expanded activity code identified six distinct daily activities, some of which were characterized by a high degree of structure and routine and others that were not. For example, cleaning up after meals was a highly structured and routinized activity. A cart containing bins for dishes, food scraps, silverware and garbage was set up for every meal in the same way. After every meal (three to four times per day) the children 
were expected to clear their dishes and put every item used for the meal in its proper receptacle. In contrast, free play, by definition, was not highly structured. Children were free to choose from a wide variety of toys and activities during this time, and although they were expected to abide by the rules of the center during free play, there were not set routines as to how they were supposed to play. Each activity, a brief operational definition, and a designation of whether it was considered to be high or low in structure and routine were identified as follows:

1. Mealtime (ME): High structure and routine. Children ate as a group three to four times a day, depending on how early a child arrived at the center in the morning (breakfast, morning snack, lunch, afternoon snack). Mealtime was coded even if the target child had chosen to abstain from the meal if everyone else in the classroom was at mealtime.

2. Meal Cleanup (CM): High structure and routine. This activity context was noted when a child began cleaning up his or her dishes after a meal on his or her own, or was asked by a teacher to do so.

3. Free play (FR): Low structure and routine. This context was coded when a child partook in self-chosen, self-directed activities using any of the available resources (e.g., toys, books, etc.). Play on the indoor play structures as well as most outdoor play was considered free play.

4. Teacher-directed Play (ST): Low structure and routine. Teacher-directed play differed from free play in that directed activities involved the use of limited resources (i.e., items that were provided by a teacher and not typically available as choices during free play) and a 
higher degree of teacher involvement than in free play. Examples of directed play activity included playing at the water table, painting and working with a variety of crafts.

5. Play Cleanup (CP): Low structure and routine. Cleaning up after play was coded if a child was asked to put away toys or supplies, or if a segment opened and cleaning was clearly in progress. Cleanup after play, whether it was directed or free, was considered a low routine activity because the variety of things that could have occurred during playtime means that cleaning up afterward would be different more often than it would be the same.

6. Transition (TR): High structure and routine. Transitions indicated a movement from one activity to another, such as washing hands after playtime before eating or putting on boots and a coat to go outside. Transition was coded when a child was prompted to begin the steps necessary to move to another activity. In cases in which a child received a code of SICOMP for initiating the steps without a reminder, TR was coded as starting when the code of SICOMP was given.

\section{Coding of Observations}

Children's behavior for each three-minute interval was coded in 10-second increments, unless the natural sequence of events required a faster pace. If no codeable behavior occurred between one 10-second mark and the next, a code of "Null" was recorded. Codeable behaviors that were sustained for longer than 10 seconds received the suffix of "ONGO". For example, a child who received a compliance code to wash his or her hands and took longer than 10 seconds to complete the task was coded for compliance at the onset of the behavior and COMPONGO at each 10-second mark thereafter until the 
hand washing was completed. Child initials, age in weeks, time of day, and location of activity (inside/outside) for each three-minute segment were also noted.

Although each three-minute segment in the full code was originally assigned an activity designation, it was necessary to recode the segments from the three times of measurement for the present study using the elaborated activity code described in the preceding section. The original coding indicated one activity, or a combination of activities for an entire segment, without an indication of what behaviors occurred during which activity or, in the case of multiple activities, when one ceased and another started. In the recoding, each segment was reviewed on videotape, while referencing the original full coder's behavior codes and notes. Revised coding sheets were created that allowed coders to assign an activity to each behavior that was recorded by the full coder.

Observational Coder Training. Coders for both the full and activity coding went through an extensive training program. The full coding training lasted six months to one year and the activity coding training lasted about three months. For both types of coders, training was done using a training tape consisting of 44 segments. These segments, or the "Gold Standard", covered the range of behaviors and activities identified in the code, drew from each time of measurement, and constituted a representative sample of the children in the study in terms of gender and age. ${ }^{1}$ An additional set of segments that contained frequent activity changes and the activities identified in the expanded code was also provided to the activity coders.

\footnotetext{
${ }^{1}$ Because of the length of time of coder involvement it was necessary to examine both within-coder consistency over time as well as cross-coder reliability.
} 
Trainees viewed these segments during weekly sessions with a trained coder and independently while comparing them to the sheets and codebook, and progressed to practicing coding those same segments. Training culminated with the coding of these segments using only the codebook to guide the trainee's decision making. These segments were then tested for reliability. Only after attaining an acceptable level of reliability on the training segments was a trainee allowed to begin coding the observations or re-coding the activities.

Reliability Testing. For the full coding, coding accuracy was assessed by conducting both within-rater and inter-rater reliability tests and using a computer program (Kindermann, 2000) to calculate an overall Kappa value. Within-rater reliability assessed each observer's reliability on the coding system after training and periodically over the course of a coder's involvement on the project. For each time of measurement, an overall Kappa value was calculated by averaging each coder's Kappa for the Gold Standard.

Within-rater reliabilities for the Time 1, Time 2 and Time 3 full coding were .89, .94, and .93 , respectively.

Inter-rater reliability tests assessed the degree to which different observers coded any given segment the same way. To determine inter-rater reliability for each measurement point's full coding, approximately $25 \%$ of each coder's segments were randomly selected for reliability testing and were coded by a second observer. In general, about four segments per observation day were chosen for assessing the reliability of the full code for each time of measurement. Inter-rater Kappa values for Time 1, Time 2, and Time 3 full coding were 
$.66, .70$, and .73 , respectively. Kappa values for both types of reliability testing were then averaged to an overall Kappa value. The overall Kappa values for Time 1, Time 2 and Time 3 were $.78, .82$, and .83 , respectively, indicating sufficient reliability.

The activity coding was a less lengthy process than was the full coding; therefore, only inter-rater reliability was assessed. To determine inter-rater reliability for each measurement point's activity coding, approximately $25 \%$ of each coder's segments were randomly selected for reliability testing and were coded by a second observer. In general, about four segments per observation day were chosen for assessing the reliability of the activity code for each time of measurement. Inter-rater Kappa values for the Time 1, Time 2 , and Time 3 activity coding were $.91, .87$, and .92 , respectively, indicating sufficient reliability.

Research Questions and Hypotheses

Do structured and routine daily activities scaffold the development of behavioral self-regulation and internalization? Are these activities "do" contexts that facilitate, rather than make difficult, compliance that leads to later internalization? This study first compared frequencies of compliant and non-compliant behaviors between routine and non-routine activity contexts to determine if there was a main effect for context on the frequency of compliant and non-compliant behaviors. The next set of hypotheses explored the main effect of context for each age group and over time, followed by an investigation of an interaction among context, age and time. Finally, the nature of the relationship between prosocial behavior and self-regulation was explored. Table 2 summarizes the 
compliant and noncompliant behaviors that were expected for each age group and their analogs (where appropriate) to Kochanska's forms of compliance. Table 3 presents activities that were characterized by low or high degrees of structure and routine.

1. In general, does the environment of the constructivist classroom support children's developing self-regulation such that it emerges earlier than age two and increases in average frequency over time?

The children of interest in this question were the toddlers, whose mean age at Time 1 was 97 weeks (1.8 years), and the transitioners, whose mean age at Time 1 was 143 weeks ( 2.75 years). The mean ages for both groups of children were below the age of three, the age at which the literature predicts that regulated behavior of this type will begin to emerge (Kochanska, Coy, \& Murray, 2001; Kopp, 1982).

- H1a: The average frequency of self-initiated compliance (SICOMP) at Time 1 will be greater than zero for both toddlers and transitioners.

- H1b: For both toddlers and transitioners there will be a linear increase in the average frequency of self-initiated compliance (SICOMP) from Time 1 to

Time 3.

2. Does the degree of structure and routine in children's daily activities affect children's ability to selfregulate?

- H2a: Behaviors indicative of self-regulation, i.e., compliance behaviors [passive compliance (COMPP), adult-initiated compliance (AICOMP), and self-initiated compliance (SICOMP)] will occur more frequently across all times of measurement 
in high structure and routine contexts [of mealtime (ME), mealtime cleanup (CM), and transitions (TR) than in low structure and routine contexts of free play (FR), directed play (ST), and playtime cleanup (CP)].

- H2b: Behaviors indicating low self-regulation, i.e., noncompliance behaviors [non-compliance through commission (NONCO), non-compliance through omission (NONO), aggression (AGG), and resource violation (RV)], will occur more frequently across all times of measurement in low structure and routine contexts than in high structure and routine contexts.

3. How does the degree of structure and routine in daily activities affect self-regulatory behavior in children of different ages?

These hypotheses address the effect of structure and routine in daily activities on compliant and non-compliant behavior for each age group.

For the oldest children (transitioners):

The pattern of behaviors is hypothesized to be the same for toddlers as it is for transitioners; however, the ratio of self-initiated compliance (SICOMP) to adult-initiated compliance (AICOMP) is likely to be higher for the older children than it will be for the younger children.

Passive compliance (COMPP), as noted in the operational definition, can be interpreted differently for older children. As children get older, compliance requiring caregiver intervention for its execution can be seen as an indicator of low self-regulation 
Table 2. Expectations for compliant and noncompliant behaviors

\begin{tabular}{|c|c|c|c|}
\hline Behavior & $\begin{array}{c}\text { Infants } \\
(\mathrm{M}=41 \text { weeks })\end{array}$ & $\begin{array}{c}\text { Toddlers } \\
(\mathrm{M}=1.8 \text { years })\end{array}$ & $\begin{array}{l}\text { Transitioners } \\
(\mathrm{M}=2.75 \text { years })\end{array}$ \\
\hline $\begin{array}{l}\text { Passive compliance } \\
\text { (COMPP) } \\
\text { Situational } \\
\text { compliance }\end{array}$ & Visible & Visible & $\begin{array}{c}\text { In conjunction with } \\
\text { noncompliance }\end{array}$ \\
\hline $\begin{array}{l}\text { Adult-initiated } \\
\text { compliance } \\
\text { (AICOMP) } \\
\text { Committed } \\
\text { compliance }\end{array}$ & $\begin{array}{l}\text { Very early } \\
\text { emergence }\end{array}$ & Visible & Visible \\
\hline $\begin{array}{l}\text { Self-initiated } \\
\text { compliance } \\
\text { (SICOMP) } \\
\text { Internalization }\end{array}$ & Not yet present & Visible & Visible \\
\hline $\begin{array}{l}\text { Noncompliance by } \\
\text { commission }\end{array}$ & $\begin{array}{c}\text { Active } \\
\text { Not allowed }\end{array}$ & $\begin{array}{c}\text { Active } \\
\text { Not allowed }\end{array}$ & $\begin{array}{c}\text { Active } \\
\text { Not allowed }\end{array}$ \\
\hline $\begin{array}{l}\text { Noncompliance by } \\
\text { omission }\end{array}$ & Passive & Passive & Passive \\
\hline Aggression & Not allowed & Not allowed & Not allowed \\
\hline Resource violation & Not allowed & Not allowed & Not allowed \\
\hline
\end{tabular}

Table 3. Low and high structure and routine activities

\begin{tabular}{cc}
\hline & \\
Low Structure and Routine Activities & High Structure and Routine Activities \\
\hline Free play & Mealtime \\
Teacher directed play & Mealtime cleanup \\
Play cleanup & Transitions \\
\hline
\end{tabular}


(i.e., a step backward). Therefore, COMPP was included as a behavior indicative of low self-regulation for the transitioners.

- H3a: For the oldest children (transitioners), self-regulatory, i.e., compliance behaviors associated with emerging internalization [self-initiated compliance (SICOMP) and adult-initiated compliance (AICOMP)] will occur more frequently in high structure and routine contexts than in low structure and routine contexts and the average frequency of self-initiated compliance (SICOMP) will be greater than the average frequency of adult-initiated compliance (AICOMP).

- H3b: For the oldest children (transitioners), behaviors indicative of low selfregulation, i.e., noncompliance [passive compliance (COMPP), non-compliance through omission (NONO), non-compliance through commission (NONCO), resource violation $(\mathrm{RV})$, and aggression $(\mathrm{AGG})$ ] will occur less frequently in the high structure and routine contexts than in the low structure and routine contexts. For the middle children (toddlers): Although the pattern of behaviors is hypothesized to be the same for toddlers as it is for transitioners, because the younger children were not as far along developmentally, the ratio of self-initiated compliance (SICOMP) to adultinitiated compliance (AICOMP) is likely to be lower for the younger children than it will be for the older children. For toddlers, exhibiting adult- and self-initiated compliant behaviors was a more newly acquired ability than it was for the transitioners, and as such it was likely that they sometimes needed more support than older children. Passive compliance (COMPP) was therefore seen as neither being associated with emerging 
internalization, nor indicative of low self-regulation, and was not included in the hypotheses for the middle children.

- H3c: For the middle children (toddlers), self-regulatory, i.e., compliance behaviors associated with emerging internalization [self-initiated compliance (SICOMP) and adult-initiated compliance (AICOMP)] will occur more frequently in high structure and routine contexts than in low structure and routine contexts and the average frequency of adult-initiated compliance (AICOMP) will be greater than the average frequency of self-initiated compliance (SICOMP).

- H3d: For the middle children (toddlers), behaviors indicative of low selfregulation, i.e., noncompliance [non-compliance through omission (NONO), noncompliance through commission (NONCO), resource violation (RV), and aggression (AGG)] will occur less frequently in the high structure and routine contexts than in the low structure and routine contexts.

For the youngest children (infants): Passive compliance (COMPP) was the only selfregulatory behavior examined for this age group. A code of COMPP was given when a child exhibited non-resistance to an intervention made by a teacher on the child's behalf; the child was seen as "going along with" the teacher's wishes, which represented a significant self-regulatory effort. Self-initiated compliance (SICOMP) and adult-initiated compliance (AICOMP) were not evaluated because, in accordance with developmentally appropriate practice, this age group was seldom given prompts to perform independent behaviors. The cross-sectional data analysis confirmed that the average frequency in infants 
for SICOMP was almost zero and the average frequency for AICOMP was very low (compared to the other age groups) (Janssen, 2005).

Additionally, infants did not regularly participate in several of the activity contexts. In general, they were not expected to clean up after themselves after meals (CM) or play (CP) and did not often engage in teacher-directed play (ST), as most directed play activities were beyond the infants' developmental level. Consequently, the average frequencies for infant behaviors were compared for the three contexts in which they did participate: Mealtime (ME, high structure and routine), Transitions (TR, high structure and routine) and Free Play (FR, low structure and routine).

- H3e: For the youngest children (infants), evidence for early self-regulation, passive compliance (COMPP), will occur more frequently in high structure and routine contexts [mealtime $(\mathrm{ME})$ and transitions $(\mathrm{TR})]$ than in a low stricture and routine context, free play (FR).

- H3f: For the youngest children (infants), behaviors indicative of low selfregulation, i.e., noncompliance [non-compliance through omission (NONO), noncompliance through commission (NONCO), resource violation (RV), and aggression (AGG)] will occur more frequently in a low structure and routine context, free play (FR), than in high structure and routine contexts [mealtime (ME) and transitions (TR)]. 
4. Does the degree of structure and routine in daily activities affect children's self-regulated behavior over time?

These hypotheses address mean level changes in compliance and noncompliance over time in the low and high structure and routine activity contexts for toddlers and transitioners taken together.

- H4a: The average frequency of compliance behaviors, including self-initiated compliance (SICOMP) and adult-initiated compliance (AICOMP), will increase from Time 1 to Time 3 in both high and low structure and routine contexts. However, at both times of measurement, mean levels of SICOMP and AICOMP will be higher in high structure and routine contexts than in low structure and routine contexts for toddlers and transitioners.

- H4b: The average frequencies for behaviors indicative of low self-regulation, i.e., noncompliance, including passive compliance (COMPP), non-compliance through omission (NONO), non-compliance through commission (NONCO), resource violation (RV), and aggression (AGG), will decrease from Time 1 to Time 3 in both high and low structure and routine contexts. However, at both times of measurement, mean levels for each of these behaviors will be lower in high structure and routine contexts than in low structure and routine contexts for toddlers and transitioners. 
5. Do structure and routine scaffold internalization such that, over time, the frequency of internalized behavior in the low structure and routine contexts catches up with the frequency of internalized behavior in the high structure and routine contexts, and are there age differences associated with the pattern of change?

- H5: For the transitioners, from Time 1 to Time 3 there should be an increase in the average frequency of SICOMP in low structure and routine contexts such that the difference in average frequency of SICOMP between the high and low routine contexts becomes attenuated, whereas for toddlers, there should be a linear increase in average frequency of SICOMP from Time 1 to Time 3 in both the low and high structure and routine contexts.

6. If the preceding research questions have been answered in the affirmative, do the more complex prosocial behaviors become more frequent over time for toddlers and transitioners?

- H6: Frequencies of complex prosocial behaviors [sharing (SHARE), helping (HELP), performing the work of adults (PWA) and assertive problem solving (APS)] will increase from Time 1 to Time 3 for children in the two oldest classrooms. 


\section{Chapter V}

Results

\section{Data Reduction}

For each time of measurement, the full and activity coding captured the frequency of each behavior and its associated activity per child per three-minute segment. For the purposes of data analysis, these raw frequencies per child were converted to average frequencies. For each behavior, a daily average frequency was calculated by dividing the raw frequency by the number of times each day a child was observed (i.e., number of threeminute segments). This procedure was done for each child.

For all analyses, the low structure and routine activity contexts of play cleanup (CP), free play (FR), and teacher-directed play (ST) were combined into a single aggregate factor: low structure and routine activity contexts. High structure and routine activities of meal cleanup (CM), mealtime (ME), and transitions (TR) were combined into a single aggregate factor: high structure and routine activity contexts.

Research Question 1: In general, does the environment of the constructivist classroom support children's developing self-regulation such that it emerges earlier than age two and increases in average frequency over time?

Two one-way repeated measures analysis of variance (ANOVA) tests were conducted to determine whether the average frequency of self-initiated compliance (SICOMP) in the longitudinal study followed the same pattern as was found in the results 
of the cross-sectional study conducted with the same data. The factor, time, had three levels (Time 1, Time 2, Time 3). The dependent variables were average frequencies of SICOMP for toddlers and transitioners. Figure 2 presents the mean levels of SICOMP from Time 1 to Time 3 for each age group.

H1a: The average frequency of selfinitiated compliance (SICOMP) at Time 1 will be greater than zero for both toddlers and transitioners. At Time 1 the average frequency of SICOMP was greater than zero for both toddlers $(M=3.86, S D=3.81)$ and transitioners $(M=2.87, S D=1.66)$.

H1b: For both toddlers and transitioners there will be a linear increase in the average frequency of self-initiated compliance (SICOMP) from Time 1 to Time 3. The linear trend was not significant for either the toddlers, $F(1,8)=.96, p=.35$, partial $-\eta^{2}=.11$ or the transitioners, $F(1,4)=2.14, p=.21$, partial $-\eta^{2}=.35$, indicating that mean levels of SICOMP did not vary significantly from Time 1 to Time 3. Although the linear trends were not significant, it is important to note that, for the transitioners, mean levels of SICOMP did increase from Time $1(M=2.87, S D=1.66)$ to Time 2 $(M=3.53, S D=2.56)$ and Time $3(M=5.02, S D=3.86)$. For the toddlers, mean levels of SICOMP increased from Time $1(\mathrm{M}=3.86, \mathrm{SD}=3.81)$ to Time $2(\mathrm{M}=$ $6.67, S D=3.43)$ and decreased at Time $3(M=5.48, S D=4.21)$. 


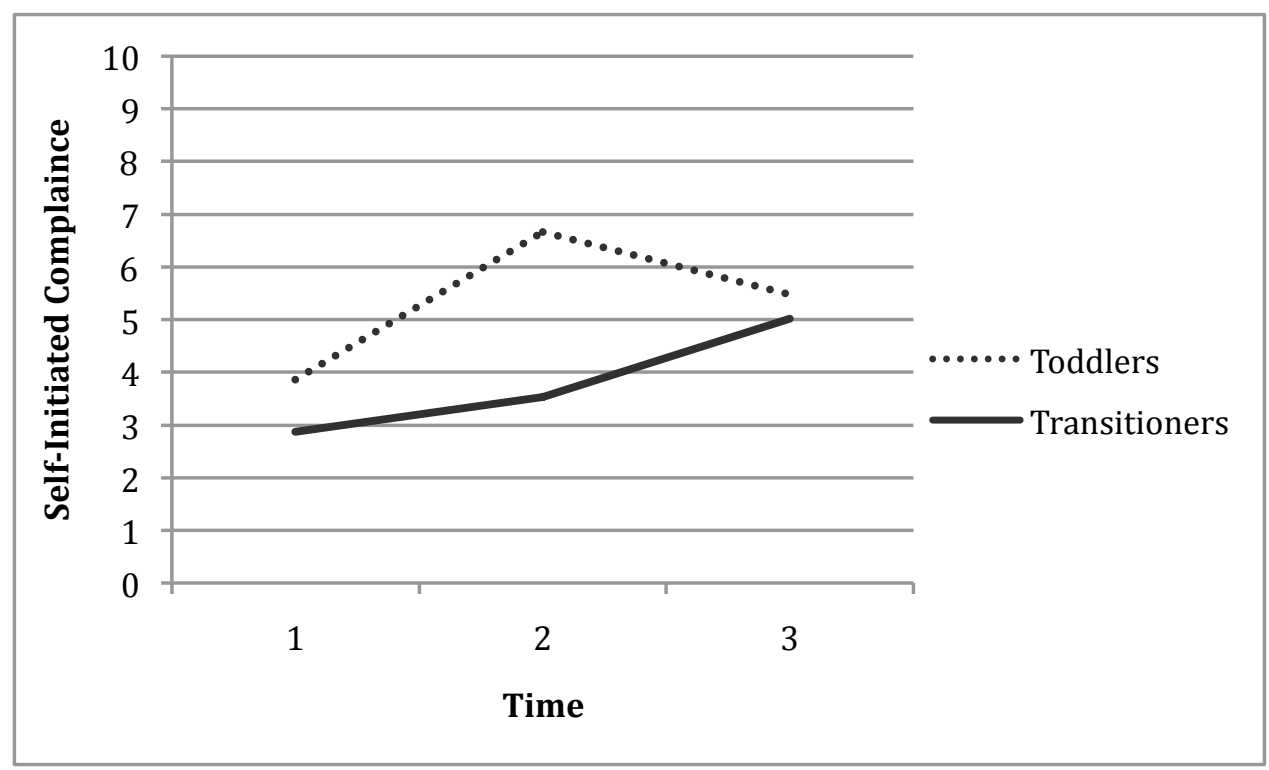

Figure 2. Mean levels of self-initiated compliance (SICOMP) from Time 1 to Time 3 for toddlers and transitioners. 
Research Question 2: Does the degree of structure and routine in children's daily activities affect children's ability to self-regulate?

A series of one-way repeated measures ANOVA tests were conducted to determine whether average frequencies of compliant and noncompliant behavior differed between low and high structure and routine activities. The factor, activity context, had two levels (low structure and routine, high structure and routine). The dependent variables for compliant behaviors were average frequencies of self-initiated compliance (SICOMP), adult-initiated compliance (AICOMP), and passive compliance (COMPP). The dependent variables for noncompliant behavior were average frequencies of noncompliance by omission (NONO), noncompliance by commission (NONCO), resource violation (RV), and aggression (AGG). Descriptive statistics for each behavior, $p$-values and estimates of effect size are presented in Table 4. Figures 3 and 4 present mean levels for compliant and noncompliant behaviors in the two activity contexts, respectively.

H2a: The average frequencies of compliance behaviors will be greater in the high structure and routine context than in the low structure and routine context.

For self-initiated compliance (SICOMP): The results for SICOMP were as predicted. The main effect for context was significant, $F(1,19)=13.04, p<.01$, partial- $\eta^{2}=.41$. Averaging over time, there were significant differences between the contexts such that the mean level of SICOMP was greater in the high structure and routine activity context $(M=7.86, S D=6.78)$ than in the low structure and routine activity context $(M=2.66, \mathrm{SD}=2.89)$. 
For adult initiated compliance (AICOMP): Results for AICOMP were not as predicted. The main effect for context was not significant, $F(1,19)=2.15$, $p$ $=.16$, partial $-\eta^{2}=.10$, indicating that, averaging over time, the mean level of AICOMP did not vary significantly between the low and high structure and routine contexts. Although the difference was not significant, it should be noted that the mean level of AICOMP was greater in the low structure and routine activity context $(M=16.85, S D=11.96)$ than in the high structure and routine activity context $(M$ $=13.02, S D=8.07$.

For passive compliance (COMPP): Results for COMPP were not as predicted. The main effect for context was not significant, $F(1,19)=.73, p=.40$, partial $-\eta^{2}=$ .04 , indicating that, averaging over time, the mean level of COMPP did not vary significantly between the low and high structure and routine contexts. Although the difference was not significant, it should be noted that the mean level of COMPP was greater in the low structure and routine activity context $(M=14.22$, $S D=9.72)$ than in the high structure and routine activity context $(M=12.76, S D=$ 8.01).

H2b: The average frequencies of noncompliant behaviors will be greater in the low structure and routine context than in the high structure and routine context.

For noncompliance by omission (NONO): The results for NONO were not as predicted. The main effect for context was not significant, $F(1,19)=.007, p=.93$, partial- $\eta^{2}=.00$, indicating that, averaging over time, the mean level of NONO did 
not vary significantly between low $(M=1.44, S D=1.19)$ and high $(M=1.46$, $S D=1.44)$ structure and routine activity contexts.

For noncompliance by commission (NONCO): The results for NONCO were as predicted. The main effect for context was significant, $F(1,19)=18.93, p<.01$, partial- $\eta^{2}=.51$. Averaging over time, there were significant differences between the contexts such that the mean level of $\mathrm{NONCO}$ was greater in the low structure and routine activity context $(M=12.55, S D=10.14)$ than in the high structure and routine activity context $(M=3.36, S D=2.51)$.

For resource violation $(R V)$ : The results for $R V$ were as predicted. The main effect for context was significant, $F(1,19)=49.78, p<.01$, partial- $\eta^{2}=.72$. Averaging over time, there were significant differences between the contexts such that mean level of RV was greater in the low structure and routine activity context $(M=4.31, S D=3.09)$ than in the high structure and routine activity context $(M=$ $.53, \mathrm{SD}=1.05)$

For aggression (AGG): The results for AGG were as predicted. The main effect for context was significant, $F(1,19)=22.20, p<.01$, partial $-\eta^{2}=.5$ Averaging over time, there were significant differences between the contexts such that the mean level of AGG was greater in the low structure and routine activity context (M $=23.36, \mathrm{SD}=21.82)$ than in the high structure and routine activity context $(\mathrm{M}=$ $1.49, \mathrm{SD}=2.51)$ 
Table 4. Descriptive statistics, $p$-values and estimates of effect size for compliant and noncompliant behaviors in low and high structure and routine activity contexts

\begin{tabular}{lcc|cc|cc}
\multicolumn{7}{c}{ Structure and Routine } \\
& \multicolumn{7}{c}{ Low } & \multicolumn{2}{c}{ High } & \\
\hline Behavior & M & SD & M & SD & partial- $\eta^{2}$ \\
\hline $\begin{array}{l}\text { Self-initiated compliance } \\
\text { (SICOMP) }\end{array}$ & 2.66 & 2.89 & 7.86 & 6.78 & .00 & .41 \\
$\begin{array}{l}\text { Adult-initiated compliance } \\
\text { (AICOMP) }\end{array}$ & 16.85 & 11.96 & 13.02 & 8.07 & .16 & .10 \\
$\begin{array}{l}\text { Passive compliance } \\
\text { (COMPP) }\end{array}$ & 14.22 & 9.72 & 12.76 & 8.01 & .40 & .04 \\
$\begin{array}{l}\text { Noncompliance by } \\
\text { omission (NONO) }\end{array}$ & 1.44 & 1.17 & 1.46 & 1.46 & .93 & .00 \\
$\begin{array}{l}\text { Noncompliance by } \\
\text { commission (NONCO) }\end{array}$ & 12.55 & 10.14 & 3.36 & 2.51 & .00 & .61 \\
$\begin{array}{l}\text { Resource violation } \\
\text { (RV) }\end{array}$ & 4.31 & 3.10 & .53 & 1.05 & .00 & .72 \\
$\begin{array}{l}\text { Aggression } \\
\text { (AGG) }\end{array}$ & 23.36 & 21.83 & 1.48 & 2.50 & .00 & .54 \\
\hline
\end{tabular}




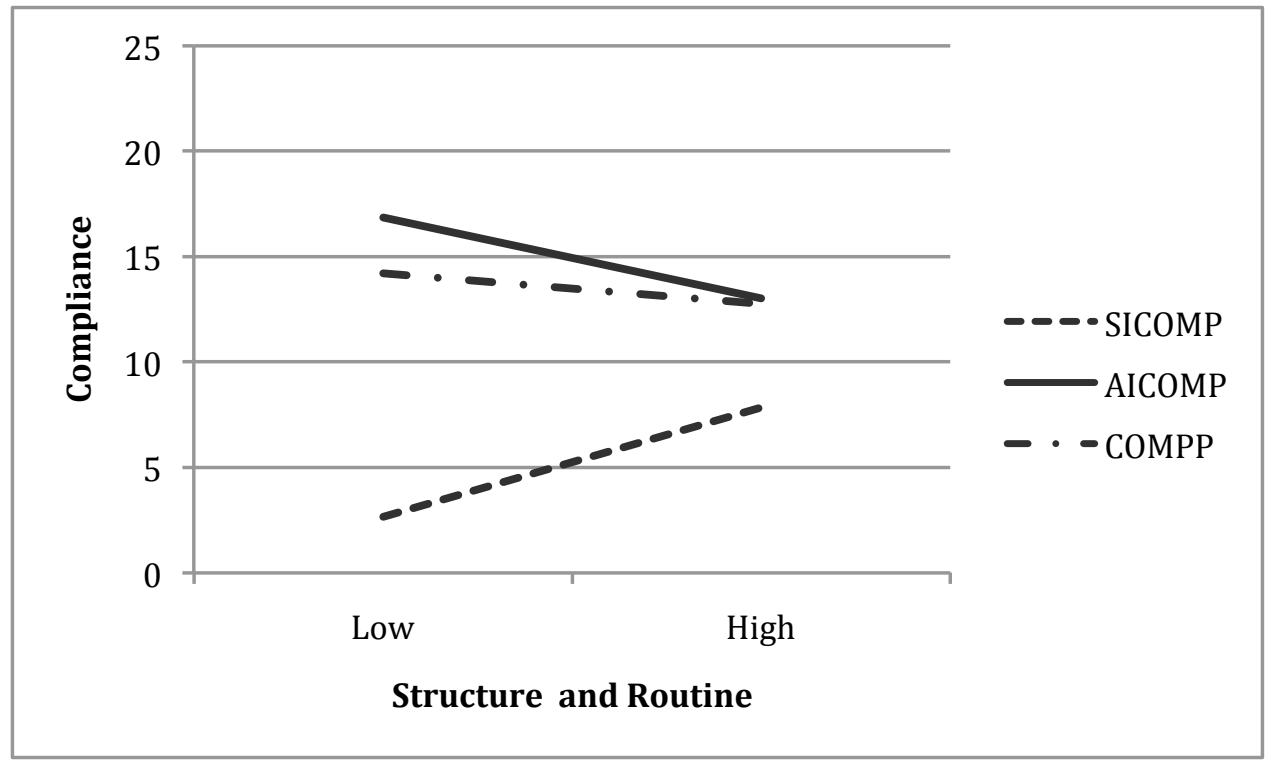

Figure 3. Main effect of activity context on compliant behavior Key: SICOMP = self-initiated compliance, AICOMP $=$ adult-initiated compliance, $\mathrm{COMPP}=$ passive compliance

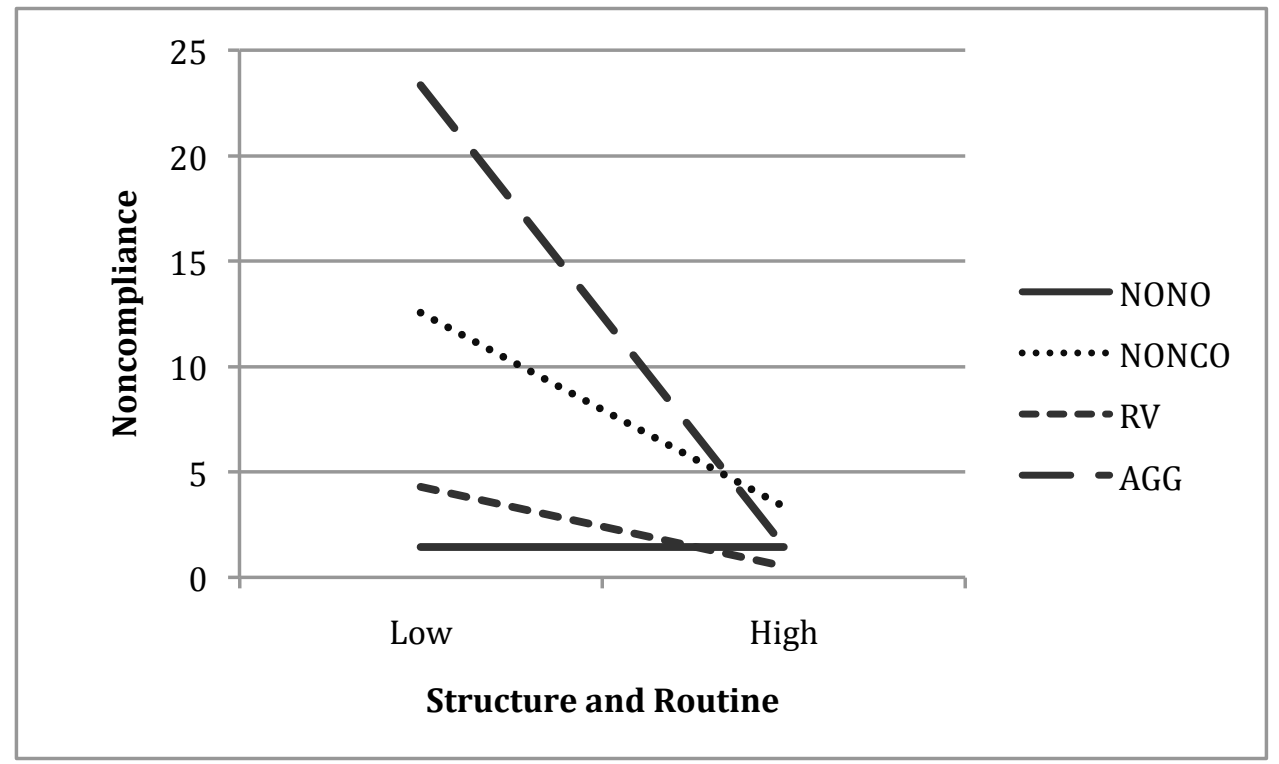

Figure 4. Main effect of activity context on noncompliant behavior Key: $\mathrm{NONO}=$ noncompliance by omission, $\mathrm{NONCO}=$ noncompliance by commission, $\mathrm{RV}=$ resource violation, $\mathrm{AGG}=$ aggression 
Research Question 3: How does the degree of structure and routine in daily activities affect self-regulatory behavior in children of different ages?

For the oldest children (transitioners): A series of one-way repeated measures ANOVA tests were conducted to determine whether average frequencies of compliant and noncompliant behavior varied between low and high structure and routine activities for this age group. The factor, activity context, had two levels (low structure and routine, high structure and routine). The dependent variables for compliant behaviors were average frequencies of self-initiated compliance (SICOMP) and adult-initiated compliance (AICOMP). The dependent variables for noncompliant behavior were average frequencies of passive compliance (COMPP), noncompliance by omission (NONO), noncompliance by commission (NONCO), resource violation (RV), and aggression (AGG). Means, p-values and estimates of effect size are presented in Table 5. Figures 5 and 6 present mean levels for compliant and noncompliant behaviors in the two activity contexts, respectively.

H3a: For transitioners, the average frequencies of compliance behaviors should be greater in the high structure and routine context than in the low structure and routine context and the average frequency of self-initiated compliance will be greater than the average frequency of adult-initiated compliance.

For self-initiated compliance (SICOMP): Results for SICOMP were partially as predicted. The main effect for context was marginally significant, $F(1,4)=4.78$, $p$ $=.09$, partial $-\eta^{2}=.54$. Averaging over time, the mean level of SICOMP tended to be greater in the high structure and routine activity context $(M=8.01, S D=5.57)$ 
than in the low structure and routine activity context $(M=3.41, S D=1.99)$.

Contrary to predictions, the average frequencies of SICOMP were not greater than the average frequencies of AICOMP.

For adult-initiated compliance (AICOMP): Results for AICOMP were not as predicted. The main effect for context was not significant, $F(1,4)=1.71, p=.26$, partial- $\eta^{2}=.30$, indicating that, averaging over time, the mean level of AICOMP did not vary significantly between the low and high structure and routine contexts. Although the difference was not significant, it should be noted that the mean level of AICOMP was greater in the low structure and routine activity context $(\mathrm{M}=$ $24.51, S D=17.02)$ than in the high structure and routine activity context $(M=$ 13.59, $S D=8.15)$

$H 3 b$ : For transitioners, the average frequencies of noncompliant behaviors will be greater in the low structure and routine context than in the high structure and routine context.

For passive compliance (COMPP): Results for COMPP were not as predicted. The main effect for context was not significant, $F(1,4)=.01, p=.92$, partial- $\eta^{2}=$ .003 , indicating that, averaging over time, the mean level of COMPP did not vary significantly between the low and high structure and routine contexts.

For noncompliance by omission (NONO): Results for NONO were not as predicted. The main effect for context was not significant, $F(1,4)=.77, p=.43$, partial- $\eta^{2}=.16$, indicating that, averaging over time, the mean level of NONO did 
not vary significantly between the low $(M=.53, \mathrm{SD}=.48)$ and the high $(\mathrm{M}=$ $1.02, \mathrm{SD}=1.35)$ structure and routine activity contexts.

For noncompliance by commission (NONCO): Results for NONCO were not as predicted. The main effect for context was not significant, $F(1,4)=3.22, p=$ .17 , partial- $\eta^{2}=.52$. Averaging over time, the mean level of NONCO did not vary significantly between the low and high structure and routine contexts. Although the difference was not significant, it should be noted that the mean level of $\mathrm{NONCO}$ was greater in the low structure and routine activity context $(\mathrm{M}=14.6$, $S D=13.05)$ than in the high structure and routine activity context $(M=4.0, S D=$ 2.94).

For resource violation $(R V)$ : Results for RV were as predicted. The main effect for context was significant, $F(1,4)=19.27, p<.01$, partial- $\eta^{2}=.83$. Averaging over time, the mean level of RV was greater in the low structure and routine activity context $(M=2.70, S D=1.23)$ than in the high structure and routine activity context $(\mathrm{M}=.27, \mathrm{SD}=.38)$.

For aggression (AGG): Results for AGG were partially as predicted. The main effect for context was marginally significant, $F(1,4)=4.40, p=.10$, partial- $\eta^{2}$ $=.52$. Averaging over time, the mean level of AGG tended to be greater in the low structure and routine activity context $(M=32.86, S D=33.22)$ than in the high structure and routine activity context $(M=4.2, S D=3.86)$. 
Table 5. Descriptive statistics for compliant and noncompliant behaviors in low and high structure and routine activity contexts for transitioners, toddlers and infants

\begin{tabular}{|c|c|c|c|c|c|c|}
\hline \multicolumn{7}{|c|}{ Structure and Routine } \\
\hline & \multicolumn{2}{|c|}{ Low } & \multicolumn{2}{|c|}{ High } & \multirow[b]{2}{*}{$p$} & \multirow[b]{2}{*}{ partial- $\eta^{2}$} \\
\hline Behavior & $M$ & SD & M & SD & & \\
\hline \multicolumn{7}{|c|}{ Transitioners } \\
\hline $\begin{array}{l}\text { Self-initiated compliance } \\
\text { (SICOMP) }\end{array}$ & 3.41 & 1.99 & 8.01 & 5.57 & $.09^{*}$ & .54 \\
\hline $\begin{array}{l}\text { Adult-initiated } \\
\text { compliance (AICOMP) } \\
\text { Passive compliance }\end{array}$ & 24.51 & 17.02 & 13.59 & 8.15 & .26 & .30 \\
\hline (COMPP) & 6.82 & 3.96 & 7.02 & 4.65 & .92 & .00 \\
\hline $\begin{array}{l}\text { Noncompliance by } \\
\text { omission (NONO) }\end{array}$ & 1.51 & 1.01 & .87 & 1.19 & .43 & .16 \\
\hline $\begin{array}{l}\text { Noncompliance by } \\
\text { commission (NONCO) }\end{array}$ & 14.60 & 13.06 & 4.00 & 2.94 & .17 & .52 \\
\hline $\begin{array}{l}\text { Resource violation } \\
\text { (RV) }\end{array}$ & 2.70 & 1.23 & .27 & .38 & $.01^{* *}$ & .83 \\
\hline $\begin{array}{l}\text { Aggression } \\
(\mathrm{AGG})\end{array}$ & 32.86 & 33.22 & 4.20 & 3.86 & $.10^{*}$ & .52 \\
\hline \multicolumn{7}{|c|}{ Toddlers } \\
\hline $\begin{array}{l}\text { Self-initiated compliance } \\
\text { (SICOMP) }\end{array}$ & 3.64 & 3.55 & 12.87 & 5.86 & $.00^{* * *}$ & .61 \\
\hline $\begin{array}{l}\text { Adult-initiated } \\
\text { compliance (AICOMP) }\end{array}$ & 18.63 & 7.78 & 18.09 & 4.99 & .87 & .00 \\
\hline $\begin{array}{l}\text { Noncompliance by } \\
\text { omission (NONO) }\end{array}$ & 2.00 & 1.30 & 2.09 & 1.51 & .85 & .00 \\
\hline $\begin{array}{l}\text { Noncompliance by } \\
\text { commission (NONCO) }\end{array}$ & 12.84 & 8.54 & 1.94 & 1.71 & $.00^{* * *}$ & .70 \\
\hline $\begin{array}{l}\text { Resource violation } \\
\text { (RV) }\end{array}$ & 3.71 & 2.67 & .08 & .17 & $.00^{* * *}$ & .69 \\
\hline $\begin{array}{l}\text { Aggression } \\
\text { (AGG) }\end{array}$ & 27.14 & 18.23 & .33 & .56 & $.00^{* * *}$ & .71 \\
\hline \multicolumn{7}{|c|}{ Infants } \\
\hline $\begin{array}{l}\text { Passive compliance } \\
\text { (COMPP) }\end{array}$ & 23.79 & 12.27 & 22.29 & 5.04 & .78 & .01 \\
\hline $\begin{array}{l}\text { Noncompliance by } \\
\text { omission (NONO) }\end{array}$ & .53 & .48 & 1.02 & 1.35 & .41 & .12 \\
\hline $\begin{array}{l}\text { Noncompliance by } \\
\text { commission (NONCO) }\end{array}$ & 10.75 & 11.99 & 5.08 & 2.31 & .24 & .26 \\
\hline $\begin{array}{l}\text { Resource violation } \\
\text { (RV) } \\
\text { Aggression }\end{array}$ & 6.56 & 3.80 & 1.42 & 1.62 & $.00^{* * *}$ & .84 \\
\hline $\begin{array}{l}\text { Aggression } \\
\text { (AGG) }\end{array}$ & 9.77 & 7.61 & .95 & 1.14 & $.04^{* *}$ & .59 \\
\hline
\end{tabular}

$* * *$ Significant at $p<.001$

** Significant at $p<.05$

${ }^{*}$ Marginally significant $(p \leq .10)$ 


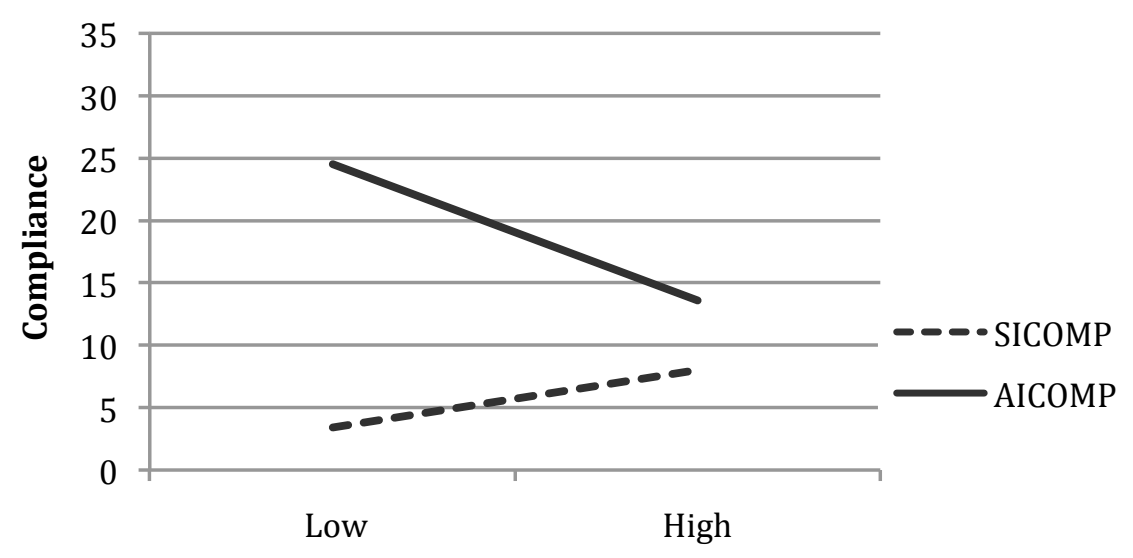

Structure and Routine

Figure 5. Effect of context on compliant behavior for transitioners

Key: SICOMP $=$ self-initiated compliance, AICOMP $=$ adult-initiated compliance

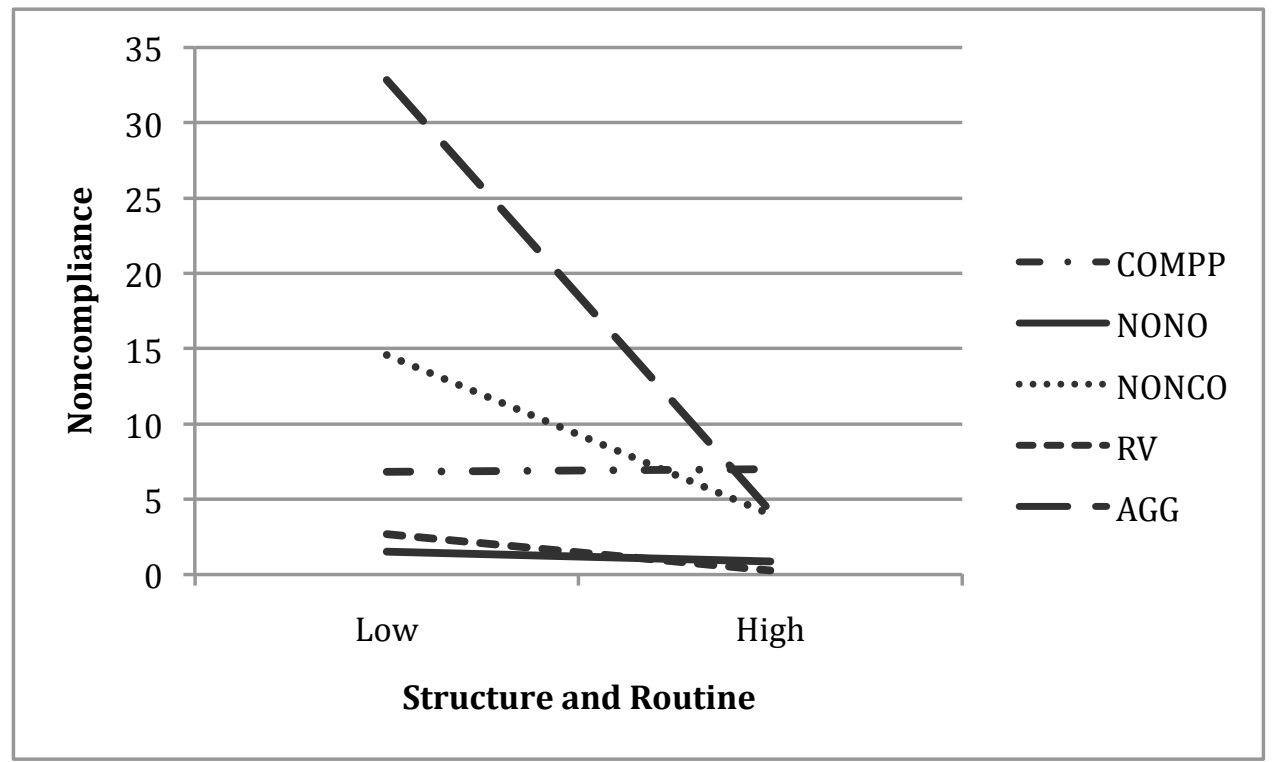

Figure 6. Effect of context on noncompliant behavior for transitioners Key: $\mathrm{COMPP}=$ passive compliance, $\mathrm{NONO}=$ noncompliance by omission, $\mathrm{NONCO}=$ noncompliance by commission, $\mathrm{RV}=$ resource violation, $\mathrm{AGG}=$ aggression 
For the middle children (toddlers): A series of one-way repeated measures

ANOVA tests were conducted to determine whether average frequencies of compliant and noncompliant behavior varied between low and high structure activities for this age group. The factor, activity context, had two levels (low structure and routine, high structure and routine). The dependent variables for compliant behaviors were average frequencies of selfinitiated compliance (SICOMP) and adult-initiated compliance (AICOMP). The dependent variables for noncompliant behavior were average frequencies of noncompliance by omission (NONO), noncompliance by commission (NONCO), resource violation $(\mathrm{RV})$, and aggression (AGG). Means, p-values and estimates of effect size are presented in Table 5. Figures 7 and 8 present mean levels for compliant and noncompliant behaviors in the two activity contexts, respectively.

$\mathrm{H} 3 \mathrm{c}$ : For toddlers, the average frequencies of compliance behaviors will be greater in the high structure and routine context than in the low structure and routine context and the average frequency of adult-initiated compliance will be greater than the average frequency of selfinitiated compliance.

For self-initiated compliance (SICOMP): Results for SICOMP were as predicted. The main effect for context was significant, $F(1,9)=12.41, p<.01$, partial $-\eta^{2}=.61$. Averaging over time, the mean level of SICOMP was greater in the high structure and routine activity context $(M=12.37, S D=5.86)$ than in the low structure and routine activity context $(M=3.64, S D=3.55)$. 
H3d: For toddlers, the average frequencies of noncompliant behaviors will be greater in low structure and routine contexts than in high structure and routine contexts.

For adult-initiated compliance (AICOMP): Results for AICOMP were not as predicted. The main effect for context was not significant, $F(1,8)=.03, p=.87$, partial- $\eta^{2}=.004$, indicating that, averaging over time, the mean level of AICOMP did not vary significantly between the low $(M=18.63, S D=7.78)$ and the high $(M$ $=18.10, \mathrm{SD}=4.99)$ structure and routine contexts. However, the average frequencies of adult-initiated compliance were greater than the average frequencies of self-initiated compliance.

$\mathrm{H} 3 \mathrm{c}$ : For toddlers, the average frequencies of non-compliance behaviors will be greater in the high structure and routine context than in the low structure and routine context.

For noncompliance by omission (NONO): Results for NONO were not as predicted. The main effect for context was not significant, $F(1,9)=.04, p=.85$, partial- $\eta^{2}=.005$, indicating that, averaging over time, the mean level of NONO did not vary significantly between the low $(M=2.0, S D=1.31)$ and the high $(M=$ $2.09, \mathrm{SD}=1.51)$ structure and routine activity contexts.

For noncompliance by commission (NONCO): Results for NONCO were as predicted. The main effect for context was significant, $F(1,9)=18.74, p<.01$, partial- $\eta^{2}=$ .70. Averaging over time, the mean level of NONCO was greater in the low structure and routine activity context $(M=12.84, S D=8.54)$ than in the high structure and routine activity context $(M=1.94, S D=1.71)$. 


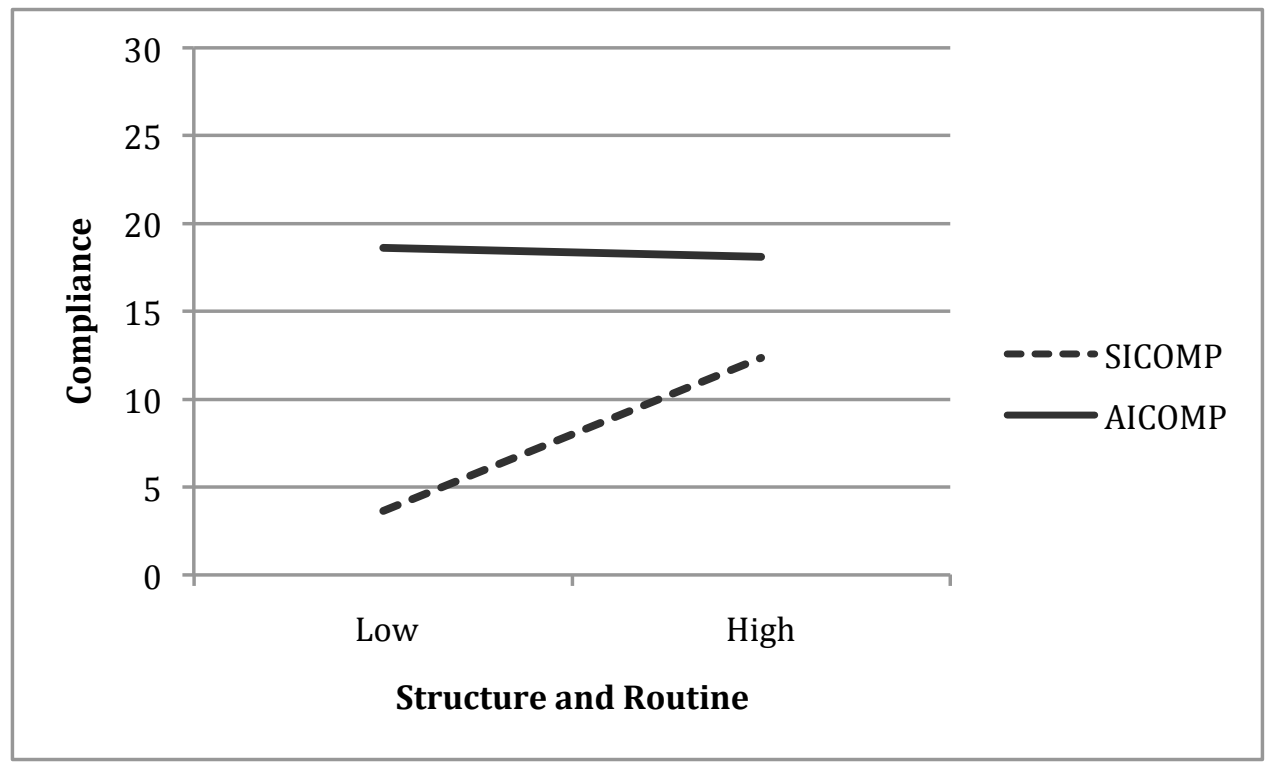

Figure 7. Effect of context on compliant behavior for toddlers

Key: SICOMP $=$ self-initiated compliance, AICOMP $=$ adult-initiated compliance

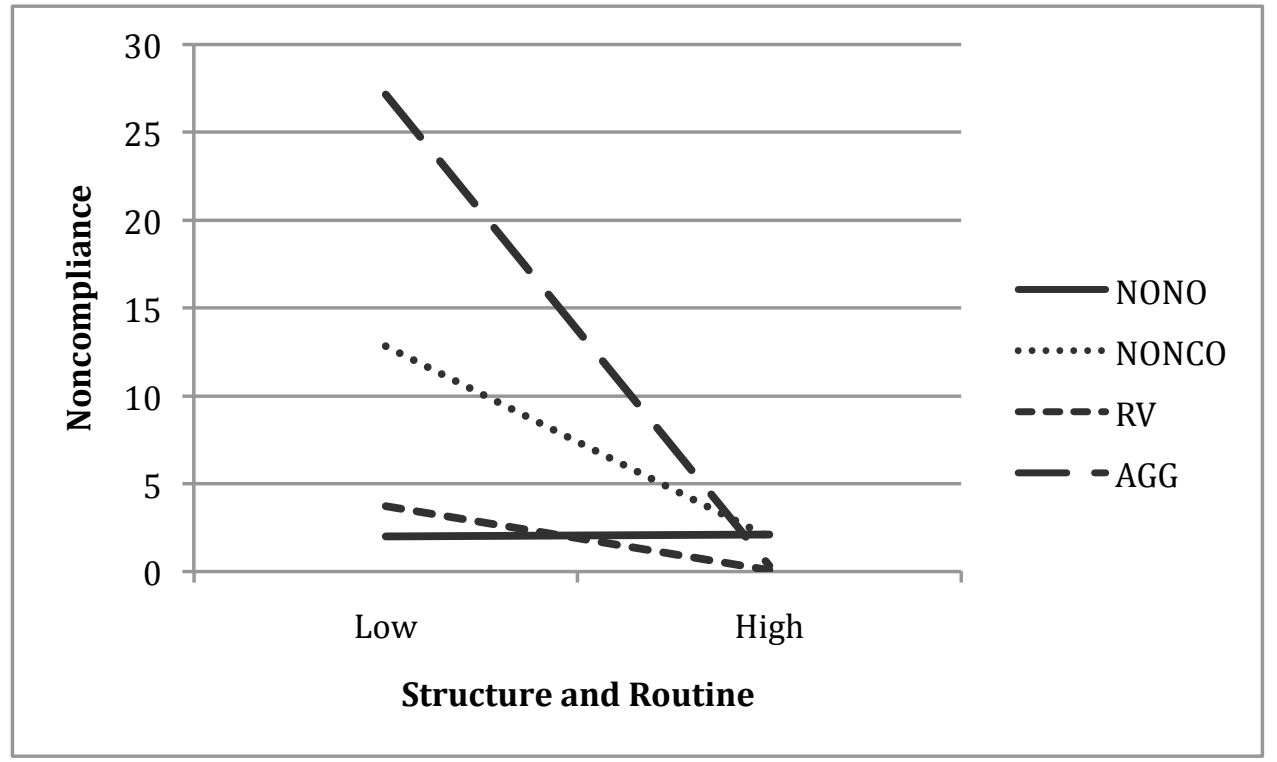

Figure 8. Effect of context on noncompliant behavior for toddlers Key: $\mathrm{NONO}=$ noncompliance by omission, $\mathrm{NONCO}=$ noncompliance by commission, $\mathrm{RV}=$ resource violation, $\mathrm{AGG}=$ aggression 
For resource violation $(R V)$ : Results for $\mathrm{RV}$ were as predicted. The main effect for context was significant, $F(1,9)=17.76, p<.01$, partial- $\eta^{2}=.69$. Averaging over time, the mean level of RV was greater in the low structure and routine activity context $(M=3.71, S D=2.67)$ than in the high structure and routine activity context $(\mathrm{M}=.08, \mathrm{SD}=.17)$.

For aggression (AGG): Results for AGG were as predicted. The main effect for context was significant, $F(1,9)=19.48, p<.01$, partial $-\eta^{2}=.71$. Averaging over time, the mean level of AGG was greater in the low structure and routine activity context $(M=27.14, S D=18.23)$ than in the high structure and routine activity context $(\mathrm{M}=.33, \mathrm{SD}=.56)$.

For the youngest children (infants): A series of one-way repeated measures ANOVA tests were conducted to determine whether average frequencies of compliant and noncompliant behavior varied between low and high structure and routine activities. The factor, activity context, had two levels (low structure and routine, high structure and routine). The dependent variable for compliant behavior was average frequency of passive compliance (COMPP). The dependent variables for noncompliant behavior were average frequencies of noncompliance by omission (NONO), noncompliance by commission (NONCO), and resource violation (RV), and aggression (AGG). Descriptive statistics, pvalues and estimates of effect size are presented in Table 5. Figures 9 and 10 present mean levels for compliant and noncompliant behaviors in the two activity contexts, respectively. 
H3e: For infants, the average frequency of compliant behavior will be greater in the high structure and routine context than in the low structure and routine context.

For passive compliance (COMPP): Results for COMPP were not as predicted. The main effect for context was not significant, $F(1,5)=.08, p=.78$, partial- $\eta^{2}=$ .02 , indicating that, averaging over time, the mean level of COMPP did not vary significantly between the low $(M=23.79, S D=12.27)$ and the high $(M=22.29, S D$ $=5.04)$ structure and routine activity contexts.

H3f: For infants, the average frequencies of noncompliant behaviors will be greater in the low structure and routine context than in the high structure and routine context.

For noncompliance by omission (NONO): Results for NONO were not as predicted. The main effect for context was not significant, $F(1,5)=.79, p=.41$, partial- $\eta^{2}=.14$, indicating that, averaging over time, the mean level of NONO did not vary significantly between the low $(M=.53, S D=.47)$ and the high $(M=1.02$, $S D=1.35)$ structure and routine activity contexts.

For noncompliance by commission (NONCO): Results for NONCO were not as predicted. The main effect for context was not significant, $F(1,5)=1.79, p=$ .24 , partial $-\eta^{2}=.26$, indicating that, averaging over time, the mean level of NONCO did not vary significantly between the low and high structure and routine activity contexts. Although the difference was not significant, it should be noted that the mean level of $\mathrm{NONCO}$ was greater in the low structure and routine 
activity context $(M=10.75, S D=11.99)$ than in the high structure and routine activity context $(M=5.08, S D=2.31)$.

For resource violation $(R V)$ : Results for $\mathrm{RV}$ were as predicted. The main effect for context was significant, $F(1,5)=27.0, p<.01$, partial $-\eta^{2}=.84$. Averaging over time, the mean level of RV was greater in the low structure and routine activity context $(M=6.56, S D=3.8)$ than in the high structure and routine activity context $(M=1.42, S D=1.63)$.

For aggression (AGG): Results for AGG were as predicted. The main effect for context was significant, $F(1,5)=7.17, p<.05$, partial $\eta^{2}=.59$. Averaging over time, the mean level of AGG was greater in the low structure and routine activity context $(M=9.77, S D=.95)$ than in the high structure and routine activity context $(\mathrm{M}=.95, \mathrm{SD}=1.14)$.

Research Question 4: Does the degree of structure and routine in daily activities affect children's selfregulated behavior over time?

A series of two-way within-subjects ANOVA tests were conducted to evaluate if differences in average frequencies of compliant and noncompliant behaviors between the low and high structure and routine activity contexts varied over time for toddlers and transitioners. The first factor, activity context, had two levels (low structure and routine, high structure and routine) and the second factor, time, had three levels (Time 1, Time 2, Time 3). The dependent variables for compliant behavior were average frequencies of selfinitiated compliance (SICOMP) and adult-initiated compliance 


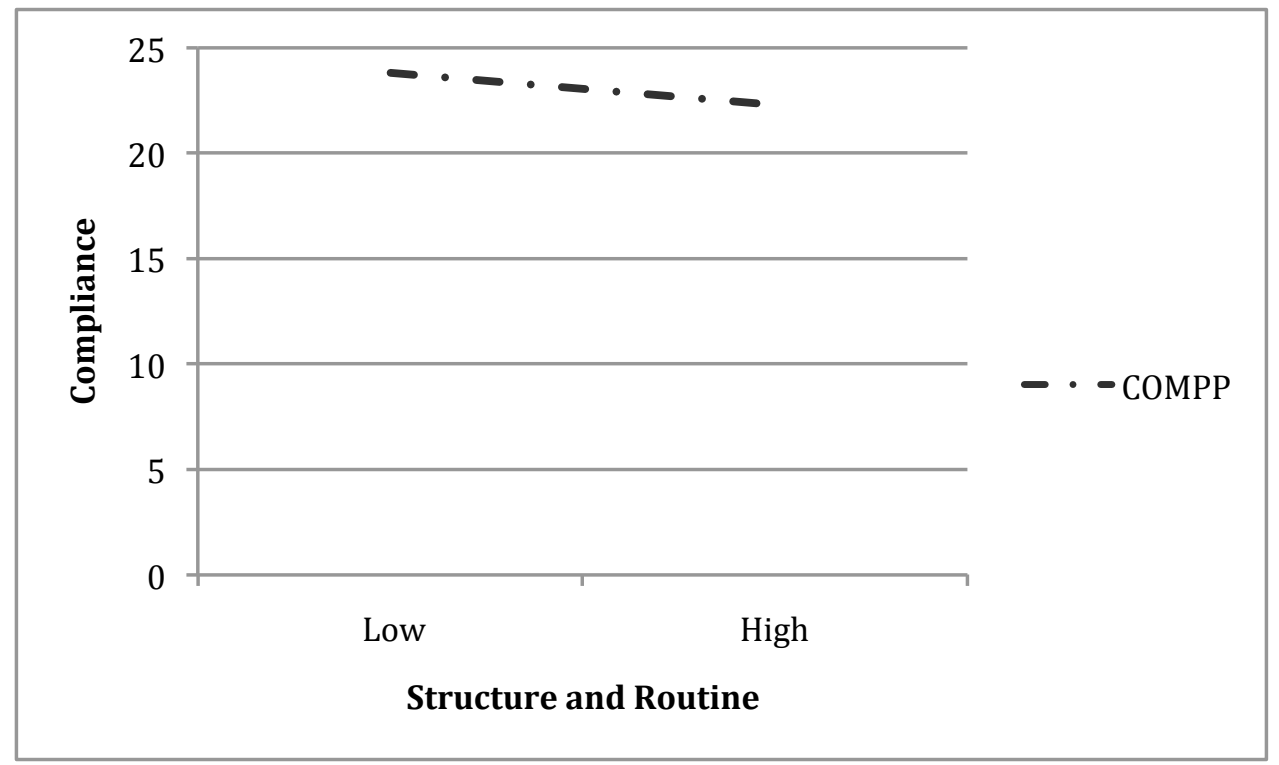

Figure 9. Effect of context on compliant behavior for infants Key: $\mathrm{COMPP}=$ passive compliance

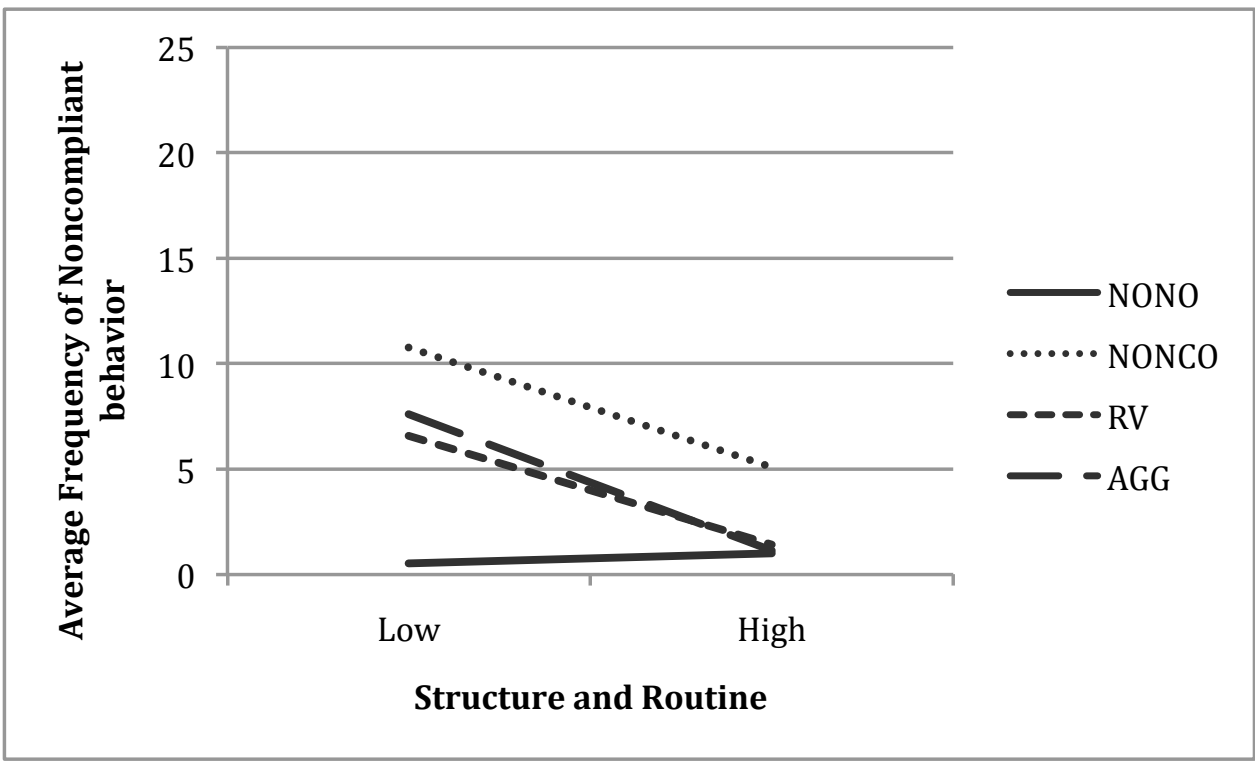

Figure 10. Effect of context on noncompliant behavior for infants Key: $\mathrm{AGG}=$ aggression, $\mathrm{NONCO}=$ noncompliance by commission, $\mathrm{NONO}=$ noncompliance by omission, $\mathrm{RV}=$ resource violation 
(AICOMP). The dependent variables for noncompliant behavior were average frequencies of noncompliance by omission (NONO), noncompliance by commission (NONCO), resource violation (RV), and aggression (AGG). Table 6 presents the means and standard deviations for compliant and noncompliant behaviors at each time of measurement. Figures 11 and 12 present the effects of context over time on the average frequency of compliant behaviors (i.e., selfinitiated and adult initiated compliance, respectively). Figures 13 through 16 present the effects of context over time on the average frequency of noncompliant behaviors (i.e., noncompliance by omission, noncompliance by commission, resource violation, and aggression, respectively).

H4a: The average frequencies of compliance behaviors will increase from Time 1 to Time 3. Mean levels of compliance behaviors will be higher in the high structure and routine context than in the low structure and routine context.

For self-initiated compliance (SICOMP): Results for SICOMP were partially as predicted. The main effect for context was significant, $F(1,13)=16.37, p<.01$, partial- $\eta^{2}=.55$. Averaging over time, mean levels of SICOMP were greater in the high structure and routine activity context $(M=3.61, S D=1.98)$ than in the low structure and routine activity context $(M=1.19, S D=.99)$.

The main effect for time was not significant, $F(2,6)=1.54, p=.23$, partial$\eta^{2}=.11$, indicating that, averaging over context, the mean level of 
SICOMP did not vary significantly over the three times of measurement.

Although not significant, average frequencies of SICOMP increased from Time $1(M=3.42, S D=3.07)$ to Time $2(M=6.25, S D=4.27)$, and from Time 1 to Time $3(M=5.32, S D=3.94)$.

For adult-initiated compliance (AICOMP): Results for AICOMP were not as predicted. The main effect for time was significant, $F(2,26)=6.42, p=.01$, partial$\eta^{2}=.33$. However, follow-up polynomial contrasts indicated a significant quadratic trend, $F(1,13)=7.85, p=.01$, partial $-\eta^{\underline{2}}=.38$, such that, averaging over context, mean levels of AICOMP increased from Time $1(M=7.75, S D=5.77)$ to Time $2(M=18.54, S D=11.52)$, then decreased from Time 2 to Time $3(M=$ 10.21, $S D=5.57$.

The main effect for context was not significant, $F(1,7)=1.36, p=.27$, partial $-\eta^{2}=$ .09. Further, averaging over time, the mean level of AICOMP was greater in the low structure and routine activity context $(M=6.91, S D=3.87)$ than in the high structure and routine activity context $(M=5.50, S D=2.13)$.

H4b: The average frequencies of non-complaint behaviors will decrease from Time 1 to Time 3. Mean levels for non-compliant behaviors will be lower in the high structure and routine context than in the low structure and routine context.

For noncompliance by omission (NONO): Results for NONO were not as predicted. Neither the main effect for context nor the main effect for time was 
Table 6. Descriptive statistics for compliant and noncompliant behaviors in low and high structure and routine activity contexts at each time of measurement for toddlers and transitioners

\begin{tabular}{|c|c|c|c|c|c|c|c|c|c|c|c|c|}
\hline \multirow[b]{3}{*}{ Behavior } & \multicolumn{4}{|c|}{$\begin{array}{c}\text { Time } 1 \\
\text { Structure \& Routine }\end{array}$} & \multicolumn{4}{|c|}{$\begin{array}{c}\text { Time } 2 \\
\text { Structure \& Routine }\end{array}$} & \multicolumn{4}{|c|}{$\begin{array}{c}\text { Time } 3 \\
\text { Structure \& Routine }\end{array}$} \\
\hline & \multicolumn{2}{|c|}{ Low } & \multicolumn{2}{|c|}{ High } & \multicolumn{2}{|c|}{ Low } & \multicolumn{2}{|c|}{ High } & \multicolumn{2}{|c|}{ Low } & \multicolumn{2}{|c|}{ High } \\
\hline & M & SD & $M$ & SD & M & $S D$ & $M$ & SD & M & SD & $M$ & SD \\
\hline $\begin{array}{l}\text { Compliance: } \\
\text { Self-initiated } \\
\text { (SICOMP) }\end{array}$ & .79 & 1.05 & 2.72 & 2.45 & 1.73 & 2.15 & 3.82 & 2.85 & 1.04 & 1.36 & 4.28 & 3.77 \\
\hline $\begin{array}{l}\text { Adult-initiated } \\
\text { (AICOMP) }\end{array}$ & 3.37 & 3.57 & 4.59 & 3.16 & 12.64 & 1.15 & 6.40 & 4.27 & 4.72 & 2.96 & 5.49 & 3.97 \\
\hline $\begin{array}{l}\text { Noncompliance: } \\
\text { Noncompliance } \\
\text { by omission } \\
\text { (NONO) }\end{array}$ & .53 & .48 & .56 & .98 & .62 & .80 & .74 & 1.25 & .67 & .76 & .36 & .69 \\
\hline $\begin{array}{l}\text { Noncompliance } \\
\text { by commission } \\
\text { (NONCO) }\end{array}$ & 1.27 & 1.91 & .42 & .78 & 8.53 & 8.65 & .90 & 1.15 & 3.59 & 3.75 & 1.25 & 1.10 \\
\hline $\begin{array}{l}\text { Resource } \\
\text { violation } \\
\text { (RV) }\end{array}$ & .90 & 1.56 & .06 & .15 & 1.22 & .81 & .04 & .13 & 1.23 & 1.51 & .05 & .14 \\
\hline $\begin{array}{l}\text { Aggression } \\
\text { (AGG) }\end{array}$ & 1.75 & 3.11 & .60 & 1.74 & 19.44 & 16.3 & 1.12 & 2.28 & 7.99 & 9.67 & .00 & .00 \\
\hline
\end{tabular}




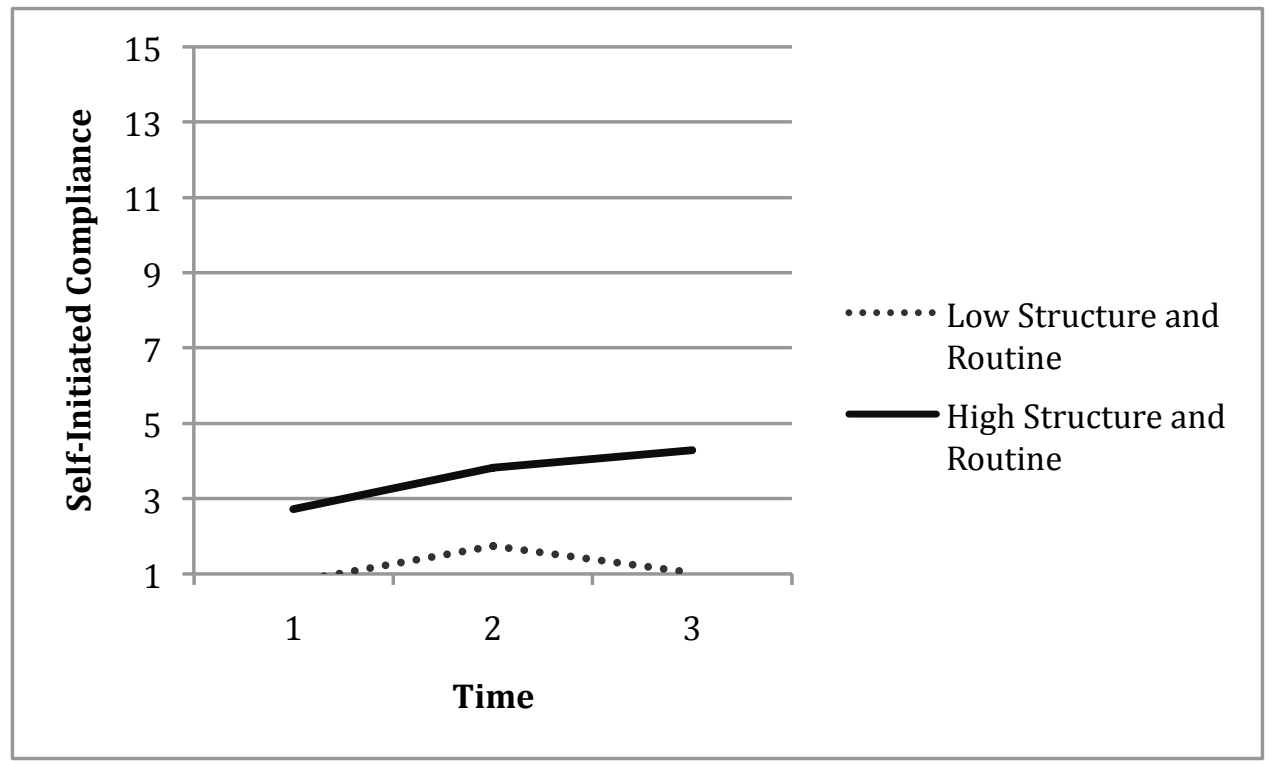

Figure 11. Effect of context over time on self-initiated compliance (SICOMP) for toddlers and transitioners

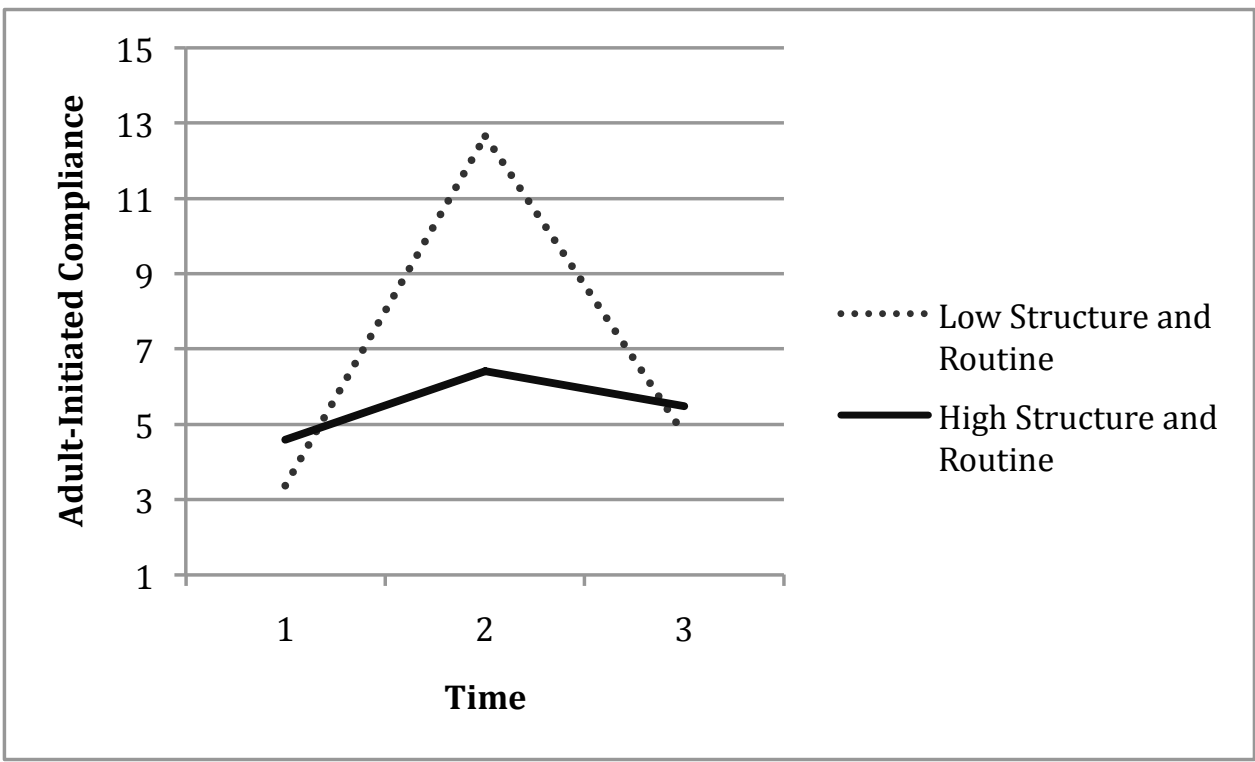

Figure 12. Effect of context over time on adult-initiated compliance (AICOMP) for toddlers and transitioners 
significant, $F(1,13)=.67, p=.19$, partial $-\eta^{2}=.01$ and $F(2,26)=.36, p=.71$, partial- $\eta^{2}=.03$, respectively.

For noncompliance by commission (NONCO): Results for NONCO were partially as predicted. The main effect for context was significant, $F(2,6)=20.79$, $p<.01$, partial $-\eta^{2}=.63$. Averaging over time, the average frequency of NONCO was greater in the low structure and routine activity context $(M=4.46, S D=3.32)$ than in the high structure and routine activity context $(\mathrm{M}=.86, \mathrm{SD}=.78)$.

The main effect for time was also significant, $F(1,7)=6.86, p=.01$, partial$\eta^{2}=.36$. However, follow-up polynomial contrasts indicated a significant linear trend, $F(1,12)=8.15, p=.01$, partial- $\eta^{2}=.41$, such that, averaging over context, mean levels of NONCO increased from Time $1(M=1.714, S D=1.86)$ to Time 3 $(M=4.83, S D=3.74)$. There was also a significant quadratic trend, $F(1,13)=6.66$, $p<.05$, partial $-\eta^{2}=.36$, such that, averaging over context, the mean level of NONCO was greater at Time $2(\mathrm{M}=8.82, S D=8.42)$ than at Time 1 and Time 3.

A significant context by time interaction was found, $F(2,24)=4.75, p<.05$, partial $-\eta^{2}=.28$. Follow-up contrasts indicated a significant quadratic trend such that it was greater in the low structure and routine activity context at Time 1, Time 2 , and Time $3(M=1.27, M=8.53$, and $M=3.59$, respectively) than in the high structure and routine activity context at Time 1 , Time 2 , and Time $3(M=.42, M=$ .90 , and $M=1.25$, respectively). 
For resource violation $(R V)$ : Results for RV were partially as predicted.

The main effect for context was significant, $F(1,7)=29.11, p<.01$, partial- $\eta^{2}=$ .69. Averaging over time, the average frequency of RV was greater in the low structure and routine activity context $(M=1.12, S D=.75)$ than in the high structure and routine activity context $(M=.05, S D=.09)$. The main effect for time was not significant, $F(2,6)=.21, p=.81$, partial $-\eta^{2}=.02$ indicating that, averaging over context, the mean level of RV did not vary significantly over the three times of measurement.

For aggression (AGG): Results for AGG were partially as predicted. The main effect for context was significant, $F(1,13)=21.44, p<.01$, partial- $\eta^{2}=.62$. Averaging over time, the average frequency of AGG was greater in the low structure and routine activity context $(M=9.73, S D=7.83)$ than in the high structure and routine activity context $(\mathrm{M}=.57, \mathrm{SD}=.97)$.

The main effect for time was significant, $F(1,13)=12.6, p<.01$, partial $-\eta^{2}=.49$.

However, follow-up polynomial contrasts indicated a significant linear trend, $F(1,13)=10.03, p<.01$, partial- $\eta^{2}=.44$, such that, averaging over context, the average frequency of AGG increased from Time $1(\mathrm{M}=2.29, \mathrm{SD}=3.78)$ to Time $3(M=7.99, S D=9.67)$. There was also a significant quadratic trend, $F(1,13)$ $=12.94, p<.01$, partial $-\eta^{2}=.50$, such that, averaging over context, the average frequency of AGG was greater at Time $2(M=19.83, S D=16.76)$ than at Time 1 and Time 3. 


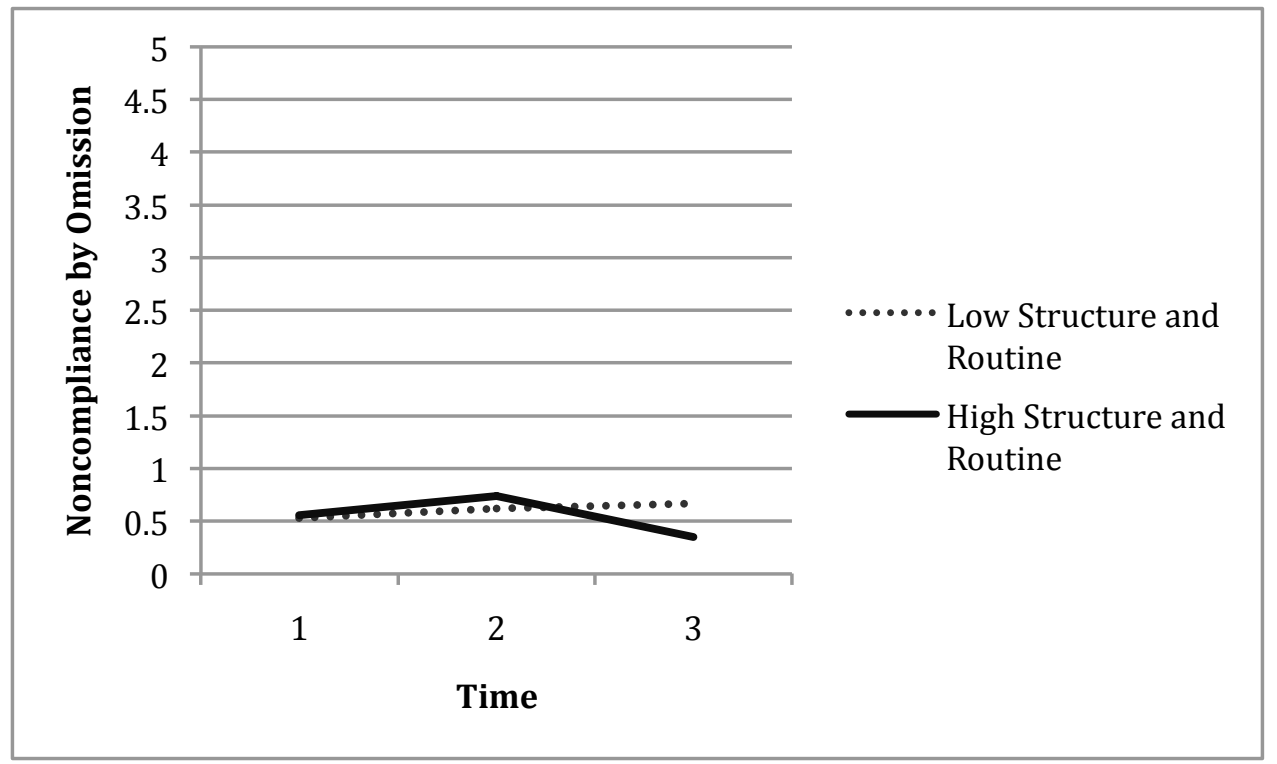

Figure 13. Effect of context over time on noncompliance by omission (NONO) for toddlers and transitioners

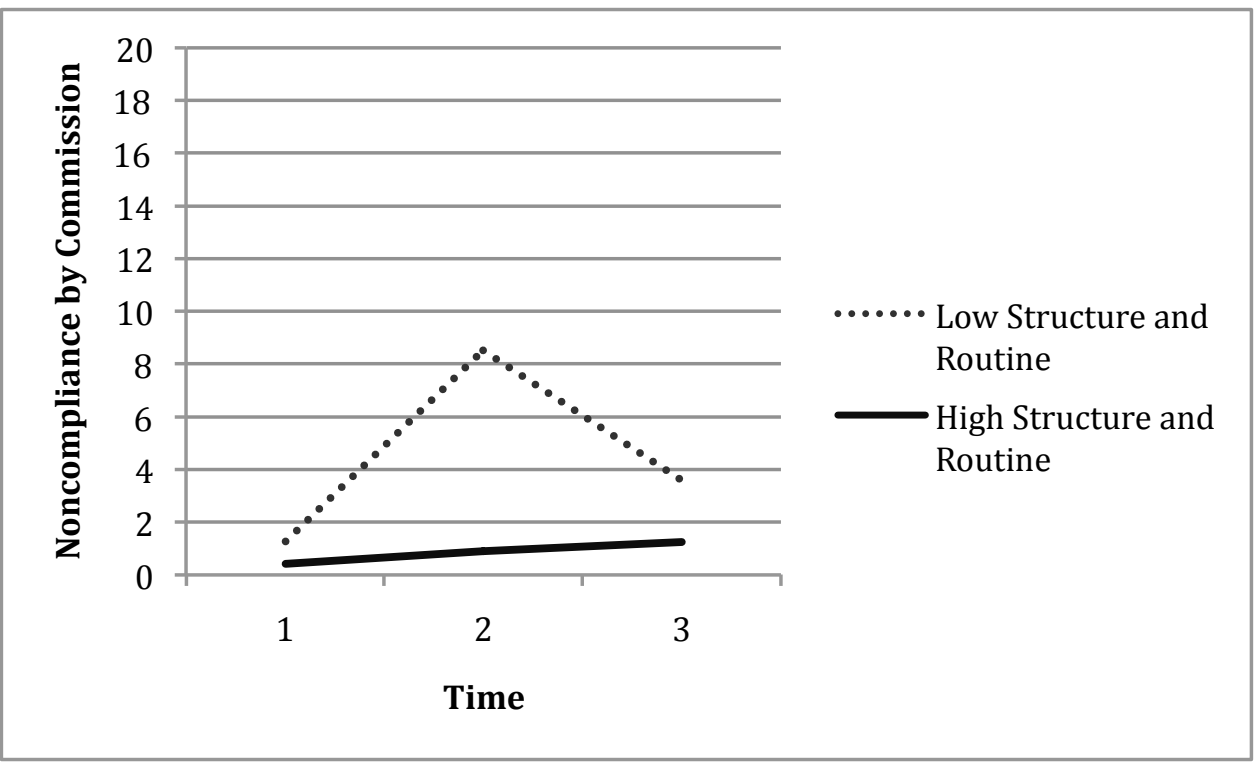

Figure 14. Effect of context over time on noncompliance by commission (NONCO) for toddlers and transitioners 


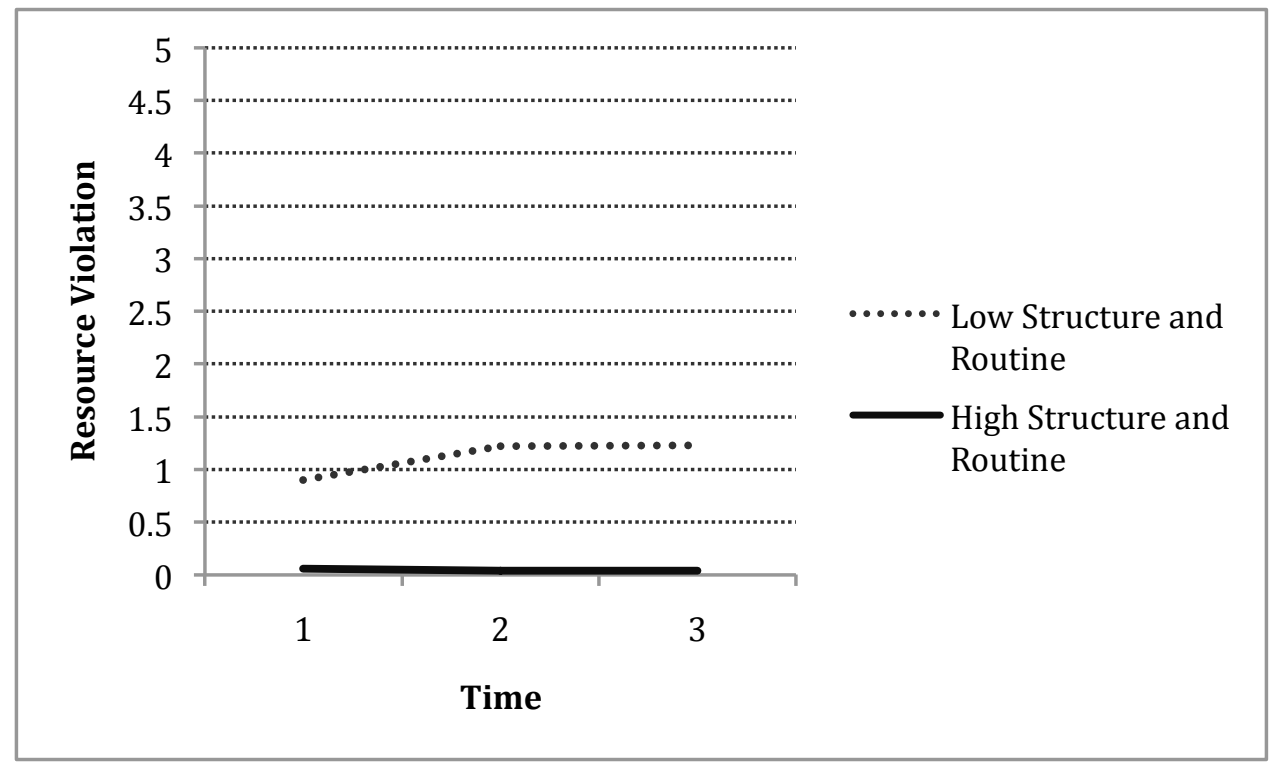

Figure 15. Effect of context over time on resource violation (RV) for toddlers and transitioners

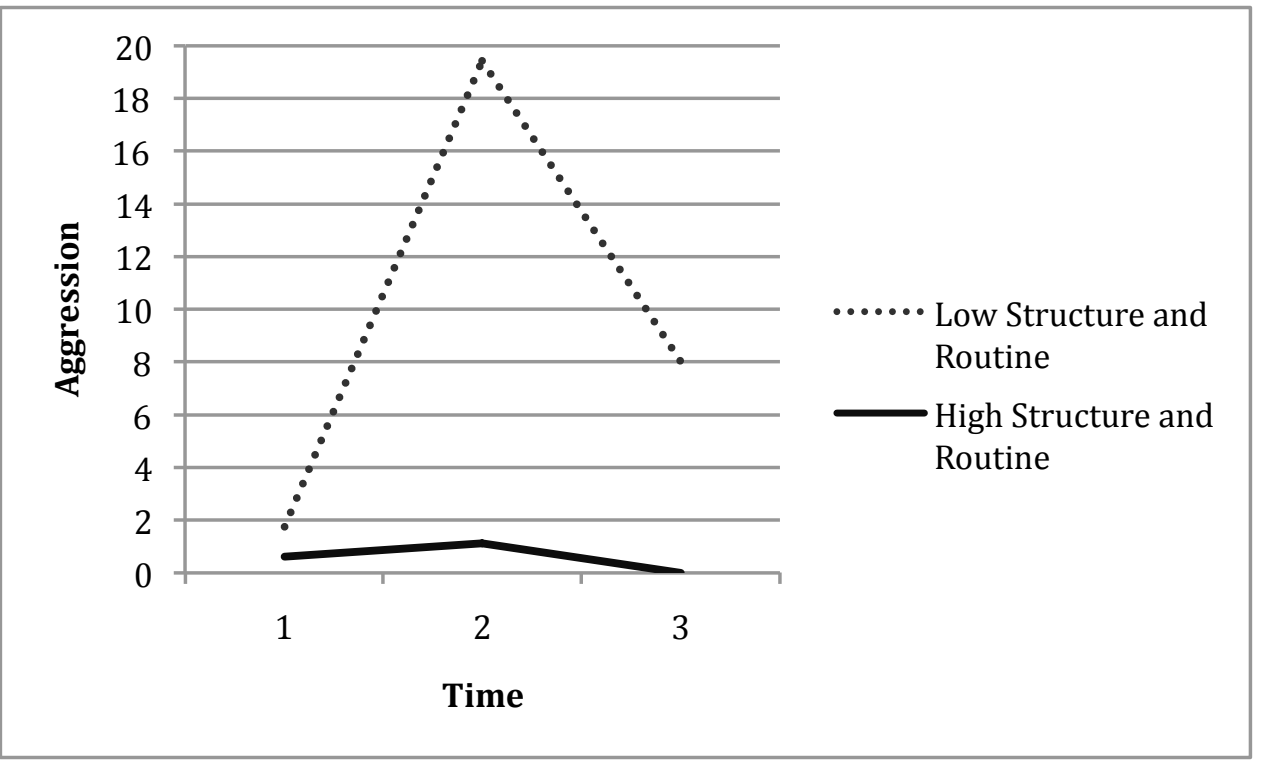

Figure 16. Effect of context over time on aggression (AGG) for toddlers and transitioners 
A significant context by time interaction was found, $F(2,26)=11.17$, $p<.01$, partial- $\eta^{2}=.46$. Follow-up contrasts indicated that the linear increase in the mean level of AGG was greater in the low structure and routine context $(M=7.99, S D=9.67)$ than in the high structure and routine context $(M=.00, S D=$ .00). The quadratic trend was also significant such that it was greater in the low structure and routine activity context at Time 1 , Time 2 , and Time $3(\mathrm{M}=1.75, \mathrm{M}$ $=19.44$, and $M=7.99$, respectively) than in the high structure and routine activity context at Time 1 , Time 2 , and Time $3(M=.60, M=1.12$, and $M=.00$, respectively).

Research Question 5: Do structure and routine scaffold internalization such that, over time, the frequency of internalized behavior in the low structure and routine contexts catches up with the frequency of internalized behavior in the high structure and routine contexts, and are there age differences associated with the pattern of change?

A $2 \times 2 \times 3$ mixed factorial ANOVA test was conducted to evaluate whether differences in average frequencies of internalized compliant behavior between the low and high structure and routine activity contexts varied over time and between children of different ages. The first within-subjects factor, activity context, had two levels (low structure and routine, high structure and routine) and the second within-subjects factor, time, had three levels (Time 1, Time 2, Time 3). The between subjects factor, age, had two levels (toddlers, transitioners). The dependent variable was average frequency of self- 
initiated compliance (SICOMP). Figures 17 and 18 present the main effect for context and the main effect for time on SICOMP for toddlers and transitioners, respectively.

H5: Do structure and routine scaffold internalization such that, over time, the frequency of internalized behavior in the low structure and routine contexts catches up with the frequency of internalized behavior in the high structure and routine contexts, and are there age differences associated with the pattern of change?

Results indicated that only the main effect for context was significant, $F(1$, $12)=12.91, p<.01$, partial $-\eta^{2}=.52$. Averaging over time and classroom (i.e., age), mean levels of SICOMP were greater in the high structure and routine activity context than in the low structure and routine activity context. The context by classroom interaction was not significant, $F(1,12)=1.24, p=.29$, partial- $\eta^{2}=.09$, indicating that, averaging over time, differences in mean levels of SICOMP between the two activity contexts did not differ significantly between the toddlers and the transitioners.

The context by time interaction was also not significant, $F(2,24)=.64$, $p=.54$, partial $-\eta^{2}=.05$, indicating that, averaging over classroom, changes in mean levels of SICOMP over time did not differ significantly between the two contexts. The main effect for time was not significant, $F(2,24)=1.20, p=.32$, partial $-\eta^{2}=$ .09 , indicating that, averaging over context and classroom, differences in mean levels of SICOMP did not change significantly over time. 


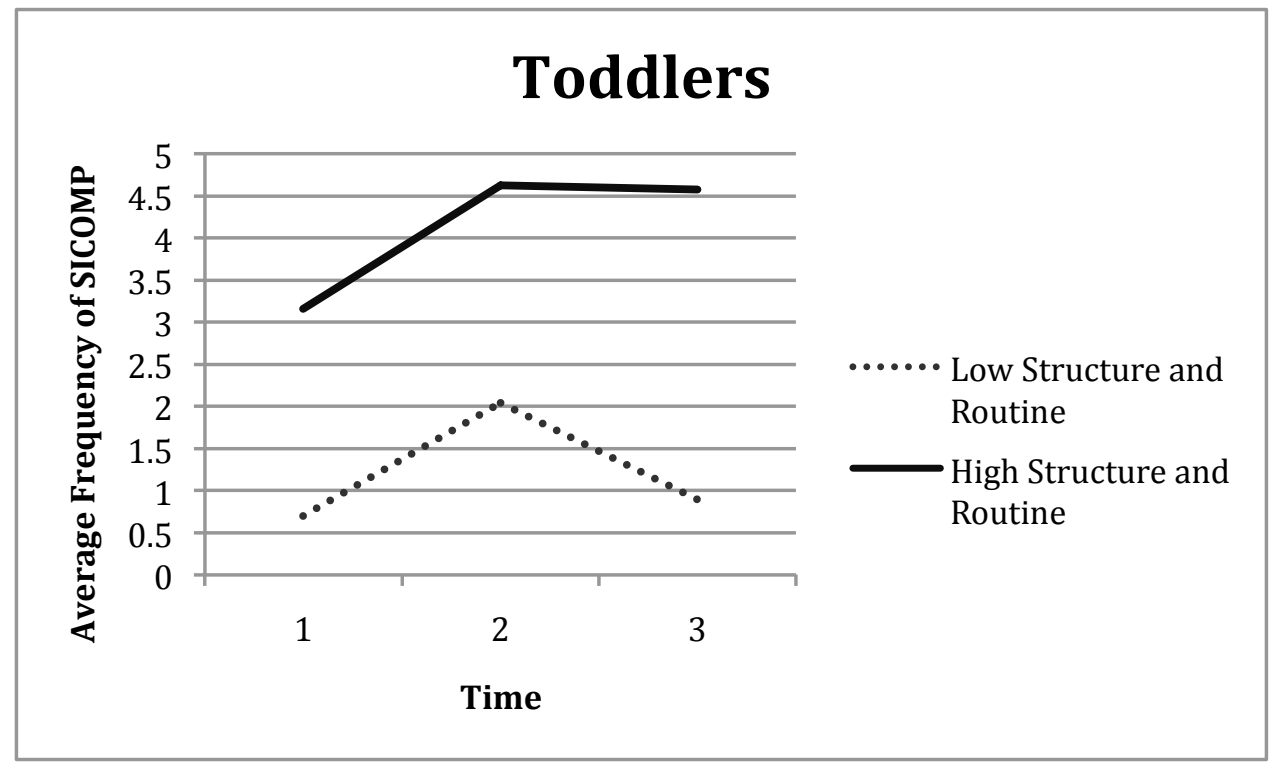

Figure 17. Effect of context and time on self-initiated compliance (SICOMP) for toddlers

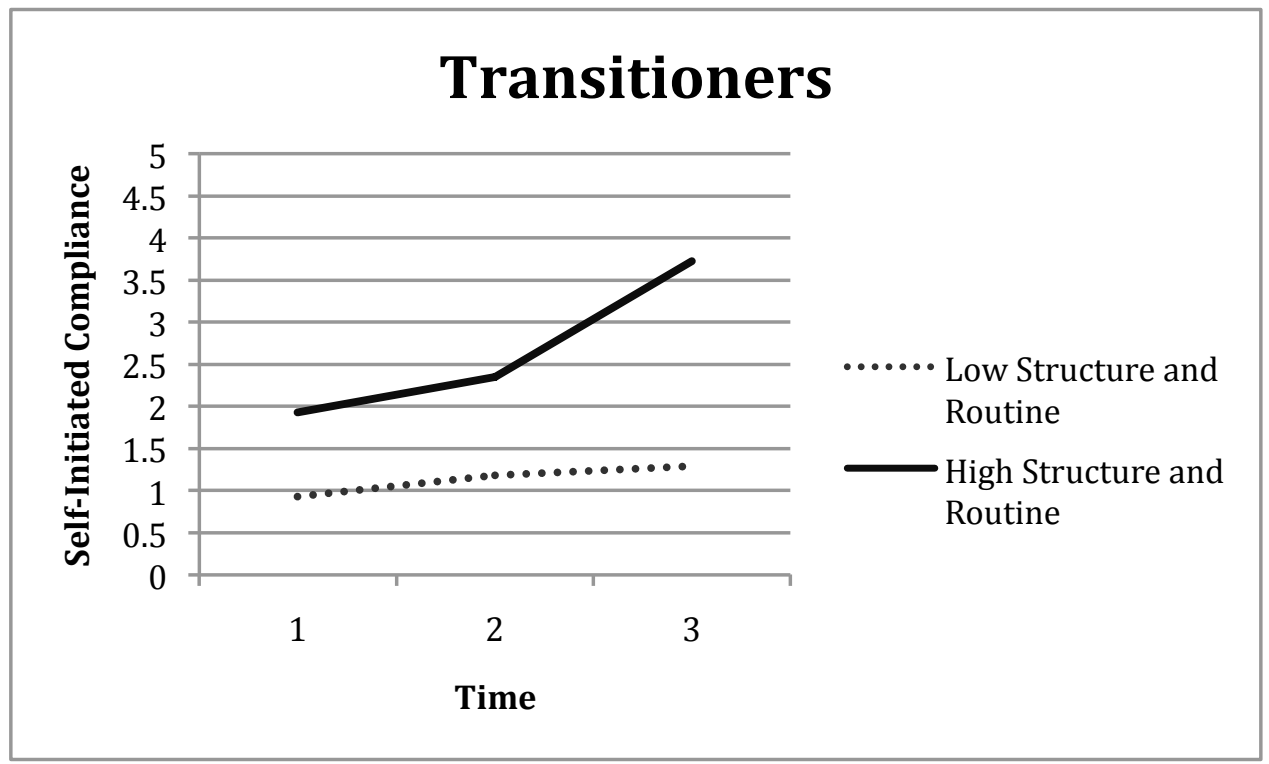

Figure 18. Effect of context and time on self-initiated compliance (SICOMP) for transitioners 
The time by classroom interaction was also not significant, $F(2,24)=$ $.55, p=.56$, partial- $\eta^{2}=.04$, indicating that, averaging over context, changes in mean levels of SICOMP over time did not differ significantly between the toddlers and the transitioners.

Finally, the context by time by classroom interaction was not significant, $F(2,24)=.004, p=.99$, partial $-\eta^{2}=.00$, indicating that there was no significant pattern of differences in mean levels of SICOMP in the two activity contexts between classrooms or over time.

Research Question 6: If the preceding research questions have been answered in the affirmative, do the more complex prosocial behaviors become more frequent over time for toddlers and transitioners?

A series of paired samples t-tests was conducted to evaluate whether the average frequencies of more complex prosocial behaviors for Time 1 increased over time as children's self-regulatory capacity developed. The dependent variables were average frequencies of complex prosocial behaviors [assertive problem solving (APS), helping (HELP), performing the work of adults (PWA) and sharing (SHARE)] at Time 1, Time 2 and Time 3. Means and standard deviations for each behavior at each time of measurement are presented in Table 7 . Figure 19 presents the average frequencies for the four complex prosocial behaviors over time.

H6: Do the more complex prosocial behaviors become more frequent over time for toddlers and transitioners? 
For assertive problem solving (APS): Results indicated that the mean levels of APS at Time $3(M=9.00, S D=7.37)$ were significantly greater than the mean levels of APS at Time $1(M=2.40, S D=3.20), t(13)=-3.59, p<.01$.

For helping (HELP): Results indicated that mean levels of HELP did not differ significantly between Time $1(M=1.47, S D=2.45)$ and Time $3(M=2.64, S D$ $=3.84), \mathrm{t}(13)=-1.07, p=.32$. However, mean levels of HELP at Time $2(\mathrm{M}=4.80$, $S D=5.80$ ) were significantly greater than mean levels of HELP at Time $1, t(14)=$ $2.16, p<.05$.

For performing the work of adults (PWA): Results indicated that mean levels of PWA did not differ significantly between Time $1(M=.60, S D=1.24)$ and Time 3 $(M=1.64, S D=2.47), t(13)=-1.23, p=.24$. However, mean levels of PWA at Time $2(M=2.3, S D=1.50)$ were significantly greater than mean levels of PWA at Time $1, t(9)=-3.0, p<.05$

For sharing (SHARE): Results indicated that the mean levels of SHARE at Time $3(M=6.43, S D=4.35)$ were significantly greater than the mean levels of SHARE at Time $1(M=3.27, S D=3.35), t(13)=-2.48, p<.05$. 
Table 7. Means and standard deviations for complex prosocial behaviors at each time of measurement for toddlers and transitioners

\begin{tabular}{|c|c|c|c|c|c|c|}
\hline & \multicolumn{2}{|c|}{ Time 1} & \multicolumn{2}{|c|}{ Time 2} & \multicolumn{2}{|c|}{ Time 3} \\
\hline Behavior & $M$ & SD & $M$ & SD & $M$ & SD \\
\hline $\begin{array}{l}\text { Assertive } \\
\text { problem } \\
\text { solving } \\
\text { (APS) }\end{array}$ & 2.40 & 3.20 & 8.13 & 8.00 & 9.00 & 7.37 \\
\hline $\begin{array}{l}\text { Helping } \\
\text { (HELP) }\end{array}$ & 1.47 & 2.45 & 4.80 & 5.80 & 2.64 & 3.84 \\
\hline $\begin{array}{l}\text { Performing } \\
\text { the work } \\
\text { of adults } \\
\text { (PWA) }\end{array}$ & .60 & 1.24 & 2.30 & 1.50 & 1.64 & 2.47 \\
\hline $\begin{array}{l}\text { Sharing } \\
\text { (SHARE) }\end{array}$ & 3.27 & 3.35 & 5.00 & 2.78 & 6.43 & 4.35 \\
\hline
\end{tabular}




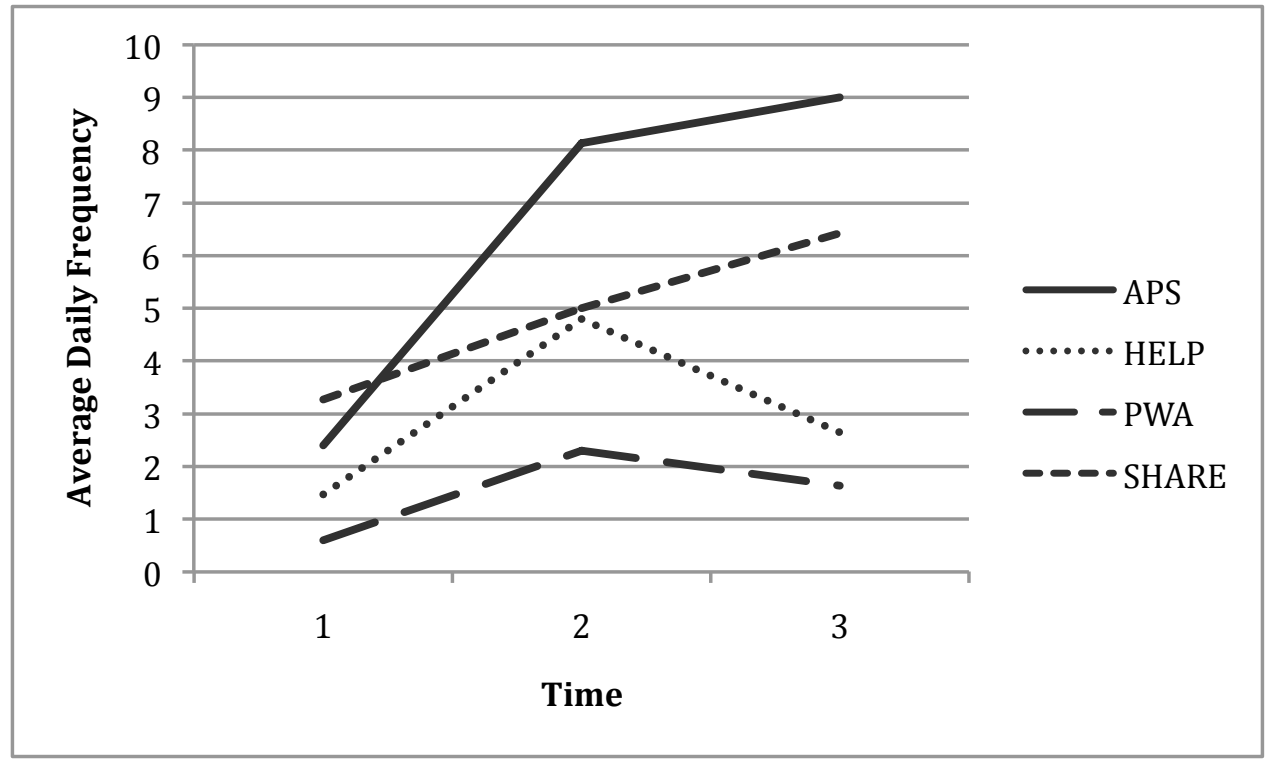

Figure 19. Average frequencies per day of complex prosocial behaviors over time Key: $\mathrm{APS}=$ assertive problem solving, $\mathrm{HELP}=$ helping, $\mathrm{PWA}=$ performing the work of adults. SHARE $=$ sharing 


\section{Chapter VI}

Discussion

The overarching goal of this study was to explore the relationship between the degree of structure and routine in children's daily activities and children's emerging capacities to self-regulate, as well as the relationship between self-regulation and complex prosocial behavior. Children's daily activities were identified as being characterized by either low [play cleanup (CP), free play (FR), and teacher directed play (ST)] or high [mealtime (ME), meal cleanup (CM), and transitions (TR)] degrees of structure and routine. Differences between the two activity contexts were analyzed for three selfregulatory behaviors, i.e., compliance behaviors [adult-initiated compliance (AICOMP), passive compliance (COMPP), and self-initiated compliance (SICOMP)], and four behaviors indicative of a lack of self-regulation, i.e., noncompliance behaviors [aggression (AGG), noncompliance by commission (NONCO), noncompliance by omission (NONO), and resource violation (RV)]. Also of interest were the effects of structure and routine on self-regulated behavior over time and for children of different ages [infants $(M=41$ weeks $)$, toddlers $(M=1.8$ years $)$, and transitioners $(M=2.75$ years $)]$. Table 8 presents the normative developmental sequence for self-regulation and the emergence of compliant behaviors that was summarized in Table 1, with the inclusion of the present study's codes for compliant and noncompliant behaviors.

While patterns for the self-regulatory behaviors of adult-initiated compliance (AICOMP) and passive compliance (COMPP) were not as expected, results showed that 
Table 8. The developmental sequence for self-regulation and compliant behavior

\begin{tabular}{|c|c|c|c|}
\hline & $\begin{array}{l}\text { Passive compliance } \\
\text { Kopp: } \\
\text { Control } \\
\text { Kochanska: } \\
\text { Situational compliance }\end{array}$ & $\begin{array}{l}\text { Adult-initiated } \\
\text { compliance } \\
\text { Kopp: } \\
\text { Self-control } \\
\text { Kochanska: } \\
\text { Committed compliance }\end{array}$ & $\begin{array}{l}\text { Self-initiated } \\
\text { compliance } \\
\text { Kopp: } \\
\text { Self-regulation } \\
\text { Kochanska: } \\
\text { Internalization } \\
\end{array}$ \\
\hline $\begin{array}{c}\text { Ages } 1-2 \\
(M=41 \text { weeks })\end{array}$ & Central & Early emergence & Not yet available \\
\hline $\begin{array}{c}\text { Ages } 2-3 \\
(\mathrm{M}=1.8 \text { years })\end{array}$ & $\begin{array}{c}\text { Decreasing } \\
\text { (No longer needed) }\end{array}$ & Central & Emerging \\
\hline $\begin{array}{c}\text { Ages } 3-4 \\
(\mathrm{M}=2.75 \text { years })\end{array}$ & $\begin{array}{c}\text { Decreasing } \\
\text { (No longer needed) }\end{array}$ & $\begin{array}{l}\text { Central } \\
\text { (leaving) }\end{array}$ & Central \\
\hline
\end{tabular}

Note: Central behaviors are those which best reflect a developmental task that is the focus of a specific stage of development 
self-initiated compliance (SICOMP), the measure of internalization, appeared to be scaffolded by the presence of structure and routine in children's daily activities such that internalized behavior occurred more frequently in high structure and routine activities than in low structure and routine activities. Moreover, with the exception of noncompliance by omission (NONO), behavior indicative of a lack of self-regulation was strongly influenced by the nature of children's activities. Noncompliance by commission $(\mathrm{NONCO})$, resource violation $(\mathrm{RV})$, and aggression $(\mathrm{AGG})$ occurred more frequently during activities characterized by low structure and routine and less frequently during high structure and routine activities. Results for changes in self-regulatory behavior over time were complicated by unexpected curvilinear relationships, which will be addresses later in this section.

In the discussion that follows, the initial analyses, which compared the findings for self-initiated compliance from the earlier cross-sectional study and the present longitudinal study, will be presented first. The next sections will address the effect of structure and routine on self-regulated behavior, the effect of structure and routine on self-regulated behavior for children of different ages, and effect of structure and routine on self-regulated behavior over time. Finally, summary comments, strengths and weaknesses of the study and possible directions for future research will be presented.

\section{Comparing the Cross-Sectional and Longitudinal Studies}

The first step in the analysis process was to determine whether the cross-sectional finding regarding early internalization, or self-initiated compliance, would be supported by 
the longitudinal data. The longitudinal study did, to a certain extent, support the cross-sectional findings. The cross-sectional study compared mean levels of self-initiated compliance among the three classrooms (i.e., infant, toddler, transitioner) and found that this indicator for internalization was present in the toddler and transitioner classrooms and increased linearly across classes, or age groups (Vale, 2006).

For the longitudinal study, which had a smaller number of participants than did the crosssectional study, self-initiated compliance was also seen at Time 1 for the toddler and transitioner groups. Although the linear increase in the average frequency of self-initiated compliance from Time 1 to Time 3 did not reach significance, it followed the same trend as in the cross-sectional study for both groups of children, increasing from Time 1 to Time 3. It is possible that fewer opportunities to exhibit SICOMP due to a seasonal shift (see discussion beginning on page 113) impacted the average frequency of SICOMP at Time 3 such that it was not as high as it might have otherwise been. Given that the linear trends in general indicate increases that are consistent with what is expected developmentally, further study including a fourth time of measurement is warranted before drawing conclusions about the patterns of change for self-initiated compliance between the crosssectional and longitudinal studies.

The Effect of Structure and Routine on Self-Regulated Behavior Self-Regulatory Behaviors (Compliance)

Because daily activities that were characterized by high levels of structure and routine should have provided children with cues to appropriate or expected behavior, it 
was predicted that the three types of compliant behavior, self-initiated compliance (SICOMP), adult-initiated compliance (AICOMP), and passive compliance (COMPP), would occur more frequently during high structure and routine activities than during low structure and routine activities.

Self-initiated compliance. Structure and routine in children's daily activities appeared to support self-initiated compliance such that average frequencies of this behavior were significantly greater in the high structure and routine activities $(M=7.86)$ than they were in the low structure and routine activities $(M=2.66)$. It is important to note that one of the high structure and routine activities, mealtime cleanup (CM), is one that Kochanska (1995) would have identified as a "do" context. "Do" contexts are those in which a child is expected to sustain an activity that he or she might not find especially enjoyable, such as putting away toys. Kochanska's research indicated that sustaining less enjoyable behaviors was difficult for children of all ages. It was posited in the present study that activities characterized by high levels of structure and routine may represent "do" contexts that support, as opposed to make difficult, children's compliant and internalized behavior, and the findings for SICOMP support this notion.

Adult-initiated compliance. Contrary to predictions, there were no significant differences in adult-initiated compliance (AICOMP) between the low and high structure and routine activities. Although not significant, it should be noted that AICOMP occurred somewhat more often in the low structure and routine activity contexts $(M=$ 16.85) than it did in the high structure and routine activity contexts $(M=13.02)$. 
A code of AICOMP was given when a child complied with a teacher's request to perform a particular behavior and was this study's analog for Kochanska's committed compliance. Adult-initiated or committed compliance is a "stepping stone" on the path toward internalized compliance. Children exhibiting this form of compliance are demonstrating that they require less caregiver support in their efforts to comply with standards and expectations, but still need reminders in order to do what is expected in a given situation.

It was predicted that this type of compliance would be supported by the presence of environmental cues for appropriate or expected behavior and would therefore occur more frequently in the high structure and routine activities than it would in the low structure and routine activities. However, it was not foreseen that during low structure and routine activities (i.e., in the absence of environmental cues for expected behavior) it was necessary for teachers to make more requests, or teacher prompts, than it was during high structure and routine activities (i.e., in the presence of environmental cues for expected behavior). Over the three times of measurement, there were twice as many teacher prompts given in the low structure and routine activity contexts $(1,272)$ than in the high structure and routine activity contexts (572). It is possible that for AICOMP, the differences were nonsignificant between the two contexts because the effects of each one cancelled the other out. The lower degree of structure and routine necessitated more teacher prompts, which in turn led to more codes of AICOMP. At the same time, the higher degree of structure and 
routine supported compliant behavior resulting in a corresponding number of codes for AICOMP in those activities.

Passive compliance. Contrary to predictions, there were no significant differences in passive compliance (COMPP) between the low and high structure and routine activities. Early in the developmental sequence for self-regulation of behavior, passive or situational compliance is a central behavior. As children get older, however, instances of passive or situational compliance may be more indicative of a lapse in a child's ability to self-regulate. Because similar trends for COMPP were found in the analyses that were conducted for the separate age groups, discussion of the reasons that might underlie the non-significant finding will be presented in the following section where differences in the meaning of passive compliance among the age groups can be more properly addressed (see page 111). Behaviors Indicating a Lack of Self-Regulation (Noncompliance)

Children in this study received codes for noncompliance when their behavior was not in accordance with the rules and expectations of the child development center (e.g., behaving aggressively, taking another's possessions). Because daily activities that were characterized by high levels of structure and routine should have provided children with cues to appropriate or expected behavior, it was predicted that the four types of noncompliant behavior, noncompliance by omission (NONO), noncompliance by commission (NONCO), resource violation (RV), and aggression (AGG), would occur less frequently during high structure and routine activities than during low structure and routine activities. 
Noncompliance by omission. Noncompliance by omission (NONO) was the only noncompliant behavior for which results were not as predicted. The average frequency of NONO did not vary significantly between the low and high structure and routine activities. Compared to other noncompliant behaviors, average frequencies for NONO were quite low and nearly equal in the low $(M=1.44)$ and the high $(M=1.46)$ structure and routine activities.

Noncompliance by omission was a sort of "passive noncompliance" in that a child received this code when he or she failed to comply with a teacher's request, but at the same time, did not actively pursue a course of action other than the one that was specified. It is important to note that this code was recorded when a child failed to begin the process of compliance by the ten second mark following a teacher prompt. It is possible that the low frequency of this behavior in low structure and routine activities was due to the fact that it was unlikely for a teacher to not intervene and guide a child toward the requested behavior in the ten second time frame that needed to elapse before NONO could have been coded.

There were certain behaviors, such as cleaning up after mealtime, that were expected of the children regardless of whether or not there was a teacher prompt to do so. A child received a code for $\mathrm{NONO}$ if he or she did not meet the expectation, but at the same time did not actively pursue another course of action. The low frequency of NONO in high structure and routine activities could indicate that the presence of these environmental cues reduced the likelihood that a child would not stay on task. 
Aggression, noncompliance by commission and resource violation. Results for all noncompliant behaviors, with the exception of noncompliance by omission (NONO), were as predicted. Mean levels of noncompliance by commission (NONCO), resource violation $(\mathrm{RV})$, and aggression (AGG) were significantly lower in the high structure and routine activities than in the low structure and routine activities. Effect sizes (partial $\eta^{2}=.61$, partial $\eta^{2}=.72$, and partial $\eta^{2}=.54$, respectively) indicated that the presence of structure and routine in children's daily activities seemed to exert a substantial influence over children's noncompliant behavior. The degree to which structure and routine were able to affect the frequency of children's noncompliant behavior may be explained in two ways.

First, noncompliance by commission, resource violations, and aggression were all actions that, within this particular setting, children were expected to refrain from doing and in this regard, they represented Kochanska's "don't" activity contexts. A "don't" context is one in which the expectation is that a child refrain from engaging in a particular activity, often one that is desirable (e.g., playing with an "off-limits" toy). Kochanska's research demonstrated that suppression of such behaviors is easier to do than the sustaining of undesirable behaviors (i.e., "do" activity contexts, discussed above). Perhaps it is partially because the suppression of behavior is easier for young children that the ability to refrain from engaging in noncompliant or "don't" behaviors was so strongly influenced by the presence of environmental cues for expected behavior in this study.

Second, the incredible skill with which the teachers in this setting guided the children's behavior was likely another contributing factor to the strength of the findings. 
Expectations for appropriate behavior were clear and consistent, particularly with regard to causing harm to others, either by aggression or resource violation. It is possible that with the presence of a high degree of structure and routine, in addition to the clarity and consistency of expectations that were ubiquitous in this setting, the likelihood that noncompliance would have occurred with any great frequency was low.

The Effect of Structure and Routine on Self-Regulated Behavior for Children of Different Ages Self-Regulatory Behaviors (Compliance)

In considering age differences among the three forms of compliant behavior analyzed in this study, it is important to bear in mind the developmental sequence for the emergence of self-regulation and compliance (see Table 8, page 88). For the youngest children in the study, the infants, passive or situational compliance was central in their development. Compliance at this young age requires a high degree of caregiver support. Most of the infants were pre-verbal and several were not yet walking at Time 1, meaning that any teacher prompts to act independently that would have resulted in a code of adultinitiated compliance were infrequent and acts of self-initiated compliance were almost nonexistent.

As children develop and acquire language, greater working memory capacity and mobility, passive compliance becomes less central. Over time, it gives way to adult-initiated compliance during toddlerhood, followed by self-initiated compliance in the late transitioner years, as the more central indicators of developing self-regulation. Accordingly, predictions for the average frequency of passive compliance between the low and high 
structure and routine activity contexts were limited to the infant age group and predictions for adult and self-initiated compliance were limited to the toddler and transitioner groups.

Self-initiated compliance. Patterns of differences in the average frequencies of SICOMP between the two activity contexts were predicted to be the same for the toddlers and transitioners, with SICOMP occurring more frequently in the high structure and routine activity contexts than in the low structure and routine activity contexts. For the convenience of the reader, Figure 20 combines data already presented in Figures 5 and 7 and presents the average frequencies of SICOMP for toddlers and transitioners in low and high structure and routine activities.

For the transitioners, although average frequencies of SICOMP were greater in the high structure and routine activity contexts than in the low, this result was marginally significant; however, the effect size $\left(\right.$ partial- $\left.\eta^{2}=.54\right)$ indicated that structure and routine in daily activities was strongly related to mean levels of SICOMP. There were only five transitioners in this study and further investigation with a larger sample of transitioners could yield a significant result.

For the toddlers, the difference between the two contexts was as predicted, i.e., the average frequency of SICOMP was significantly greater in the high structure and routine activities than it was in the low. For both groups of children, the developmental window for the emergence and solidification of SICOMP was open so they were sensitive to the 
presence of environmental cues for expected behavior that support efforts at internalized compliance.

The developmental sequence also suggests that for the toddlers, internalization is a newer behavior and that for the transitioners, who are farther along the developmental continuum for self-regulation, internalization should be occurring more and more regularly. Accordingly, it was expected that the average frequency of SICOMP would be greater for the transitioners than it was for the toddlers. However, contrary to predictions, mean levels of SICOMP for the transitioner group were lower than they were for the toddler group. In low structure and routine activities mean levels of SICOMP were nearly equal between the toddlers and transitioners $(M=3.64$ and $M=3.41$, respectively $)$ and in high structure and routine activities the mean level of SICOMP was greater for the toddlers $(M=12.87)$ than it was for the transitioners $(M=8.01)$.

It is possible that this difference is related to the study's design. A goal of the larger study was to observe every child for equal amounts of time across equal amounts of each daily activity. However, five transitioners and nine toddlers were observed, meaning that there were more observations per activity recorded for the toddler group than for the transitioner group, which inflated the average frequency of SICOMP for the toddler group.

Adult-initiated compliance. Patterns of differences in the average frequencies of adultinitiated compliance (AICOMP) between the two activity contexts were predicted to 


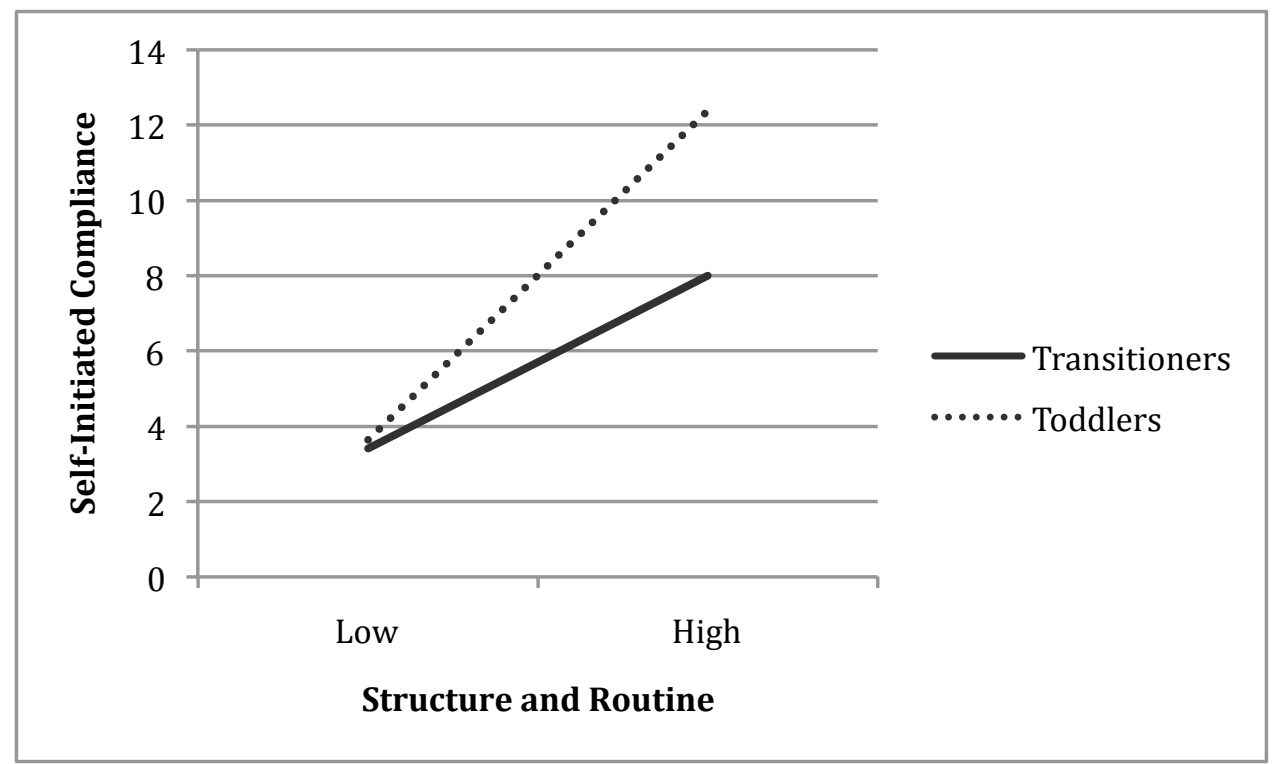

Figure 20. Average frequencies of self-initiated compliance (SICOMP) per day for toddlers and transitioners in two activity contexts 
be the same for the toddlers and transitioners, with AICOMP occurring more frequently in the high structure and routine activity contexts than in the low structure and routine activity contexts. In keeping with the developmental sequence for self-regulation and compliance, it was also expected that toddlers would exhibit more AICOMP than would the transitioners.

Contrary to predictions, there were no significant differences in the average frequency of AICOMP between the two activity contexts for either the toddlers or the transitioners. Also counter to predictions, the toddler group exhibited less AICOMP than did the transitioners, but only in the low structure and routine activity contexts. Figure 21 (also combining data already presented in Figures 5 and 7) presents the average frequencies of AICOMP for toddlers and transitioners in the two activity contexts.

Although the differences in AICOMP were not significant between the two contexts for either age group, the pattern of differences provides a useful illustration of the developmental sequence for compliant behavior. For transitioners, mean levels of AICOMP were lower in the high structure and routine activities $(M=13.59)$ than they were in the low structure and routine activities $(M=24.51)$, whereas for toddlers, mean levels of AICOMP remained nearly equal between the low and high structure and routine activities $(M=18.63$ and $M=18.09$, respectively). For the transitioners, adult-initiated or committed compliance was becoming a less central behavior. It is possible that environmental cues for expected behavior served to scaffold internalization for the transitioners such that committed compliance began to give way to internalized compliance 
during activities that were high in structure and routine (see the following section for a discussion of internalized compliance). On the other hand, for toddlers, for whom adult-initiated or committed compliance was a more central behavior, the presence of a higher degree of structure and routine in daily activities appeared to have less of an impact on the frequency of this behavior.

Passive compliance. The presence of structure and routine in daily activities was predicted to provide cues for expected behavior such that passive compliance (COMPP) was predicted to be more frequent in high structure and routine activities than in low structure and routine activities. Contrary to the prediction, the average frequency of COMPP was nearly equal between the two contexts.

Part of the reason may lie in how COMPP was coded. A code of COMPP was given under two sets of circumstances; first, when a child did not resist a teacher's attempt to redirect his or her behavior, and second, when a child did not resist a teacher's intervention on his or her behalf (e.g., face wash, nose wipe, help putting on shoes or coat). Unfortunately, these two sets of circumstances were not differentiated in the analyses of COMPP for this study. It is possible that non-resistance to interventions was equally likely to occur in both activity contexts. The infants, whose mean age was 41 weeks, needed more help with self-care activities as described above, which therefore resulted in codes for COMPP that were distributed somewhat evenly between the low and high structure and routine activities. Without knowing the ratio of COMPP in response to redirection compared to COMPP in response to intervention for each of the two activity contexts, it is 


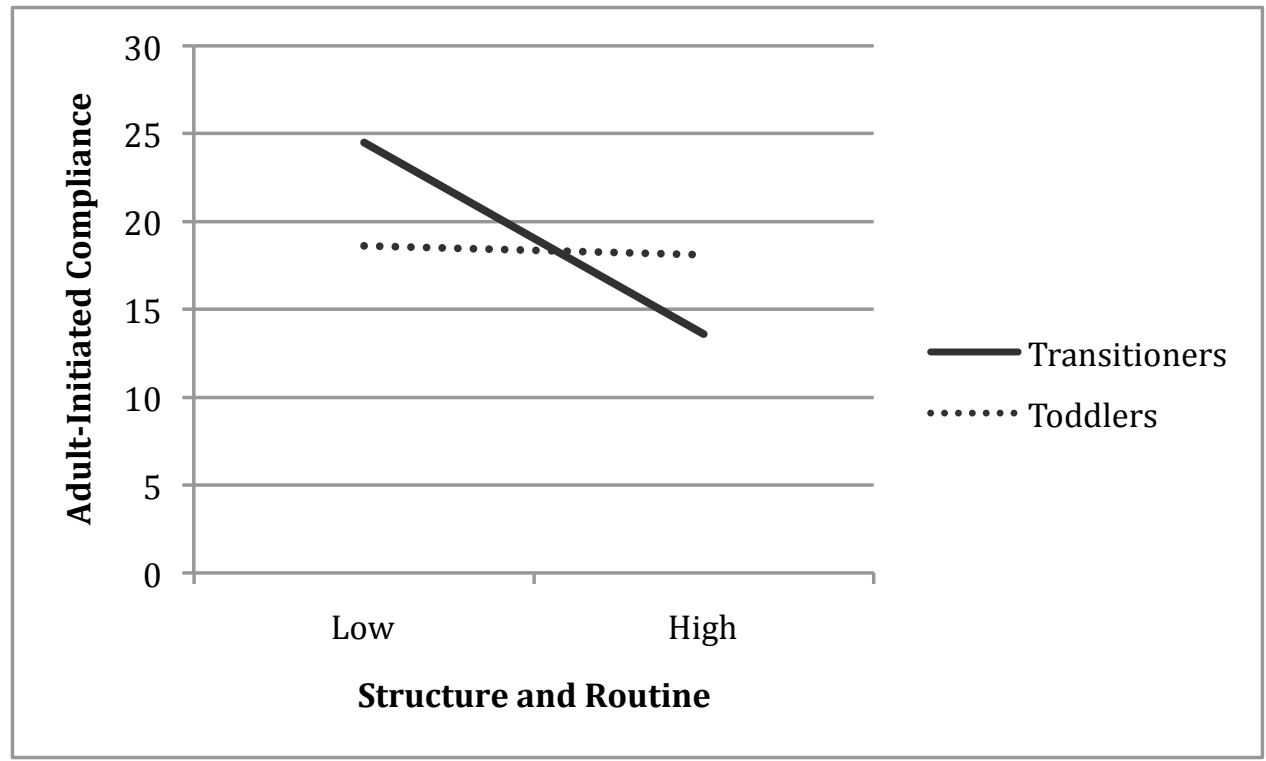

Figure 21. Average frequencies of adult-initiated compliance (AICOMP) per day for toddlers and transitioners in two activity contexts 
difficult to draw conclusions about whether or not the presence of structure and routine supports compliance at this age.

It is also possible that behaviors that are central in the developmental sequence are less malleable because that centrality also indicates the absence of a developmental window. For the infants, limitations in language, working memory capacity, and mobility meant that adult-initiated compliance was not possible, or even expected - the developmental window that allows movement from situational compliance toward committed compliance was not yet open. In the absence of the capacity to move forward in the developmental sequence, perhaps greater degrees of structure and routine in daily activities have less influence over behavior than they might when the developmental window is open.

Behaviors Indicating a Lack of Self-Regulation (Noncompliance)

Because daily activities that were characterized by high levels of structure and routine should have provided children with cues to appropriate or expected behavior, it was predicted that the four types of noncompliant behavior, noncompliance by omission (NONO), noncompliance by commission (NONCO), resource violation (RV), and aggression (AGG), would occur less frequently during high structure and routine activities than during low structure and routine activities for children in each age group.

With the exception of noncompliance by omission, results for children of all ages were generally as predicted, with effect sizes indicating strong relationships between an activity's degree of structure and routine and mean levels of noncompliant behavior (See Table 4 in the Results section for estimates of effect size). The rationales for these 
relationships presented in the previous section relate to the findings for the separate age groups as well; therefore, the following discussion addresses only differences among age groups for the noncompliant behaviors.

Noncompliance by omission. Patterns of differences for mean levels of noncompliance by omission (NONO) were much the same for children of different ages as they were for the three age groups taken as a whole, as discussed in the previous section.

Noncompliance by omission appeared to be a low-frequency behavior for children of all ages and there were no significant differences in average frequencies of NONO between the low and high structure and routine activities for the infants, toddlers and transitioners. Figure 22 combines data previously presented in Figures 6, 8, and 10 and presents average frequencies for NONO for the three age groups in the low and high structure and routine activities.

Noncompliance by commission. Noncompliance by commission (NONCO) is a behavior that often occurs in toddler and preschool age children for the same reasons that underpin aggressive behavior. Not surprisingly, average frequencies for NONCO followed patterns similar to those found for aggression for both groups of older children; however, only toddlers showed a significant difference between the low $(M=12.84)$ and high $(M=$ 1.94) structure and routine activities. Figure 23 combines data previously presented in Figures 6,8 , and 10 and presents average frequencies for $\mathrm{NONCO}$ for the three age groups in the low and high structure and routine activities. 


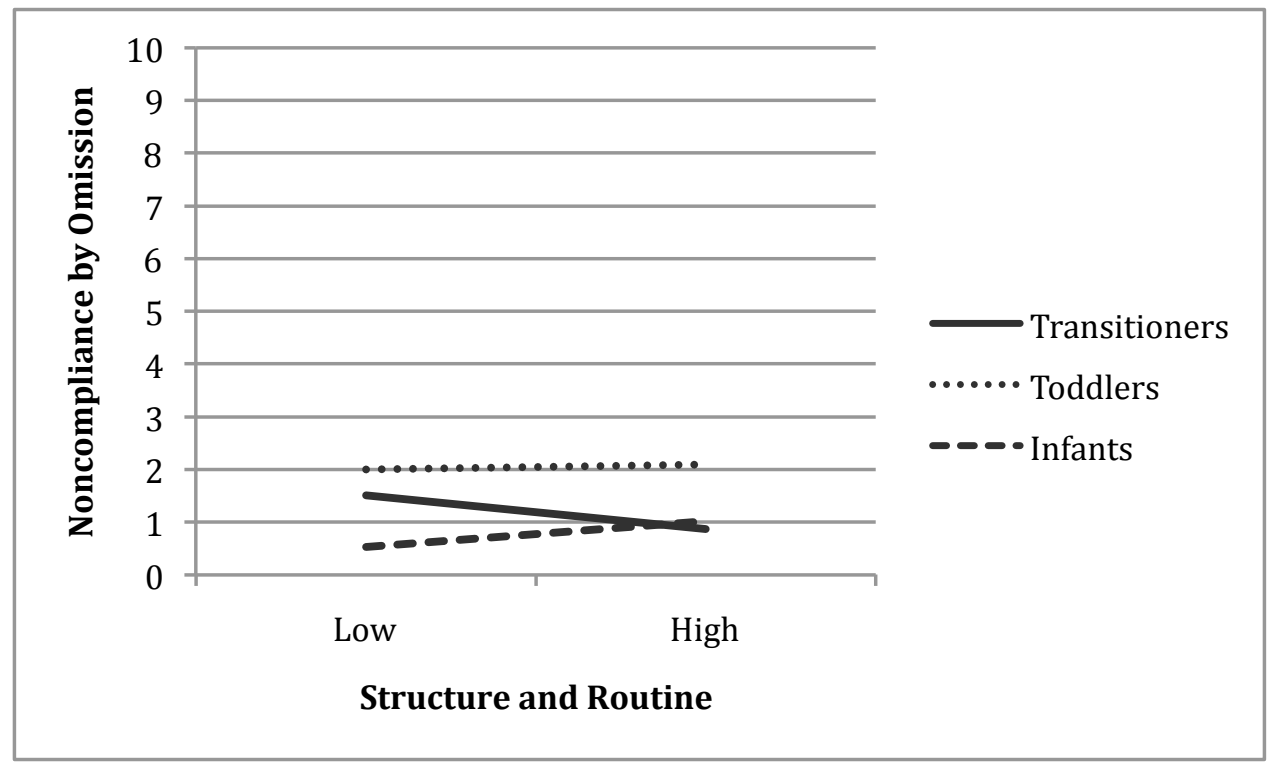

Figure 22. Average frequencies of noncompliance by omission (NONO) per day for the three age groups in two activity contexts 
The non-significant finding for the transitioners may be due to variability within the group for $\mathrm{NONCO}$ in the low structure and routine activities $(\mathrm{M}=14.60, \mathrm{SD}=$ 13.06). The estimate of effect size (partial- $\eta^{2}=.52$ ) indicated a strong relationship between the degree of structure and routine present in daily activities and the frequency of noncompliant behavior for this age group; therefore, further study with a larger sample of transitioners could yield a significant result.

Results for infants were also not significant, but the differences were in the predicted direction, with the average frequency of NONCO being greater in the low structure and routine activities $(M=10.75)$ than it was in the high structure and routine activities $(M=5.08)$. According to the developmental sequence, infants in this study were early in the control stage of self-regulation. According to Kopp (1982), children in this stage of development are beginning to comply with caregiver requests and to be able to inhibit prohibited behaviors, but the ability to perform these behaviors consistently is constrained by memory and cognitive processing limitations.

As discussed previously, the centrality of passive or situational compliance at this age may be related to the non-significant finding for infants. However, in order to most accurately understand the findings it would be helpful to know what happened following a code for noncompliance. Unfortunately, such sequencing was not included in the analyses for the present study. For example, a code for NONCO followed by a code for passive compliance [COMPP (e.g., a child allowed redirection of a noncompliant behavior)] is a sequence of behaviors that could illustrate situational compliance and the need for extra 


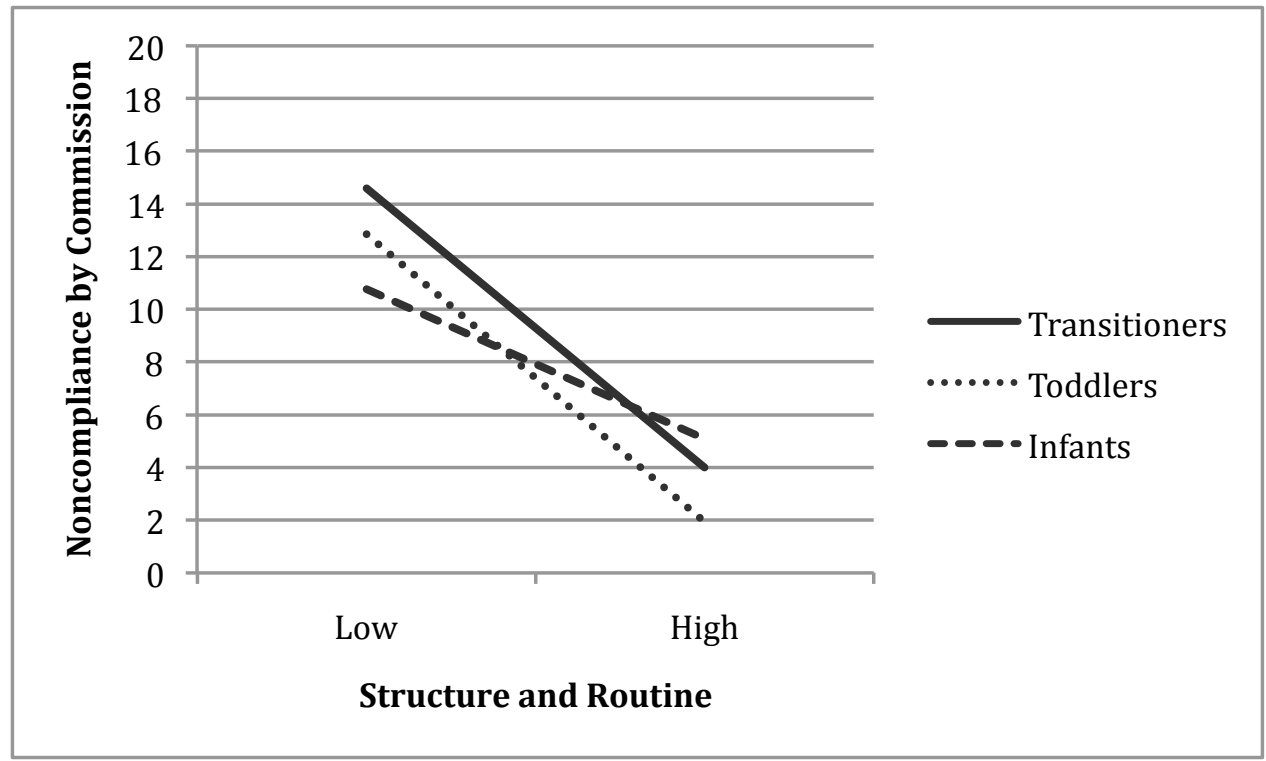

Figure 23. Average frequencies of noncompliance by commission (NONCO) per day for the three age groups in two activity contexts 
support for early self-regulatory efforts. If these sequences of behaviors were to occur more frequently in high structure and routine activities than in low structure and routine activities it would be possible to speak more directly to the effect of structure and routine in daily activities for the infant age group.

Resource violation. For all groups of children, average frequencies of resource violation $(\mathrm{RV})$ were significantly lower in the high structure and routine activities than they were in the low structure and routine activities. Estimates of effect size for transitioners, toddlers and infants (partial- $\eta^{2}=.83$, partial $-\eta^{2}=.69$, and partial- $\eta^{2}=.84$, respectively) indicated that structure and routine in daily activities exerted a strong influence over children's ability to limit engaging in resource violation. Figure 24 combines data previously presented in Figures 6, 8, and 10 and presents average frequencies for RV for the three age groups in the low and high structure and routine activities.

It is important to keep in mind that rules regarding the taking of another's belongings were clear and the teachers at the center were quick to intervene and explain the rationale for the rules when instances of this behavior occurred; however, the presence of environmental cues for acceptable behavior appeared to provide extra support, particularly for the older two groups of children for whom the mean levels of RV were almost zero. Mean level differences in RV among the three groups of children illustrate the differences among Kopp's stages of control, self-control, and emerging self-regulation. In the low structure and routine activities, mean levels of RV for infants $(M=6.56)$ were nearly twice what they were for toddlers $(M=3.71)$ and nearly three times the mean level 


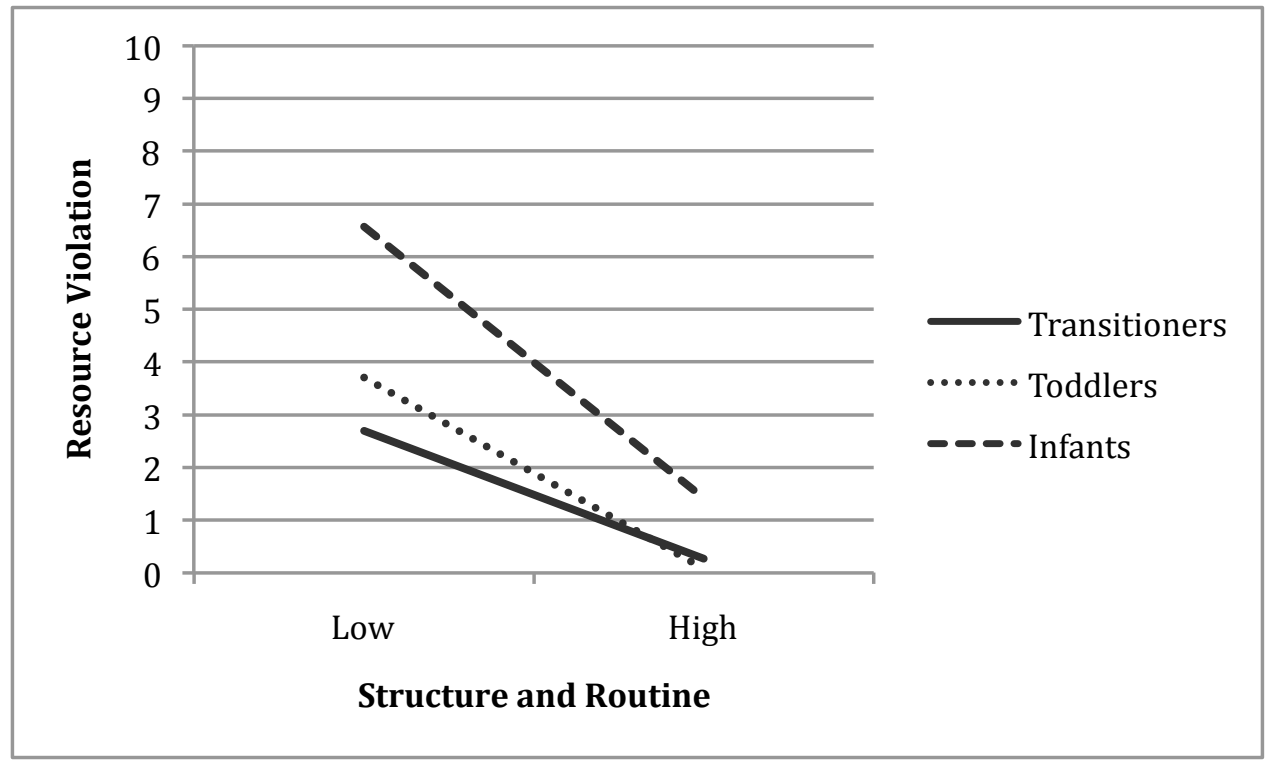

Figure 24. Average frequencies of resource violation (RV) per day for the three age groups in two activity contexts 
of RV for transitioners $(M=2.70)$. Recall that the self-regulatory efforts of children in the control stage are constrained by, among other things, language limitations. An infant, therefore, was more likely to reach out and take an object from another since he or she was likely unable to use words to make a request. Conversely, toddlers and transitioners, who were able to communicate verbally, or were perhaps able to retrieve something that they wanted from a cupboard or cubby, displayed resource violations less frequently, indicating movement to the stage of self-control. In the presence of additional scaffolding for self-regulation (i.e., in high structure and routine activities), however, even the infants $(M=1.42)$ were able to better regulate their behavior.

Aggression. Transitioners and toddlers tended to exhibit more aggressive behavior than did infants. Mean levels of aggression (AGG) were significantly greater in the low structure and routine activities for transitioners $(M=32.86)$ and toddlers $(M=27.14)$ than for infants $(M=9.77)$. Mean levels in the high structure and routine activities were greater for the transitioners $(M=4.2)$ than they were for the toddlers and infants $(M=.33$ and $M$ $=.95$, respectively). Figure 25 combines data previously presented in Figures 6, 8, and 10 and presents average frequencies for AGG for the three age groups in the low and high structure and routine activities.

Aggressive acts included instances of physical and/or verbal aggression that were directed toward adults, peers or inanimate objects (e.g., hitting, kicking an object). Aggression may have occurred more frequently for the older children because most aggressive actions were dependent on a certain level of physical development (i.e., mobility, 
dexterity) and/or verbal ability. With mobility and language also comes the need for exploration and discovering the limits of one's environment. The differences in mean levels of aggression between the low and high structure and routine activities for the older groups of children indicated that in the presence of environmental cues (i.e., structure and routine) children were better able to understand the limits, or what behaviors were and were not acceptable. Estimates of effect size for all age groups [transitioners (partial- $\eta^{2}=$ .52 ), toddlers (partial- $\eta^{2}=.71$ ), and infants (partial- $\left.\left.\eta^{2}=.59\right)\right]$ illustrate the strong influence that environmental cues have on children's ability to behave in accordance with standards and expectations with regard to keeping aggressive behavior under control.

Passive compliance. Situational or passive compliance (COMPP), as a marker for emerging self-regulation, was indicative of a positive developmental trend for the youngest children, the infants, in the present study. However, when transitioners, for whom situational compliance was a less central behavior (i.e., it had given way to committed compliance and internalized compliance), needed the level of support for self-regulation that characterizes situational compliance, passive compliance may have been indicative of a failure of self-regulation. For the older children a code of passive compliance almost always followed a teacher prompt to do or stop doing a particular behavior. If a child was noncompliant with the request, a teacher would have used gentle guidance to redirect the child's behavior. For this reason, COMPP was included as a noncompliant behavior for the transitioners and was expected to occur less frequently during high structure and routine activities than during low structure and routine activities. 


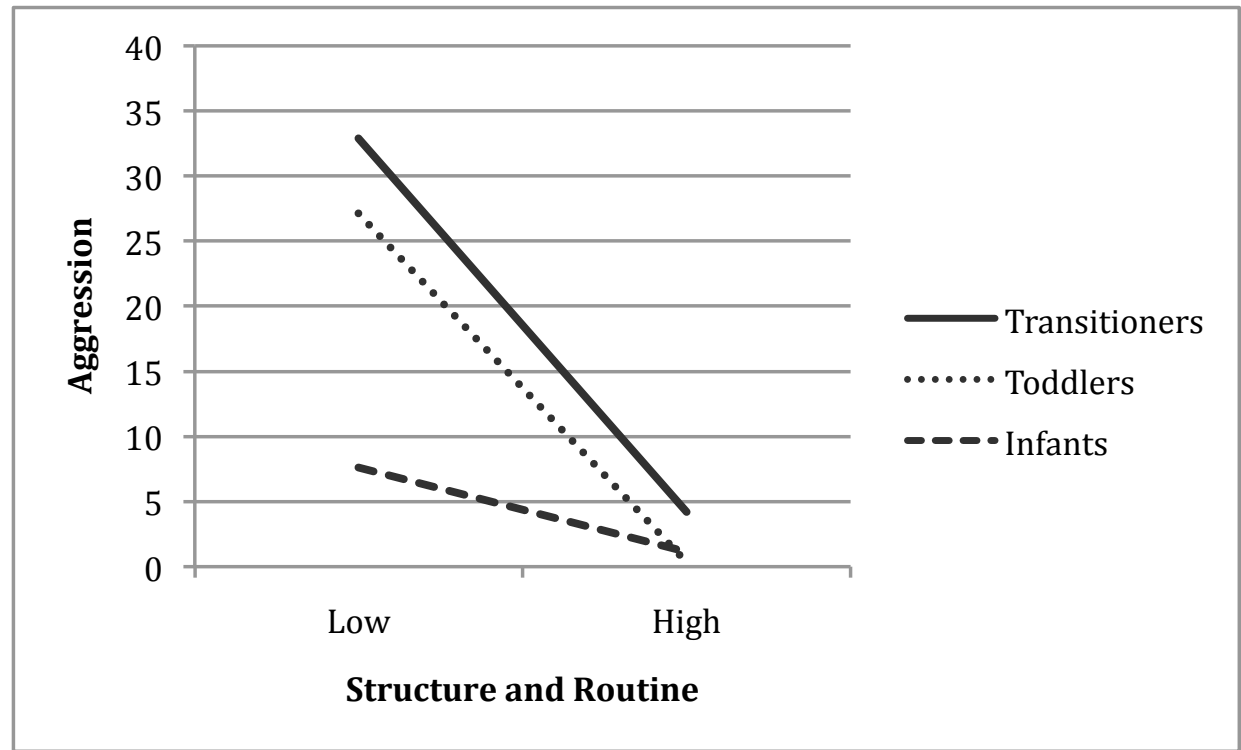

Figure 25. Average frequencies of aggression (AGG) per day for the three age groups in two activity contexts 
Results were not as predicted, in that mean levels of COMPP did not differ significantly between the two contexts and were, in fact, nearly equal between the low $(M=$ $6.82)$ and high $(M=7.02)$ structure and routine activities. This pattern would be easier to interpret if the nature of the preceding noncompliant behavior were known. For example, a child who was upset and behaving aggressively could have had a difficult time stopping his or her aggressive behavior and might have needed extra support from the teacher to bring the behavior under control. It is important to note that mean levels of COMPP for the transitioners were substantially lower in both activity contexts than they were for the infant group, indicating that, for the most part, the older children had "outgrown" this behavior. If behavior sequences had been analyzed and the preceding noncompliant behavior codes could be linked with the COMMP codes, it might be possible to establish that passive compliance for older children is more likely to occur in situations such as the one described above.

The Effect of Structure and Routine on Self-Regulated Behavior Over Time

Linear increases for compliance and decreases for noncompliance over time were predicted; however, in general, patterns of change in the average frequencies of compliant and noncompliant behaviors over time did not follow the linear trends that were predicted. With only a few exceptions, behaviors tended to increase from Time 1 to Time 2 , then decrease from Time 2 to Time 3. As the specific findings are discussed it will be helpful keep in mind some possible explanations for this pattern of change over time. These 
explanations are also limitations to the study, but will be discussed here because they deal explicitly with the time component of the study.

First, the three times of measurement used in the present study were not evenly spaced over the six-month duration of the larger study. Data were collected for three weeks at each time of measurement with Time 1 beginning February $22^{\text {nd }}$, Time 2 beginning June $7^{\text {th }}$, and Time 3 beginning August $1^{\text {st }}$. In other words, more developmental time elapsed between Time 1 and Time 2 than did between Time 2 and Time 3 .

Secondly, the seasonal shift from winter at Time 1 to summer at Time 3 may have impacted what was observed in certain high structure and routine activities. For example, transitions that took place during the Time 1 data collection sometimes involved putting on coats and waiting by the door for a teacher, behaviors whose execution on the part of a child were associated with a compliance code. During the Time 3 data collection, however, coats were not necessary and the children were often free to move from inside to outside as they desired. Thus, the change of seasons meant that, in certain situations, children had fewer opportunities to engage in compliant and/or internalized behaviors.

The summer season also impacted low structure and routine activities. During the Time 3 data collection, children spent more of their playtime, both free and directed, outdoors than they did at Time 1; therefore, a larger percentage of observable behaviors were exhibited outside. Table 9 presents the number of self-regulatory behaviors observed at each time of measurement indoors and outdoors. The outdoor play area at the center was quite large and included multiple play structures, sandboxes, a paved path on which to 
ride tricycles, and open grassy spaces. As such, the children had more space to themselves and free play often involved less direct interaction with peers than it did indoors, thereby impacting the frequencies of behaviors that involved peer interactions (e.g., aggression, sharing, SICOMP for turn taking, etc.)

Finally, it may be important to bear in mind that in the Pacific Northwest, where this study was conducted, the winter days are generally overcast and comparatively short, which may have played a role in the lower frequencies of behavior at Time 1 . By the time the June data collection began (i.e., Time 2), children had spent a long winter indoors and in this part of the country early summer can continue to be cool and wet. As summarized in Table 9 , at Time 2 , only $22 \%$ of the total number of self-regulatory behaviors observed occurred outdoors; the children were still spending a large majority of their time inside. There may have been a degree of "cabin fever" among the children, which potentially had an impact on the sharp increase in average frequencies of behaviors indicative of a lack of self-regulation, i.e., non-compliance, at Time 2.

Self-Regulatory Behaviors (Compliance)

It was predicted that there would be significant linear increases for adult-initiated compliance (AICOMP) and self-initiated compliance (SICOMP) over time in both activity contexts, but that mean levels of AICOMP and SICOMP would be significantly greater in the high structure and routine activities than in the low structure and routine activities.

Adult-initiated compliance. As in the analyses for the separate age groups, mean levels of adult-initiated compliance (AICOMP) did not differ significantly between the two 
activity contexts. There were significant differences in the average frequency over time; however, rather than the linear trend that was predicted, there was a significant quadratic trend which indicated that mean levels of AICOMP increased from Time 1 to Time 2, then decreased from Time 2 to Time 3. Unfortunately, information regarding the sequence of behaviors leading up to the code of AICOMP was not included in the analyses but would be necessary in order to interpret this result.

Adult-initiated compliance was coded when a child responded appropriately to a teacher prompt, which could have been either a request to correct a noncompliant behavior (i.e., a request that redirected the child toward compliance), or a simple reminder (e.g., "Time to wash hands"). In order to properly interpret the quadratic trend one would need to differentiate between the two types of prompts. If the average frequency of AICOMP in response to reminders increased, it could be indicative of movement through the developmental sequence - as children got better at self-regulation it became easier to comply with such requests. In turn, a decrease in mean levels of AICOMP in response to reminders, such as the one seen from Time 2 to Time 3 , might have been related to the changes in the nature of children's activities (i.e., fewer opportunities for compliant behavior) that were presented in the introduction to this section of the discussion.

On the other hand, if the average frequency of AICOMP in response to requests to redirect noncompliant behavior increased, it could be illustrating children's increased mobility and "testing the limits" of what constitutes permissible behavior. The decrease in mean levels of AICOMP seen from Time 2 to Time 3 might have indicated that there were 
Table 9. Number of observations of self-regulatory behaviors by location for each time of measurement

\begin{tabular}{lcccc}
\hline & Inside & Outside & Total & $\begin{array}{c}\text { Percent Observed } \\
\text { Outside }\end{array}$ \\
\hline $\begin{array}{l}\text { Time 1 } \\
\text { February 21- March 11 }\end{array}$ & 889 & 46 & 935 & $5 \%$ \\
$\begin{array}{l}\text { Time 2 } \\
\text { June } 7-\text { June 29 }\end{array}$ & 1824 & 530 & 2354 & $22 \%$ \\
$\begin{array}{l}\text { Time 3 } \\
\text { August 1-August 22 }\end{array}$ & 806 & 627 & 1433 & $44 \%$ \\
\hline
\end{tabular}


fewer prompts needed as children began to understand and remember some of the rules and expectations. It is also possible that if there were an increase from Time 1 to Time 2 specifically for AICOMP in response to a request to redirect behavior, the onset of spring and resultant "cabin fever" could also be a contributing factor.

In either scenario (i.e., reminder or redirection), it is also possible that AICOMP declined because it was being displaced by increases in internalized, i.e., self-initiated, compliance. However, within the framework of this study, such a conclusion is difficult to draw because average frequencies of self-initiated compliance were also confounded with the change of season (see detailed discussion of self-initiated compliance below).

Selfinitiated compliance. The average frequency of self-initiated compliance (SICOMP) was significantly greater in the high structure and routine activities than it was in the low structure and routine activities, as predicted. However, the linear increase in SICOMP from Time 1 to Time 3 was not significant. It is interesting to note that the average frequencies of SICOMP in the low and high structure and routine activities followed the predicted pattern and increased from Time 1 to Time 2; however, from Time 2 to Time 3, mean levels of SICOMP increased only slightly in the high structure and routine activities and actually decreased in the low structure and routine activities.

It is possible that the patterns of change from Time 2 to Time 3 reflect the seasondriven changes in the nature of children's daily activities. First, there were fewer opportunities to display self-initiated compliance during transitions, a high structure and routine activity, at Time 3 than there were at either Time 1 or Time 2, which could 
account for the slowed trajectory of SICOMP. Secondly, low structure and routine activities, particularly free play, occurred outside more frequently during Time 3 than during Time 1 or Time 2. Free play, when outdoors, was also associated with fewer opportunities for self-initiated compliance and could account for the decrease in mean levels of SICOMP from Time 2 to Time 3 in the low structure and routine activities. Behaviors Indicating a Lack of Self-Regulation (Noncompliance)

It was predicted that noncompliant behaviors would decrease over time in both activity contexts, but that mean levels of noncompliance would be lower in the high structure and routine activity context than in the low structure and routine activity context. Mean levels for noncompliance by commission, resource violation, and aggression were significantly greater in the low structure and routine activities than they were in the high structure and routine activities. However, the change in season may have generated anomalies in the average frequencies of these behaviors over time, and findings regarding the effect of structure and routine in daily activities on noncompliant behavior over time should be interpreted with this idea in mind.

Noncompliance by commission and aggression. Although the effect for activity context was significant for both noncompliance by commission (NONCO) and aggression (AGG) as mentioned above, results for these noncompliance behaviors were otherwise not as predicted. For both behaviors the significant linear trends indicated that mean levels of NONCO and AGG increased from Time 1 to Time 3, as opposed to the linear decreases in these behaviors over time that were predicted. Despite the overall increases, however, 
significant quadratic trends indicated that mean levels of NONCO and AGG spiked at Time 2, then decreased from Time 2 to Time 3.

Moreover, significant time by activity context interactions that had not been predicted were found. The mean level increase for NONCO was greater in the low structure and routine activities from Time 1 to Time $3(M=1.27$ and $M=3.59$, respectively) than it was in the high structure and routine activities $(M=.42$ and $M=1.25$, respectively). It should be noted that the mean level of $\mathrm{NONCO}$ in the high structure and routine activities increased from Time 1 to Time 3, contrary to predictions, although this behavior was quite low in average frequency. For AGG, the mean level was greater in the low structure and routine activities and increased from Time 1 to Time $3(\mathrm{M}=1.75$ and $M=7.99$, respectively), whereas it was lower in the high structure and routine activities and decreased, as predicted, from Time 1 to Time $3(M=.60$ and $M=.00$, respectively). In interpreting these results, there are several considerations: the overall increases in NONCO and AGG from Time1 to Time 3, the spike and decline pattern from Time 2 to Time 3, and how the differences in mean levels of NONCO and AGG over time relate to the degree of structure and routine in daily activities. As discussed previously, increases in noncompliant behavior can occur as children get older and test the limits of their environments. The increases in $\mathrm{NONCO}$ and $\mathrm{AGG}$ over time mirror the findings for the individual age groups, which indicated that these behaviors occurred more frequently in the toddler and transitioner groups (i.e., the only two age groups included in the change 
over time analyses) than in the infants. The decreases in mean levels of NONCO and AGG from Time 2 to Time 3, however, may be interpreted several ways.

These decreases could be related to the change in season. At Time 3, during the height of summer, free play (a low structure and routine activity) took place outdoors more often than indoors, and, as such, play was often more solitary. Fewer direct interactions with peers could have meant fewer opportunities to engage in noncompliant behavior, particularly aggression. Aggression was originally coded as having been directed toward an adult, a peer, or an object, but for the present study's analyses, these designations were collapsed into one code for aggression. If future studies were to incorporate these distinctions, the ratio of aggression directed at peers to aggression directed at objects or adults could indicate whether or not more solitary play at Time 3 had an impact on the frequency of children's aggressive behavior. Although codes indicating who or what was the target were not applied to instances of $\mathrm{NONCO}$, it is reasonable to expect that the same rationale would apply. For example, NONCO might have been coded during playtime (either free or teacher directed) if a child did not allow another his or her turn during a game. This type of interaction would have occurred less often if play were more solitary.

The fact that the June data collection was conducted during the onset of spring may also be related to the spikes in average frequencies of NONCO and AGG at Time 2 . Higher levels of noncompliance at this time might be an indication that the children had 
spent a long winter indoors. Following this rationale, the decrease at Time 3 would relate to a relief from "cabin fever."

On the other hand, the explanation could be developmental - over time children came to understand the standards and expectations at the center, became better at selfregulating their behavior and tested the limits less at Time 3 than they did at Time 2, a developmental change that may have been supported by the presence of structure and routine in daily activities. Such interactions between context and time, however, were predicted only for internalized behavior or self-initiated compliance (see following section). Structure and routine in daily activities were expected to scaffold emerging internalization such that mean levels of self-initiated compliance (SICOMP) in the low structure and routine activities were expected to "catch up" to mean levels of SICOMP in the high structure and routine activities over time.

It is possible that a similar process was at work for non-compliant behavior as well. The significant activity context by time interaction could indicate that the high structure and routine activities supported the internalization of rules and standards with regard to prohibited behaviors (as opposed to expected behaviors) such that, over time, the average frequency of noncompliance in low structure and routine activities began to "drop down" toward the lower average frequencies of noncompliance that characterized the high structure and routine activities.

Resource violation. The effect of activity context was significant, such that resource violations (RV) occurred less frequently in high structure and routine activities than they 
did in low structure and routine activities; however, contrary to predictions, the mean level of RV did not decrease significantly from Time 1 to Time 3. Recall from the analyses for separate age groups that the average frequencies for RV decreased as children got older. The analyses for the effect of structure and routine over time included only the toddler and transitioner groups, for whom RV was a relatively low frequency behavior. It is possible that the average frequencies were low enough at Time 1 that a significant decrease in RV would have been difficult to detect because of a floor effect. Interactions Among Structure and Routine, Age, and Time It was expected that structure and routine in children's daily activities would scaffold internalized behavior (i.e., self-initiated compliance, SICOMP) such that, for the oldest children in the study (i.e., transitioners) the lower average frequencies of internalized behavior that were associated with the low structure and routine activities would "catch up" to the higher levels of internalized behavior that were present in the high structure and routine activities. The interaction between age, time and activity context was not significant; however, there were several patterns of interest.

For the toddlers, the mean level of SICOMP increased in both activity contexts from Time 1 to Time 2, with the average frequency of SICOMP being greater in the high structure and routine activities than it was in the low structure and routine activities, as predicted. Rather than continuing to increase in this manner from Time 2 to Time 3 , mean levels of SICOMP decreased in the low structure and routine activities and leveled 
off in the high structure and routine activities. These two patterns of change likely reflect that there were fewer opportunities to exhibit SICOMP in both contexts at Time 3.

For the transitioners, mean levels of SICOMP in low structure and routine activities did not "catch up" to levels of SICOMP in the high structure and routine activities as predicted; however, the average frequency of SICOMP did not decline, even in the absence of opportunity from Time 2 to Time 3 , as it did for the toddlers. Further, rather than leveling off from Time 2 to Time 3, mean levels of SICOMP for the transitioners in the high structure and routine activities continued to increase.

If the notion that many of the unpredicted findings and/or non-significant trends discussed thus far are due to the changed nature of children's activities at Time 3 were to be supported in future studies, how might the patterns of change in SICOMP for the transitioner group over time be explained? One thought is that as children internalized the standards and expectations for their environments, they became more able to create their own opportunities to engage in behavior that reflects the standards and expectations they have come to accept. Or, put within Kopp's developmental framework, children were beginning to demonstrate self-regulation that is flexible and adaptable. A child who has internalized the behavior and rationale for cleaning up after oneself after mealtime, for example, might extend that behavior to another context and stop to pick up litter outside during playtime.

According to the developmental sequence, it is also possible that SICOMP increased because internalized compliance replaced committed compliance. If a mixed 
factorial ANOVA including the same interactions as were predicted for self-initiated compliance (SICOMP) were conducted for adult-initiated compliance (AICOMP), this effect could perhaps be demonstrated.

\section{Complex Prosocial Behaviors}

Good self-regulatory skills are associated with a host of positive outcomes for children, including engaging in prosocial behavior. When children are younger, prosocial behavior tends to be spontaneous and often encourages social partners to share in their experiences. As children mature, prosocial behaviors become less spontaneous and more reasoned and, as a result, are thought to be underpinned by the ability to self-regulate. Complex behaviors of interest in the present study were assertive problem solving (APS), helping behaviors (HELP), performing the work of adults (PWA) and sharing (SHARE). It was predicted that if children's ability to self-regulate increased over time, then these prosocial behaviors would follow suit and increase from Time 1 to Time 3 . Of the four behaviors, there were significant increases in the average daily frequency of both APS and SHARE from Time 1 to Time 3.

There were no significant differences from Time 1 to Time 3 in the average daily frequencies of HELP and PWA. However, for HELP there was a significant increase in helping behaviors from Time $1(M=1.47)$ to Time $2(M=4.80)$ and a decrease from Time 2 to Time $3(M=2.64)$, such that the Time 1 to Time 3 difference was non-significant. PWA followed the same pattern, with a significant increase in the average daily frequency of the behavior from Time $1(M=.60)$ to Time $2(M=2.30)$ and then a decrease from 
Time 2 to Time $3(M=1.64)$. As with compliance and noncompliance, these results may reflect patterns of change that are more related to the change of season at Time 3 than to the relationship between emerging self-regulation and prosocial behavior.

It is possible that changes in the nature of the children's activities at Time 3 meant that there were fewer opportunities to engage in these behaviors. For example, helping was coded when a child cleaned up after another person or engaged in teaching behaviors (e.g., giving advice or instructions). As mentioned previously, children spent more time outdoors during Time 3 and free play at this time of measurement tended to be more solitary. Less direct interaction with peers could have meant fewer opportunities to engage in helping behaviors, particularly teaching behaviors.

Performing the work of adults was coded when a child engaged in work-related behavior that fell outside the scope of his or her regular responsibilities and included helping teachers wipe down tables or assisting with setting out a meal. As many of the activities that were typically classified as PWA occurred indoors, the ability to engage in this behavior was limited during Time 3 as the children spent a larger portion of their time outdoors. Further study including another measurement point could help to determine whether or not the decreases in HELP and PWA from Time 2 to Time 3 were related to changes in the nature of children's activities that were associated with the summer season.

$$
\text { Strengths and Limitations }
$$

Strengths. This study was one of the first to take a longitudinal look at emerging self-regulation and its relationship to prosocial behavior in a natural setting while taking 
into account the influence of environmental cues for expected behavior within that setting. Examining the role of context vis-à-vis environmental cues to behavior (i.e., structure and routine in daily activities) is an important contribution as most studies that have examined context have done so in terms of caregiver-child relationships or the impact of other characteristics of home and/or school environments.

A major strength of this study was that it was observational and conducted in a natural setting. The use of observational methods was particularly important for capturing the frequency with which children exhibited internalized compliance or evidence of internalization. Kochanska (1995) used parent reports of internalized behavior at home and observations conducted in a laboratory setting, both of which have limitations. There is always a danger that parental reports reflect some degree of parental bias and may not be a valid representation of a child's actual behavior.

With regard to laboratory observations, it is important to first remember that internalized behavior is that which reflects a child's acceptance of the standards and expectations of his or her environment. Second, the flexibility and adaptability required in order to extend what has been internalized for one situation to different situations is an ability that, according to Kopp, is not acquired until preschool age or later (i.e., in the selfregulation stage). By definition, a laboratory setting is not a familiar environment for children and would thus require that a child have that flexibility and adaptability in order to be able to exhibit internalized behavior. Only by observing children in a natural setting 
are we able to observe evidence of internalization as it emerges in younger children, and track its developmental trajectory over time.

Another strength is the richness and density of the data collected for each participant that this study's design permitted. Through the use of video recording the study was able to track more self-regulatory and prosocial behaviors than would have been possible had real-time observations been used. Even with the use of video, sample sizes are smaller by necessity when using observational methods than when using, for example, survey methods, and low power is therefore a concern. However, when power is low, as it was in this study, significant effects represent conservative estimates and may therefore be particularly meaningful.

The tradeoff between power and the type of data is that one can collect a small amount of data from a large number of individuals (i.e., high power, low density of information) or a large amount of data from a few individuals (i.e., low power, high density of information). When trying to understand a complex developmental phenomenon, particularly in a population that is too young to provide researchers with meaningful selfreported information, the benefits of observational methods outweigh the shortcomings.

Limitations. Limitations related to seasonal changes and influences as well as those stemming from the amount of developmental time that elapsed between measurement points were presented in the section addressing changes in self-regulatory behaviors over time (see page 113). One of these limitations was the lack of homogeneity within certain activities over time. Changes in the nature of transitions and free play, in particular, at 
Time 3 made interpreting the trends in children's self-regulatory behavior difficult. Recall that the present study was part of a larger study that included four times of measurement. The three measurement times chosen for analysis constituted the longest span of time, which was practical when thinking in terms of changes in children's behavior related to development and practice, or the effect of structure and routine on behavior over time. However, inclusion of the data that were collected beginning in mid-April in the analyses would have provided three measurement points for which the activities were less heterogeneous. Linear trends in the frequency of children's self-initiated compliance, for example, across three times of measurement, followed by the leveling off or decreases at the last time would have lent support for the notion that changes in the frequency of behavior in the late summer months had more to do with the change of season than development or effects of structure and routine.

A second limitation relates to the code itself and the manner in which repetitions of certain behaviors were coded. For example, during cleanup after playtime, when a teacher asked for toys (e.g., balls, blocks, other small items) to be put away, a child was coded for adult-initiated compliance every time an item went into its container. Coding each of these types of actions as adult-initiated compliance generated high frequencies of the behavior for certain segments that were not necessarily valid representations of how much compliant behavior the children were actually engaging in. Although it was possible for the self-initiated compliance code to be subject to the same shortcoming, there were 
few, if any instances of SICOMP being exhibited in situations such as the one described above.

Aggression was coded according to the same guideline, which was acceptable when aggression was directed toward another child or adult; however, children also received a code for aggression (e.g., hitting, kicking, punching) when it was directed toward an inanimate object. The latter form was often a repetitive behavior for a child. For example, in one such instance a child was coded for aggression throughout a segment as she hit a tree stump with a toy broom.

Coding repetitive behaviors in this way led to high standard deviations, particularly for the two behaviors illustrated above, and may have impacted the significance of some findings. A possible solution would be to designate a cut point at which repetitions of the same behavior are coded as an ongoing process rather than as discrete events. The coding system used in this study allowed for the capture of duration of behavior through the use of the designation "ongoing" (ONGO) at the end of the behavior code. This designation was given every ten seconds for as long as the behavior continued. Future coding of the repetitive behaviors described above could make use of this system as a way to avoid artificially inflating the frequencies of behaviors that are subject to repetition (e.g., after a certain number of repetitions a behavior could be designated as ongoing).

Unequal numbers of children in each group may have made drawing accurate comparisons among ages difficult, particularly between the transitioners and the toddlers, as they were the children for whom the developmental window for internalization was 
open. In the case of the present study, transitioners (and infants) could have been over-observed among the different activities, or the toddlers could have been underobserved to make the number of observations among the three age groups more equal. Lastly, it is possible that age and classroom effects were confounded. In other words, what appeared to be differences among children of different ages could have been reflecting differences among classrooms, or teachers (i.e., teaching style). While likely a practical concern for studies conducted in many other types of day care settings, in the constructivist classroom rules and expectations for behavior were clear and consistently upheld by the teachers (i.e., what constituted noncompliant behavior was the same for infants, toddlers, and transitioners).

Teachers did use developmentally appropriate practice, which by definition means the use of different strategies for guiding behavior for children of different ages. For example, an infant that was engaged in a noncompliant behavior likely elicited a "handson" intervention (i.e., physical guidance toward compliance) that was accompanied by an explanation of what the teacher was doing and why. On the other had, a teacher's first response to a toddler or transitioner might have been to issue a prompt to change his or her behavior without immediate physical guidance. However, it must be emphasized that even though the responses to noncompliant behavior may have differed, the guidelines for appropriate behavior were consistent across all three classrooms or age groups. 


\section{Implications and Directions for Future Research}

Despite the presence of several unexpected trends, the data collected for this study demonstrated that the environmental cues that typify high structure and routine activities influenced children's ability to exhibit self-regulated behavior. The findings demonstrated that, in a natural setting during structured activities that were part of a regular routine, even the younger children (i.e., toddlers whose mean age was 1.8 years) were regularly able to sustain tedious behaviors, such as cleaning up after a meal. Further, this behavior often occurred independent of a reminder from an adult - it was internally motivated or selfinitiated. In Kochanska's (1995) laboratory research, being able to demonstrate compliant behavior during this type of activity (i.e., Kochanska's "do contexts") was difficult for all the children in her study, regardless of age. The data collected in the natural setting suggest that the conceptualization of "do contexts" could be expanded to include structured and routine daily activities; although tedious, these activities may actually support children's efforts to self-regulate and demonstrate internalization of standards and expectations.

The findings have implications for parenting and early childhood education as well. The development of strong self-regulatory skills in early childhood plays a key role in ensuring positive outcomes, including academic success and good peer and/or other social relationships as children move through their school age years, so it is important that parents and caregivers understand what can be done to support their development. Providing structure and routine for young children within the context of their daily activities is a way to scaffold children's early efforts at self-regulation that is neither difficult 
nor costly. Such scaffolding could have a significant impact on the quality of children's school and social experiences as they mature.

Although not hypothesized within the framework of this study, it is worth noting that changes in the nature of society and culture may be working against children's efforts toward internal monitoring of behavior. For example, technological advances mean that the entertainment and even educational material that children are exposed to are dispensed with remarkable speed. Learning to self regulate requires time and practice both of which may be in short supply given the pace at which the use of technology for education and entertainment is increasing. Working structure and routine into activities that are a part of daily life could support self-regulation in such a way as to offset any negative effects exposure to technology might have on developing self-regulation.

Such support may also be particularly important for children who have selfregulation difficulties due to temperament, developmental delays or attention deficits. The opportunity to become competent at self-regulating is especially rewarding for these children and is a critical factor in overcoming such disadvantages. The larger study used parent reports to collect data about the children's temperament. Future work with this data set could include the temperament data to determine if there exist differential effects for structure and routine among children of varying temperaments.

Over the course of interpreting this study's findings, limitations of the study's design came to light and explanations for the trends that were found were put forth, both of which inform future research. Inclusion of the observations that were made during the 
larger study's second time of measurement in April could help differentiate changes in behavior related to seasonal shifts from those related to maturation and make more clear the benefits conveyed by the provision of structure and routine. Inclusion of the April data would provide three points of measurement for which the daily activities were more homogeneous. Including these data would also mean that there would be four equally spaced times of measurement, thereby providing more information about how the spike in frequency of behavior unfolded (e.g., was the increase gradual from February to June or were frequencies fairly equal from February to April, with the jump occurring from April to June?).

If seasonal effects were to be identified, taking them into consideration when designing longitudinal studies could mean studying a phenomenon for an entire seasonal cycle. While such consideration may not be warranted for the study of every phenomenon or age group, it may be particularly relevant for the study of self-regulation in young children. Self-regulation is the ability that makes us, as adults, work productively through rainy days and keeps us on task when the sun comes out. Young children, by definition, have yet to fully develop this capability and their behavior may be more susceptible to influence by those types of environmental factors.

\section{Conclusion}

Although not all of this study's predictions were supported in the findings, there was strong evidence that daily activities characterized by the presence of environmental cues for expected behavior supported children's efforts to become effective managers of 
their own behavior. Specifically, during activities that provided a greater degree of structure (i.e., a set protocol) and were routine (i.e., predictable and frequent), average frequencies of internalized behavior were greater and average frequencies of noncompliant behavior were lower than they were in activities with a lesser degree of structure and routine.

The findings also suggested that Kochanska's (1995) conceptualization for contexts of compliance could be expanded to include "do contexts" (i.e., sustaining of tedious behavior) that support rather than hinder children's ability to demonstrate compliant, or self-regulated behavior. Within high structure and routine activities, such as cleaning up after mealtime, not only were the children in this study able to sustain what could be considered to be a tedious activity, they often initiated the necessary behaviors independently.

Learning how to effectively self-regulate one's behavior has been clearly demonstrated to be a key developmental task, the accomplishment of which is associated with a host of positive outcomes for children. As such, there has been a wealth of research on how to best support this emerging capacity in young children, much of which has focused on relationships between children and their caregivers. Caregivers are a key source of support in children's development of self-regulation; however, the present study has demonstrated that other aspects of the environment are important as well. Its determination that the provision of structure and routine in children's daily activities has 
an impact on emerging self-regulatory skills contributes to and fills a gap in the existing developmental literature. 


\section{References}

Bronson, M. B. (2002). Self-regulation in early childhood: Nature and nurture. New York: The Guilford Press.

Calkins, S. D., Smith, C. L., Gill, K. L., \& Johnson, M. C. (1998). Maternal interactive style across contexts: Relations to emotional, behavioral and physiological regulation during toddlerhood. Social Development, 7, 350-369.

Calkins, S. D. \& Fox, N. A. (2002). Self-regulatory processes in early personality development: A multilevel approach to the study of childhood social withdrawal and aggression. Development and Psychopathology, 14, 477-498.

Calkins, S. D. (2007). The emergence of self-regulation: Biological and behavioral control mechanisms supporting toddler competencies. In C.A. Brownell \& C.B. Kopp (Eds.), Socioemotional development in the toddler years (pp. 261- 284). New York: The Guilford Press.

DeGuzma, M. R. T., Edwards, C. P., \& Carlo, G. (2005). Prosocial behaviors in context: A study of the Gikuyu children of Ngecha, Kenya. Applied Developmental Psychology, 26, 542-558.

DeVries, R. \& Zan, B. (1994). Moral classrooms, moral children: Creating a constructivist atmosphere in early education. New York: Teachers College Press, Columbia University. 
Dix, T., Stewart, A. D., Gershoff, E. T., \& Day, W. H. (2007). Autonomy and reactions to being controlled: Evidence that both compliance and defiance may be positive markers in early development. Child Development, 78, 1204-1221.

Eisenberg, N. (1998). Prosocial development. In W. Damon (Ed.) \& N. Eisenberg (Volume Ed.), Handbook of child psychology (pp. 701-778). New York: John Wiley \& Sons, Inc.

Eisenberg, N., Cumberland, A., Spinrad, T. L., Fabes, R. A., Shepard, S. A., Reiser, M.,...Guthrie, I. K. (2001). The relations of regulation and emotionality to children's externalizing and internalizing problem behavior. Child Development, 72, $1112-1134$.

Gralinski, J. H. \& Kopp, C. B. (1993). Everyday rules for behavior: Mothers' requests to young children. Developmental Psychology, 29, 573-584.

Hay, D. F. \& Rheingold, H. L. (1983). The early appearance of some valued social behaviors. In D. L. Bridgeman (Ed.), The nature of prosocial development: Interdisciplinary theories and strategies (pp. 73-93). New York: Academic Press.

Hay, D. F., Caplan, M., Castle, J. C., \& Stimson, C. A. (1991). Does sharing become increasingly "rational" in the second year of life? Developmental Psychology, 27, 987-993.

Hay, D. F. \& Cook, K. V. (2007). The transformation of prosocial behavior from infancy to childhood. In C.A. Brownell \& C.B. Kopp (Eds.), Socioemotional development in the toddler years (pp. 100-131). New York: The Guilford Press. 
Janssen, J. (2005). Self-regulation in very young children in constructivist classrooms. (Unpublished master's thesis). Portland State University, Portland, OR).

Jennings, K. D., Sandberg, I., Kelley, S. A., Valdes, L., Yaggi, K., Abrew, A., \& MaceyKalcevic, M. (2008). Understanding of self and maternal warmth predict later selfregulation in toddlers. International Journal of Behavioral Development, 32, 108-118.

Kindermann, T. A. (2000). Observation Kappa (Version 7.3). [Computer Program\}. Portland State University, Department of Psychology.

Kochanska, G., Aksan, N., \& Koenig, A. L. (1995). A longitudinal study of preschoolers' conscience: Committed compliance and emerging internalization. Child Development, 66, 1752-1769.

Kochanska, G., Coy, K. C., \& Murray, K. T. (2001). The development of self-regulation in the first four years of life. Child Development, 72, 1091-1111.

Kochanska, G. (2002). Mutually responsive orientation between mothers and their young children: A context for the early development of conscience. Current Directions in Psychological Science, 11, 191-195.

Kopp, C. B. (1982). Antecedents of self-regulation: A developmental perspective. Developmental Psychology, 18, 199-214.

Kopp, C. B. (2001). Self-regulation in childhood. In N. Eisenberg (Ed.), N. J. Smelser \& P. B. Baltes (Series Eds.), International encyclopedia of the social and behavioral sciences (Vol. 3.14, article \#134). New York: Pergamon. 
Skinner, E., Johnson, S., \& Snyder, T. (2005). Six dimensions of parenting: A motivational model. Parenting: Science and Practice, 5, 175-235.

Snyder, M. \& Ickes, W. (1985). Personality and social behavior. In G. Lindzey \& E. Aronson (Eds.), Handbook of social psychology (pp. 883-947). New York: Random House.

Staub, E. (1979). Positive social behavior and morality, Volume 2. New York: Academic Press.

Vale, E. (2006). Early moral sense: Behavioral self-regulation, temperament, and prosocial behavior in young children in child-centered classrooms. (Unpublished doctoral dissertation). Portland State University, Portland, OR.

Vaughn, B. E., Kopp, C. B., \& Krakow, J. B. (1984). The emergence and consolidation of self-control from eighteen to thirty months of age: Normative trends and individual differences. Child Development, 55, 990-1004. 
Appendix: Activity Codes and Instructions for Coding

Activity Contexts

FR - Free play: Child partakes in self-chosen, self-directed activities using any of the available resources (toys, books, etc.). Play in the multi-purpose room, as well as most outdoor play, is considered free play.

Note 1: Sometimes within the course of free play (or structured play) a teacher will ask a child for help or assistance with a specific task. For example, a child might be asked to run an errand or help a teacher with her work (PWA - performing work of adults). These activities do not constitute a movement to another activity continue coding free play.

ST - Teacher directed play: Play initiated by a teacher who directly supervises and sometimes participates in the activity. It involves limited resources (not usually available to the children) such as clay, paint, chalk, construction paper, stamps and printing materials, cooking materials, etc. which are controlled and distributed by the supervising teacher. Indoor teacher directed activities include water tables, sand tables, making necklaces, preparing food, planting plants, painting, musical instruments and playing with flubber. Use of the water table outside for activities involving water is considered teacher directed play.

Note 1: Some activities (in particular, swinging a bat at a ball tethered to the ceiling in the barn) can be considered structured or free play depending on whether or not there is a supervising teacher. 
Note 2: If the target child is moving back and forth between free play and a structured activity, code for structured play when the child is engaged in the activity with "hands on."

ME - Mealtime: Children eat as a group 3 to 4 times a day (breakfast, AM snack, lunch, PM snack). Code mealtime even if the target child has chosen to abstain from the meal (if everyone else in the classroom is at mealtime). In general, begin coding for meal when the target child sits down at the table.

Note 1: If the target child is in the kitchen/eating area but is not sitting down code for meal if either of the following happens:

1. It is clearly mealtime. Some indications of mealtime are: The other children are at tables waiting for food to be served, the teachers are preparing to serve the meal, food carts are visible.

2. If there is a teacher prompt to sit down, code ME as starting with the teacher prompt.

Note 2: Code for meal as soon as it is discernable that it is mealtime (indicators in \#1 above) because a teacher prompt may come after it can be determined that ME has started. Use the teacher prompt, if it occurs, as an indicator that meal has started if contextual cues do not provide a clear indicator.

CM - Mealtime cleanup: The target child begins cleaning up his or her own dishes from a meal or has been prompted to do so by a teacher. If there is a teacher prompt to clean up after a meal, begin coding CM at the first code for compliance or non-compliance 
(AICOMP, NONCO, NONO) after the teacher prompt. If cleaning up is selfinitiated begin coding $\mathrm{CM}$ when the target child begins movement toward the interim activity and/or receives a code for SICOMP.

Note 1: Occasionally, a child will help a teacher with her cleaning duties. When a child is not cleaning up his or her own mess (toys or dishes) the activity code is not cleanup. These behaviors are generally coded as PWA and should carry an activity code that is aligned with what is going on for the class - usually free play, or perhaps structured play.

CP- Playtime cleanup: Code in the following situations:

1. The target child is instructed to clean up toys or supplies. Code for CP at the first code for compliance or non-compliance (AICOMP, NONCO, NONO) after the teacher prompt.

2. The segment opens and it is clearly cleanup time.

3. If the target child is in the group and within earshot when a teacher calls out "Cleanup time." Even if the target child is not specifically named by the teacher, but is clearly part of the group being prompted, the activity is still cleanup for the target child. Code for CP at the first code for compliance or non-compliance (AICOMP, NONCO, NONO) after the teacher prompt.

Note 1: Occasionally, a child will help a teacher with her cleaning duties. When a child is not cleaning up his or her own mess (toys or dishes) the activity code is not cleanup. These behaviors are generally coded as PWA and should carry an activity 
code that is aligned with what is going on for the class - usually free play, or perhaps structured play.

Note 2: Washing hands is usually indicative of a transition (see below); however, if a messy play activity such as finger painting necessitates hand washing code CP. TR - Transitions:

1. Transitions are characterized by movement from one activity to another and involve interim routines such as washing hands after free play before mealtime, waiting to use the bathroom or hanging up a coat and putting away boots after coming in from outside. Transitions can be the result of a teacher prompt or self-initiated.

Note 1: When the nature of a play activity necessitates washing up afterwards (i.e., finger painting), a code of $\mathrm{CP}$ is given.

2. Begin coding for the transition after a teacher prompt indicating a change of activity at the first code for compliance or non-compliance (AICOMP, NONCO or NONO). When the transition is self-initiated begin coding for the transition when the target child begins movement toward the interim activity and/or receives a code for SICOMP (not all actions that signal a transition fall into the category of following the rules of the center and, as such, do not have an SICOMP code attached to them). Stop coding when a new (nontransitional) activity begins. It may be necessary to watch the child's behavior for a portion of the segment in order to determine if and when a transition occurs. 
Note 1: Free play following a transition is coded as beginning either when the child enters a free play area or when the child is "hands on" with a toy or object used during free play.

3. Record a code for transitions by indicating the activity the child is coming from, then TR for the transition, followed by the activity the child engages in that occurs after the transition. For example, if a child has just finished cleaning up after free play and goes to wash hands before a meal, the code would be "CLTRME."

4. If either the activity prior to or following the transition cannot be determined from the context of the segment, enter an "XX." For example, a target child washing up after free play may take the rest of the segment to complete the task. If, during the course of the transition there is no teacher prompt or dialog to indicate what will be happening next, the code for the transition would be "FRTRXX." If the child is transitioning for the entire segment, but there is some indication of the following activity code for the activity. For example, a teacher may say, "Wash your hands because it is time for lunch."

5. During the summer, when the door to the outside is left open, a transition ends when the transition activity (shoes on, clothing change) is complete, as it is not possible for the children to wait by the door for the next activity.

Note 1: Short-term activities that interrupt a more long-term activity are not coded as a different activity. For example, a nose blow or face wash during free play is not coded as TR. Also: re-doing a transitional activity that was not done properly the first time (going back and hanging up a coat during free play). 


\section{Notes for infants:}

1. Face and hand washing while seated at table before a meal is coded as transition.

2. Face and hand washing while seated at table after a meal is coded CM.

3. Waiting to go outside after a coat has been put on is a transition, even for the infants who may be waiting for the others to have their coats put on for an entire segment. Code TR even if the infant is engaged in play while waiting.

\section{Notes on Locations:}

1. Particularly during nice weather, the doors to the outdoor play areas are left open and the children are able to move freely between indoors and outside during free play. There are typically no transitions in these situations (no coats and boots are required, nor do the children need to wait at a closed door for the teacher).

2. Often the children will "flit" between the two locations. In these instances, change the location code when the target child sustains 20 seconds in a single location. 